WSRC-TR-2001-000140, Rev. 0

SRT-RPP-2001-00031

\title{
Preliminary Dynamic Modeling of the Hanford Waste Treatment Plant Melter Offgas Systems (U)
}

Frank G. Smith, III

August 15, 2001

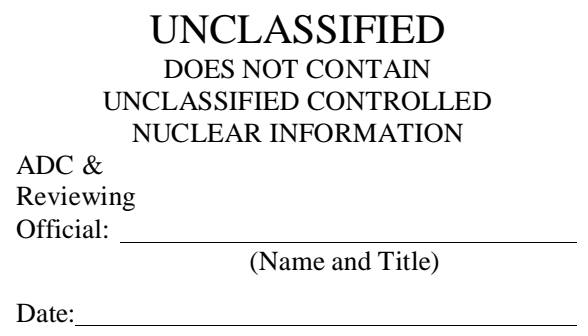

Westinghouse Savannah River Company

Savannah River Site

Aiken, SC 29808

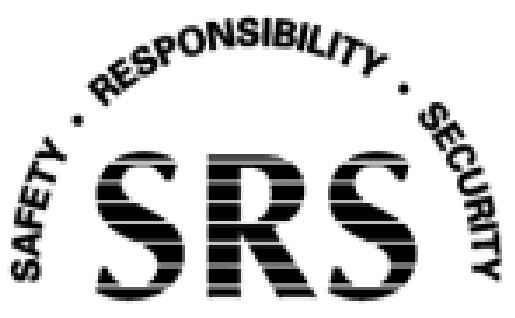

Prepared for the U.S. Department of Energy under Contract No. DE-AC0996SR18500 
This document was prepared in conjunction with work accomplished under Contract No.

DE-AC09-96SR18500 with the U.S. Department of Energy.

\section{DISCLAIMER}

This report was prepared as an account of work sponsored by an agency of the United States Government. Neither the United States Government nor any agency thereof, nor any of their employees, makes any warranty, express or implied, or assumes any legal liability or responsibility for the accuracy, completeness, or usefulness of any information, apparatus, product or process disclosed, or represents that its use would not infringe privately owned rights. Reference herein to any specific commercial product, process or service by trade name, trademark, manufacturer, or otherwise does not necessarily constitute or imply its endorsement, recommendation, or favoring by the United States Government or any agency

thereof. The views and opinions of authors expressed herein do not necessarily state or reflect those of the United States Government or any agency thereof.

This report has been reproduced directly from the best available copy.

Available for sale to the public, in paper, from: U.S. Department of Commerce, National Technical Information Service, 5285 Port Royal Road, Springfield, VA 22161, phone: (800)

553-6847, fax: (703) 605-6900, email: orders@ntis.fedworld.gov online ordering: http://www.ntis.gov/ordering.htm

Available electronically at http://www.doe.gov/bridge

Available for a processing fee to U.S. Department of Energy and its contractors, in paper, from: U.S. Department of Energy, Office of Scientific and Technical Information, P.O. Box 62, Oak Ridge, TN 37831-0062, phone: (865 ) 576-8401, fax: (865) 576-5728, email: reports@ adonis.osti.gov 
Keywords: Dynamic Model Melter Offgas

Pressure Drop

Aspen Custom Modeler

Retention: Permanent

\section{Preliminary Dynamic Modeling of the Hanford Waste Treatment Plant Melter Offgas Systems (U)}

Frank G. Smith, III

Publication Date: August 15, 2001

Westinghouse Savannah River Company

Savannah River Site

Aiken, SC 29808



Prepared for the U.S. Department of Energy under Contract No. DE-AC09- 


\section{$\underline{\text { Approvals }}$}

F. G. Smith, III, Author SRTC, Immobilization Technology

M. V. Gregory, Technical Reviewer SRTC, Engineering Development

C. T. Randall, Program Integration Manager SRTC, Immobilization Technology

D. A. Crowley, L4 Manager SRTC, Immobilization Technology 


\section{$\underline{\text { Table of Contents }}$}



HLW System Flowsheet.................................................................................. 2

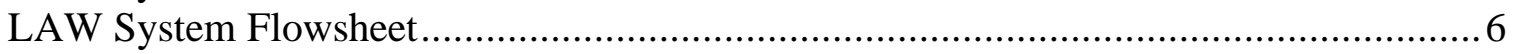

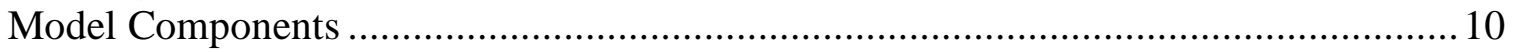

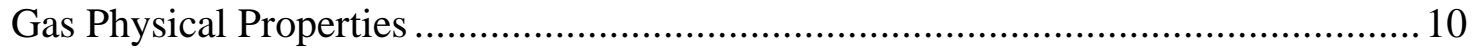

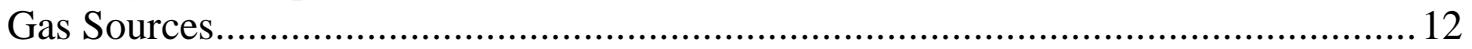

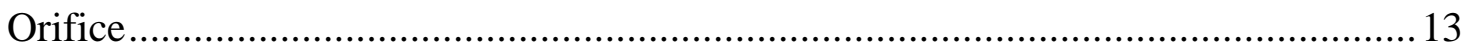

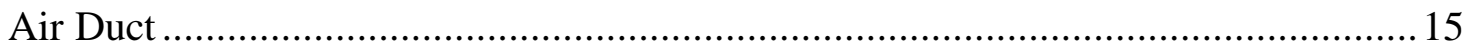



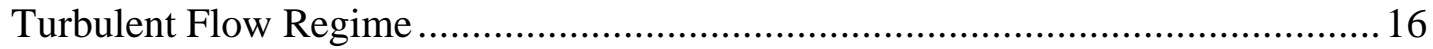

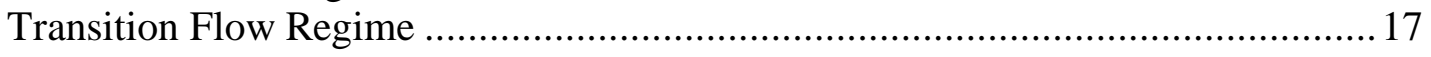

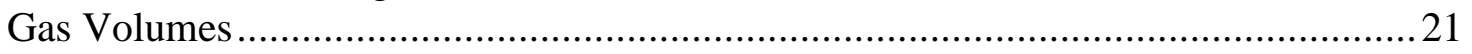

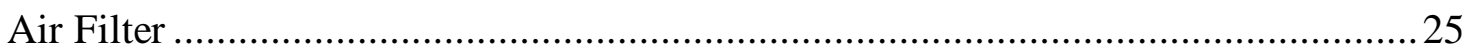

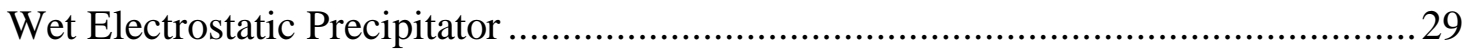

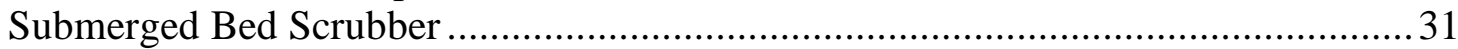



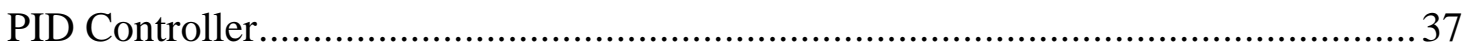

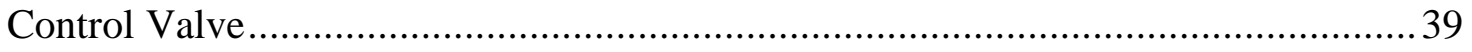

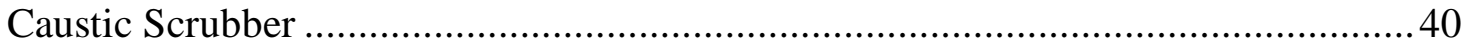

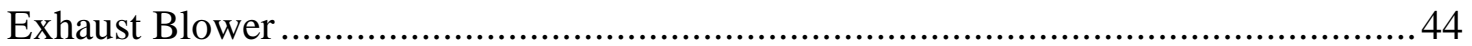

HLW Primary and Stack Exhaust Blowers.................................................... 44

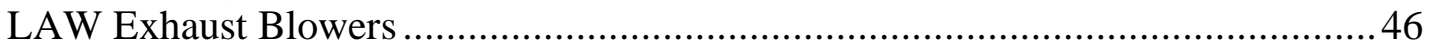

Thermal Catalytic Oxidizer Unit...................................................................... 48

Thermal Catalytic Oxidizer/Selective Catalytic Reducer................................... 49

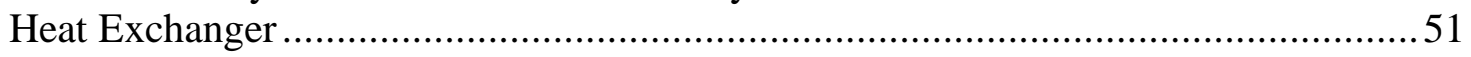

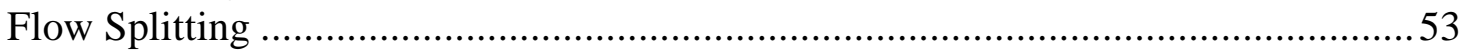

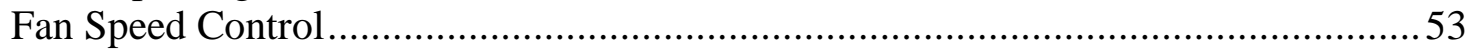

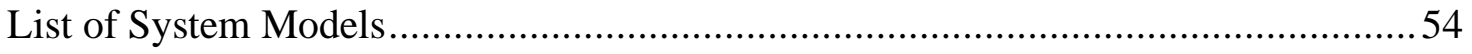

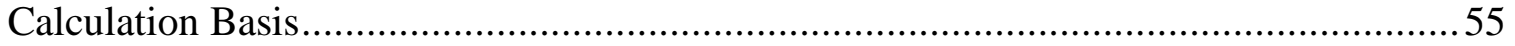

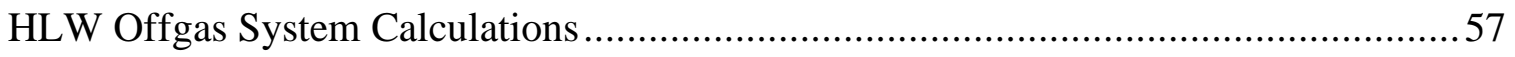

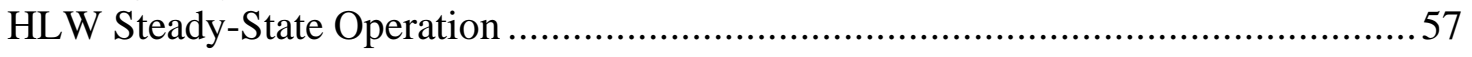

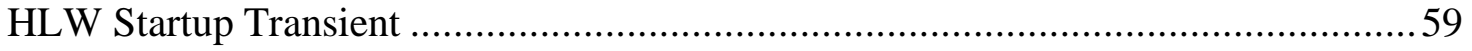

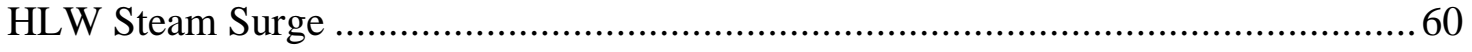

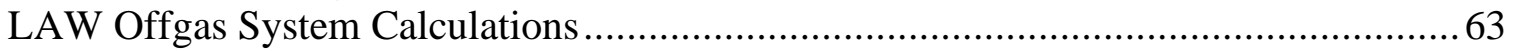

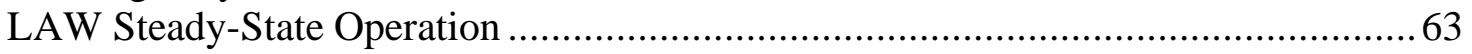

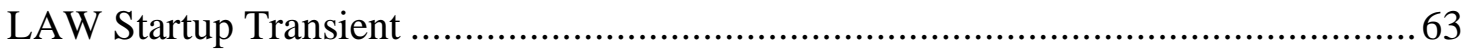

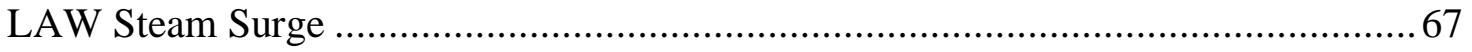

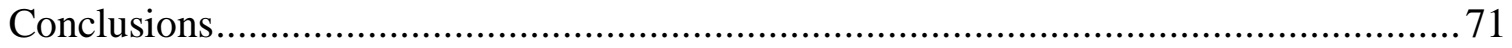

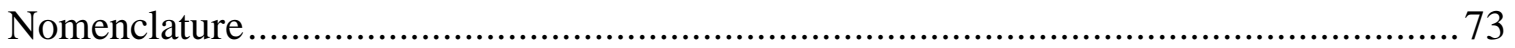

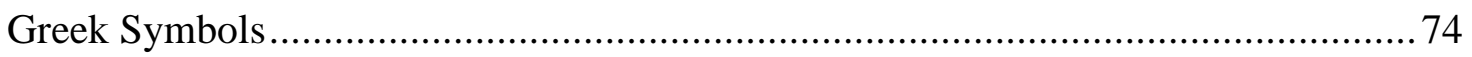

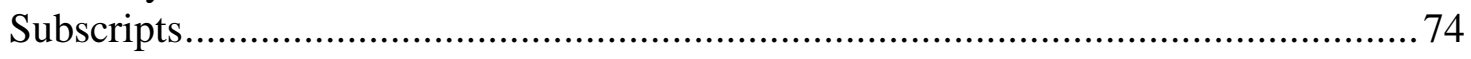

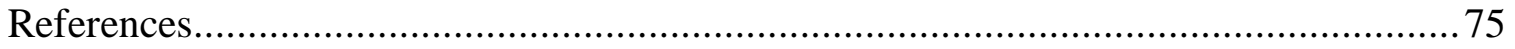

Appendix A: Derivation of Loss Coefficient Relationship ....................................... 77 


\section{Table of Figures}

Figure 1. ACM model of HLW melter offgas system.......................................... 4

Figure 2. Schematic illustration of vessel model. ..........................................................5

Figure 3a. ACM model of three LAW melter systems. .......................................... 8

Figure 3b. ACM model of common LAW melter offgas system. ................................ 9

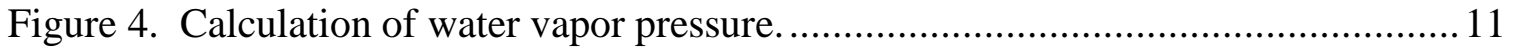

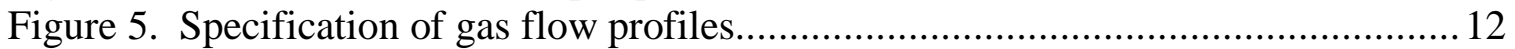

Figure 6. Comparison of orifice pressure functions............................................... 14

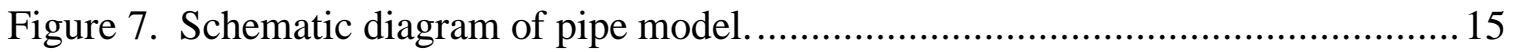

Figure 8. Friction factor correlation developed for dynamic model. ............................. 18

Figure 9. Schematic representation of flow through tank gas space ............................22

Figure 10. Schematic representation of general filter model....................................25

Figure 11. Fit to manufacturer's data for HEME pressure drop...................................26

Figure 12. Illustration of gas flow through cylindrical HEME.................................28

Figure 13. Schematic diagram of WESP model. ....................................................29

Figure 14. Schematic diagram of Submerged Bed Scrubber model. ............................. 31

Figure 15. Correlation of SBS pressure oscillation amplitude as a function of gas

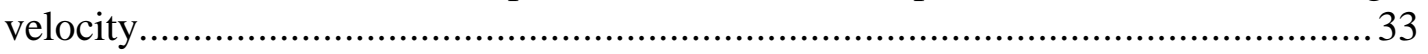

Figure 16. Schematic diagram of Heater model. ............................................... 34

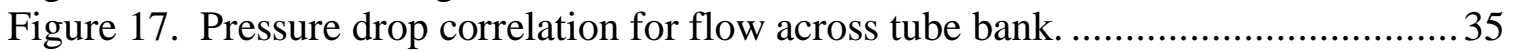

Figure 18. Schematic diagram of caustic scrubber model........................................ 40

Figure 19. Pressure drop correlation for flow through mesh demister........................ 42

Figure 20. Correlations for HLW blower operating curves................................... 45

Figure 21. Operating curves for LAW primary blower......................................... 46

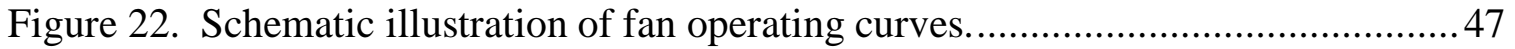

Figure 23. Schematic diagram of Thermal Catalytic Oxidizer Unit. ........................... 48

Figure 24. Schematic diagram of catalytic unit model.......................................... 49

Figure 25. Schematic diagram of plate heat exchanger model.................................51

Figure 26. HLW melter steam surge and ADS steam fluctuations...............................56

Figure 27. LAW melter steam surge and ADS steam fluctuations............................56

Figure 28. HLW melter pressure during startup and 7X steam surge...........................61

Figure 29. HLW control valve operation at $92 \%$ full blower speed. .............................61

Figure 30. HLW melter pressure during startup and $7 \mathrm{X}$ steam surge...........................62

Figure 31. HLW control valve operation at $100 \%$ full blower speed............................ 62

Figure 32. LAW Melter 1 pressure during startup and $4 \mathrm{X}$ steam surge with pressure

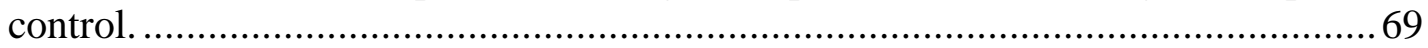

Figure 33. LAW Melter 1 pressure during startup and $4 \mathrm{X}$ steam surge with design basis

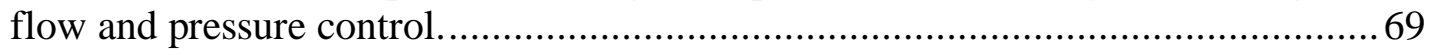

Figure 34. LAW SBS gas flow during startup and 4X steam surge in Melter 1 with design basis flow and pressure control. .................................................. 70

Figure 35. LAW control valve action during startup and 4X steam surge in Melter 1 with design basis flow and pressure control. 


\section{Table of Tables}

Table 1. Gas Sources to HLW Offgas System Model....................................................2

Table 2. Gas Sources to LAW Offgas System Model.................................................. 6

Table 3. Model Fittings and Loss Coefficients........................................................ 15

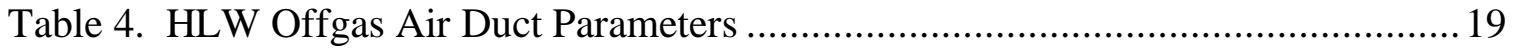

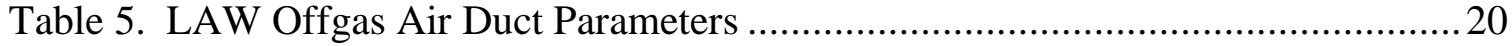

Table 6. Duct Entrance and Exit Loss Coefficient Calculation ....................................20

Table 7. Characteristics of Gas Space Models.......................................................... 21

Table 8. Dynamic Gas Volumes in System Models ...................................................... 24



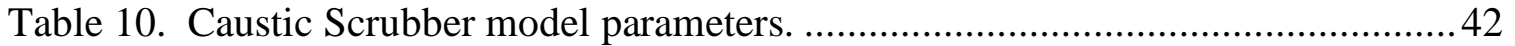

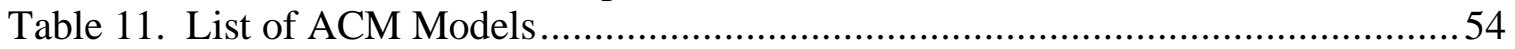

Table 12. HLW Steady-State Unit Outlet Pressures and Gas Flows ............................58

Table 13. HLW Steady-State Duct Pressure Drops ...............................................59

Table 14. LAW Steady-State Unit Outlet Pressures and Gas Flows ............................65

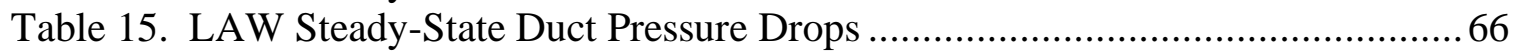

\section{$\underline{\text { Acronyms }}$}

\begin{tabular}{|c|c|}
\hline \multicolumn{2}{|c|}{ ACM ..............Aspen Custom Modeler } \\
\hline ADS .... & \\
\hline HEME. & ..High Efficiency Mist Eliminator \\
\hline HEPA.. & .High Efficiency Particle Air \\
\hline HLW. & .High Level Waste \\
\hline LAW. & ..Low Activity Waste \\
\hline & .Low Pressure \\
\hline MT.. & .Metric Tons \\
\hline PID ... & Proportional Integral Derivative \\
\hline RPP. & .River Protection Project \\
\hline SBS.. & Submerged Bed Scrubber \\
\hline SCR & ..Selective Catalytic Reducer \\
\hline TCO.. & .Thermal Catalytic Oxidizer \\
\hline VVS .... & Vessel Ventilation System \\
\hline WESP & ..Wet Electrostatic Precipitator \\
\hline & ..Waste Treatment Plant \\
\hline
\end{tabular}




\section{Preliminary Dynamic Modeling of the Hanford Waste Treatment Plant Melter Offgas Systems (U)}

\section{$\underline{\text { Introduction }}$}

Dynamic models of the High Level Waste (HLW) and Low Activity Waste (LAW) melter offgas systems for the proposed River Protection Project (RPP) Waste Treatment Plant (WTP) at the Hanford Site have been developed using Aspen Custom Modeler (ACM Version 10.2) software from Aspen Technology, Inc. This report documents preliminary versions of the models that include the components of the offgas systems from the melters through the exhaust stacks and the vessel ventilation systems. The models consider only the two major chemical species in the offgas stream: air and steam or water vapor. Model mass and energy balance calculations are designed to show the dynamic behavior of gas pressure and flow throughout the offgas systems in response to transient driving forces. As such, the models are structured to give accurate pressure drop calculations throughout the offgas systems. Detailed calculations of the steady-state pressure drop through the offgas systems have been performed separately by Hanford design engineers (see references). The dynamic models are largely based on these calculations and incorporate the most significant factors identified by the steady-state analysis. While they do not contain all of the details included in the steady-state calculations, the models have previously been shown to accurately reproduce the steadystate system pressure profiles when run under identical conditions. These comparisons to the independent steady-state solution serve as a validation of the dynamic models.

This report is titled preliminary modeling because some aspects of the offgas systems have not yet been included in the models at this point. However, it was determined that the project should provide a preliminary description of the work and some results of sample calculations to assist the Hanford design work and planning for further modeling work. Known modeling omissions are listed in the conclusion section of this report. The calculated results are also termed preliminary since neither the model nor the input data have been formally checked. Nevertheless, this report provides an accurate description of the models as they now exist, lists some of the model input parameters, and provides calculated results that, at a minimum, indicate the computational capabilities of the dynamic models.

This report covers model development work performed between May, 2000 and April, 2001. In April, 2001 the modeling work was temporarily stopped pending a review by new RPP-WTP project management. Prior to the work stoppage, it was requested by the customer that a draft report be written describing the status of the dynamic offgas modeling work. This report formally issues that draft report incorporating review comments received from the customer. 


\section{HLW System Flowsheet}

Figure 1 shows a schematic diagram of the flowsheet used to model the HLW melter offgas system. The flowsheet is based on the system description given by Rouse (2000a). The flowsheet diagram was printed directly from the ACM model representation of the system. Solid lines in the figure indicate gas flow paths while dashed lines show control signals. Gas lines labeled Duct_xx, Header_xx, or L3xxxx are models of actual gas ducting where pressure drop calculations are performed. Other gas lines labeled Sxx or ISxx are simply connecting lines that transfer gas from the source point to the destination but where no pressure drop calculation is performed.

The melter gas plenum (Melter_1) is the starting point for the HLW model. There are five sources of gas flow into the meter plenum including air inleakage from the melt cell (Cell_1) through an orifice (Air_Leak_1). From the melter plenum, the gas passes through a film cooler where it is mixed with cool air and (possibly) low pressure steam. From the film cooler, the gas flows to the pressure control point where control air, metered through Valve_1, is added to control the melter pressure. Control_11 uses the melter pressure to set the control valve stem position. Sources of gas flow into the HLW system are listed in Table 1 (Rouse, 2000m). The fixed values shown in the table are nominal steady-state operating flows. Fluctuations in the melter steam flow caused by slurry feed through variable rate Air Displacement Slurry (ADS) pumps are modeled by setting a time varying profile in feed stream ADS_1. Half of the total steam is assumed to be generated by a constant flow and half by the transient profile. Similarly, to model steam surges, the melter surge flow is ramped through a transient profile defined through the model input. The steam surge is added to the nominal steam flow. Therefore, a 7X steam surge is interpreted as the total steam flow through the melter increasing to 7 times the nominal value which requires a surge flow 6 times nominal. The control air flow rate is set by the control scheme which attempts to maintain a constant melter pressure of -5 inches of water relative to the melter cell pressure of -1 inches water.

Table 1. Gas Sources to HLW Offgas System Model

\begin{tabular}{|l||l|c|}
\hline \multicolumn{1}{|c||}{ Gas Source } & \multicolumn{1}{c|}{ Stream Description } & Flow (kg/s) \\
\hline \hline Steam_1 & Constant steam flow in melter & 0.047 \\
\hline ADS_1 & Time varying steam flow in melter & 0.047 \\
\hline Surge_1 & 7X steam surge in melter & $0.566(+6 \mathrm{X})$ \\
\hline Purge_1 & Purge air flow to melter & 0.031 \\
\hline Cell_1 & Air inleakage to melter through orifice & Variable \\
\hline \hline Cool_Air_1 & Air flow to film cooler & 0.183 \\
\hline LP_Steam_1 & Low pressure steam flow to film cooler & 0 \\
\hline Control_Air_1 & Air flow to melter pressure control mixer & Variable \\
\hline \hline 26 VVS Tanks & Air flow into vessel ventilation system tanks & Fixed + Variable \\
\hline
\end{tabular}


From the pressure control mixer, gas flow passes through a Submerged Bed Scrubber (SBS), Scrubber_1 and Wet Electrostatic Precipitator (WESP), Precipitator_1. The SBS plenum, WESP inlet, and WESP outlet units model significant gas volumes associated with the offgas equipment. Following the WESP, the gas flow enters the vent mixer where it is mixed with the offgas from the vessel ventilation system. The vessel ventilation system is modeled by the 26 vessels, 26 laterals, 25 headers and 25 mixing tees arranged in the flow network shown in the lower half of the Figure 1. Control_2 attempts to maintain a constant pressure in Header_25 by adjusting the valve stem position in Valve_2. Fixed air and steam flows into the HLW vessels were set to nominal values reported by Meeuwsen (2001) for the preliminary calculations presented in this report.

Each "vessel" shown in the Vessel Ventilation System (VVS) network is a composite model as illustrated in Figure 2. The model, ACM model Vessel_System, includes a fixed source of gas flow into the vessel gas space representing purge air and other additions to the vessel, a variable gas source representing air inleakage into the vessel from the surrounding cell, an orifice, and the vessel gas space. Air inleakage is modeled as flow through an orifice that is a function of the pressure difference between the vessel gas space and the surrounding cell.

After mixing with the vessel ventilation gas, the offgas stream flows through a High Efficiency Mist Eliminator (HEME), a preheater, and two banks of High Efficiency Particle Air (HEPA) filters. The stream is then split between two identical booster fans. Both fans are modeled to allow calculating fan failure accident scenarios. Exiting the fans, the gas streams are recombined before passing through a caustic scrubber. From the caustic scrubber, the offgas passes through a thermal catalytic oxidizer unit. The oxidizer has been broken down into its individual parts for modeling purposes. These parts are: cold side of the heat exchanger, preheater, catalytic oxidizer, and hot side of the heat exchanger. From the thermal catalytic oxidizer, the gas passes through another two sets of HEPA filters and is again split into two streams for two identical stack fans. After the stack fans, the offgas streams are recombined and exit the system at the discharge of Duct_25.

The calculations performed in each of the individual models of the offgas system units are described in detail below. Further details of the dimensions and construction of the HLW offgas system are also provided in the discussion below. 
Figure 1. ACM model of HLW melter offgas system.

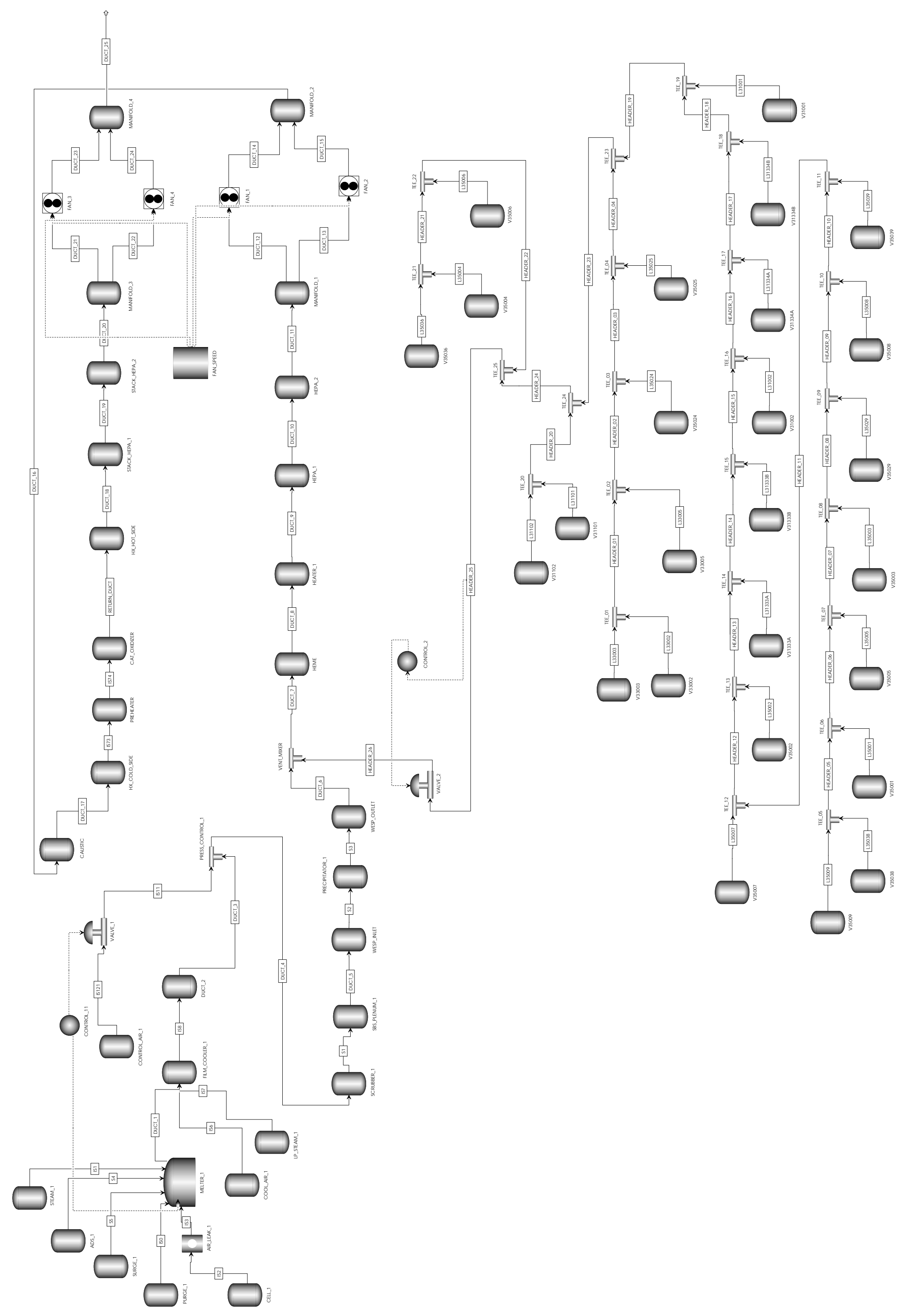




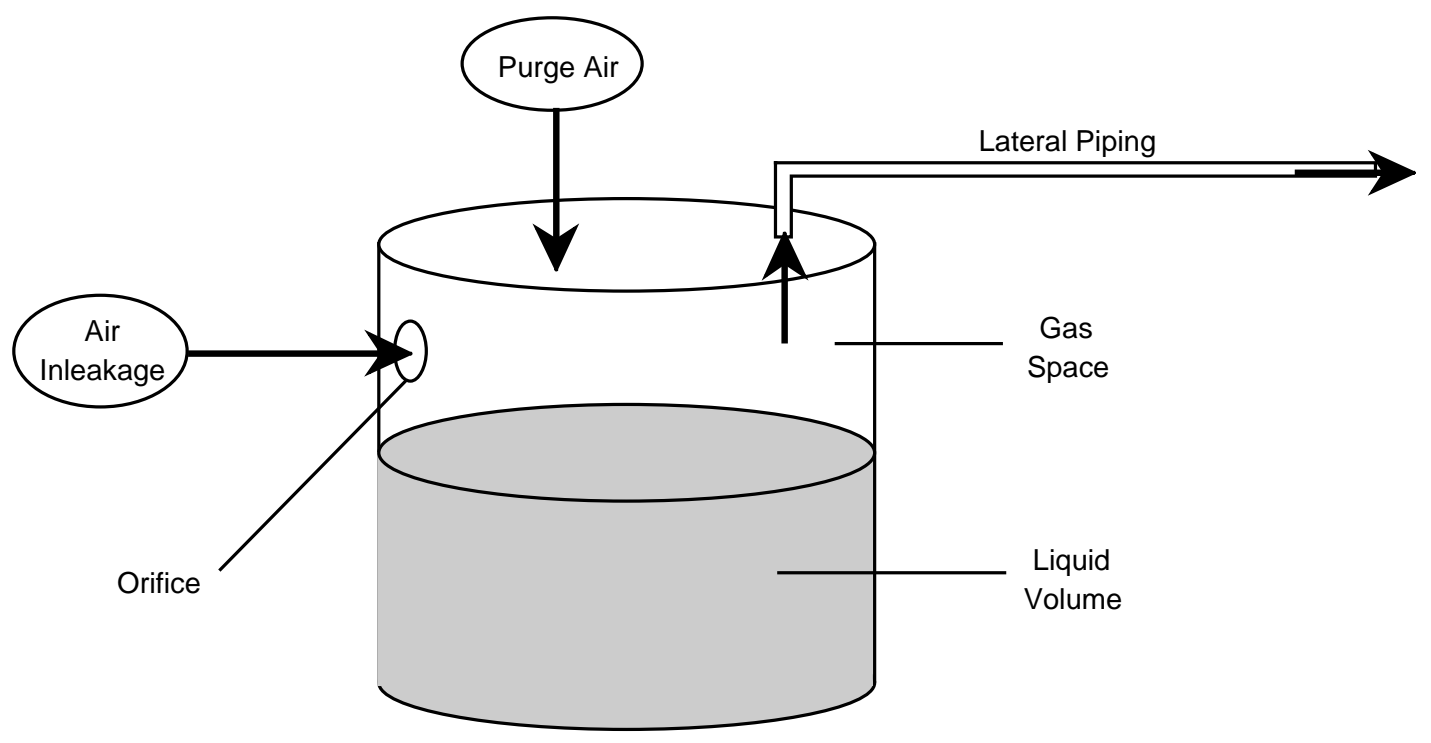

Figure 2. Schematic illustration of vessel model. 


\section{$\underline{\text { LAW System Flowsheet }}$}

Figures $3 \mathrm{a}$ and $3 \mathrm{~b}$ show schematic diagrams of the flowsheet used to model the LAW melter offgas system. The flowsheet is largely based on the system descriptions given by Anderson and Berrios (1999), Berrios (2000), and Rouse (2000a) although it includes some modifications of the original design. As for the HLW system, the LAW process flow diagrams have been printed directly from the ACM model to provide an accurate picture of how the system has been simulated.

As shown in Figure 3a, the LAW system consists of three melters with dedicated control systems, film coolers, submerged bed scrubbers, and wet electrostatic precipitators connected to a common offgas train. The LAW melter systems have essentially the same configuration as that described for the HLW system with the exception that a second control loop that attempts to maintain a constant gas flow out of the SBS has been added. Sources of gas flow into the LAW system are listed in Table 2 (Rouse, 2000m). The fixed values shown in the table are nominal steady-state operating flows. Fluctuations in the melter steam flow caused by slurry feed through variable rate air displacement pumps are modeled by setting a time varying profile in streams ADS_1, ADS_2, and ADS_3. To model steam surges, the melter surge flow is ramped through a transient profile defined through the model input. The control air flow rate is set by the control scheme which attempts to maintain a negative melter pressure of -5 inches of water relative to the melter cell pressure of -1.5 inches water or controls for constant SBS gas flow.

Table 2. Gas Sources to LAW Offgas System Model

\begin{tabular}{|l||l|c|}
\hline \multicolumn{1}{|c|}{ Gas Source } & \multicolumn{1}{c|}{ Stream Description } & Flow (kg/s) \\
\hline \hline Steam_1,3 & Constant steam flow in melter & 0.038 \\
\hline ADS_1,3 & Time varying steam flow in melter & 0.038 \\
\hline Surge_1,3 & 4X steam surge in melter & $0.229(+3 \mathrm{X})$ \\
\hline Purge_1,3 & Purge air flow to melter & 0.061 \\
\hline Cell_1,3 & Air inleakage to melter through orifice & Variable \\
\hline \hline Cool_Air_1,3 & Air flow to film cooler & 0.092 \\
\hline LP_Steam_1,3 & Low pressure steam flow to film cooler & 0.056 \\
\hline Control_Air_1,3 & Air flow to melter pressure control mixer & Variable \\
\hline \hline 12 VVS Tanks & Air flow into vessel ventilation system tanks & Fixed + Variable \\
\hline
\end{tabular}

As shown in Figure 3b, gas flow from the vessel ventilation system is mixed with the melter offgas downstream of the point where the offgas streams from the three melters combine. The vessel ventilation system is modeled by 12 vessels, 12 laterals, 13 headers and 12 mixing tees arranged in the flow network shown in the lower half of the Figure 3b. As before, each vessel in the network is the composite model illustrated in Figure 2 including a fixed source of gas flow into the vessel gas space and air inleakage into the vessel from the surrounding cell. Control_4 attempts to maintain a constant gas flow in Header_13 by adjusting the valve stem position in Valve_4. Fixed air and steam flows 
into the LAW vessels were set to the nominal values reported by Fergestrom and Meeuwsen (2000) for the preliminary calculations presented in this report.

After mixing with the vessel ventilation gas, the offgas stream flows through a preheater, and two banks of HEPA filters. The stream is then split between two parallel sets of two identical booster fans operating in series. All four fans are explicitly modeled to allow calculating fan failure accident scenarios. Exiting the fans, the gas streams are recombined before passing through a thermal catalytic oxidizer unit. As in the HLW system, the oxidizer has been broken down into its individual parts for modeling purposes. These parts are: cold side of the heat exchanger, preheater, catalytic oxidizer, primary catalytic reduction unit, secondary catalytic reduction unit, and hot side of the heat exchanger. From the thermal catalytic oxidizer, the gas passes through a caustic scrubber and then exits the system at the discharge of Duct_32.

The calculations performed in each of the individual models of the offgas system units are described in detail below. Further details of the dimensions and construction of the LAW offgas system are also provided in the discussion below. 
Figure 3a. ACM model of three LAW melter systems.
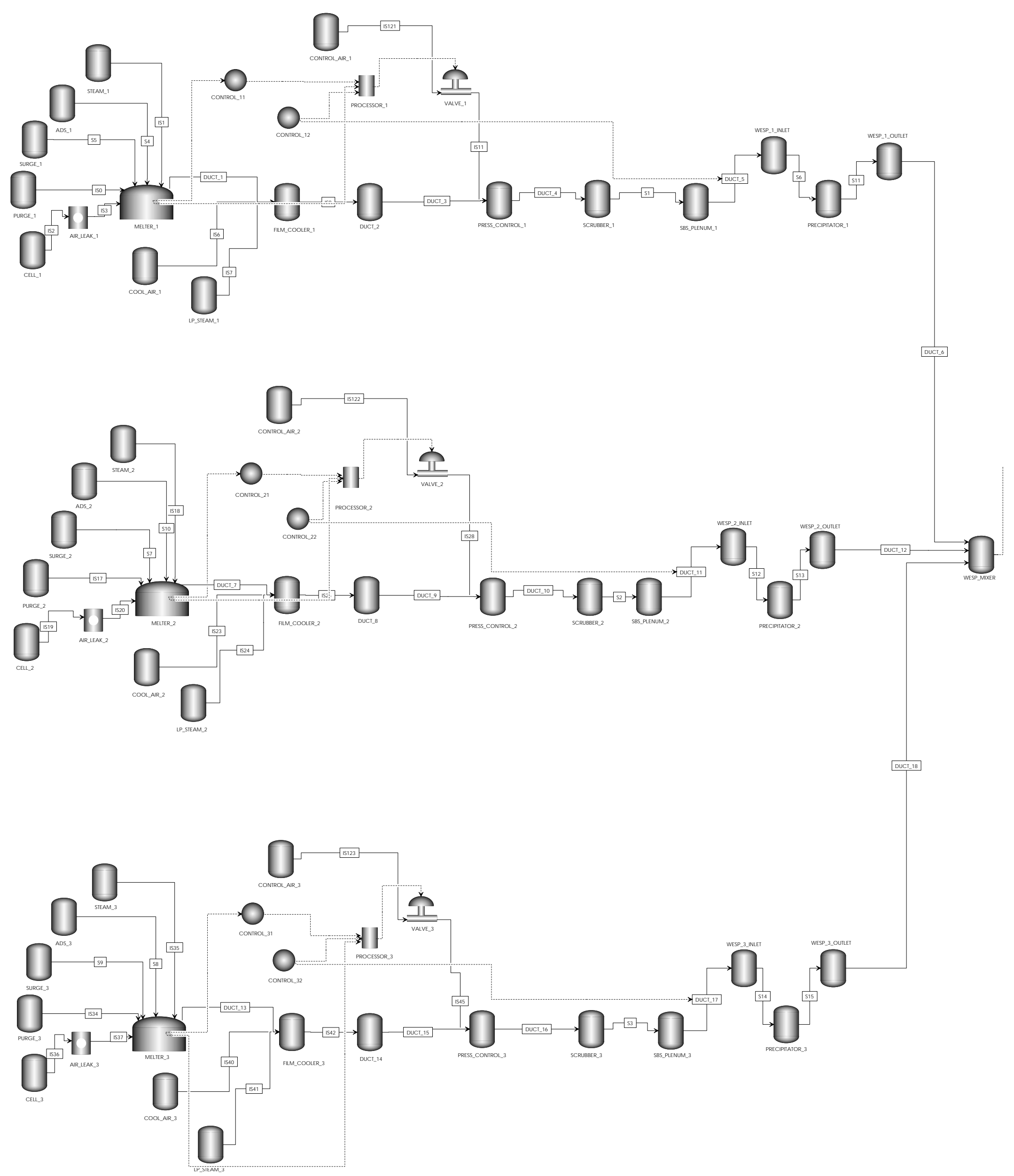
Figure 3b. ACM model of common LAW melter offgas system.

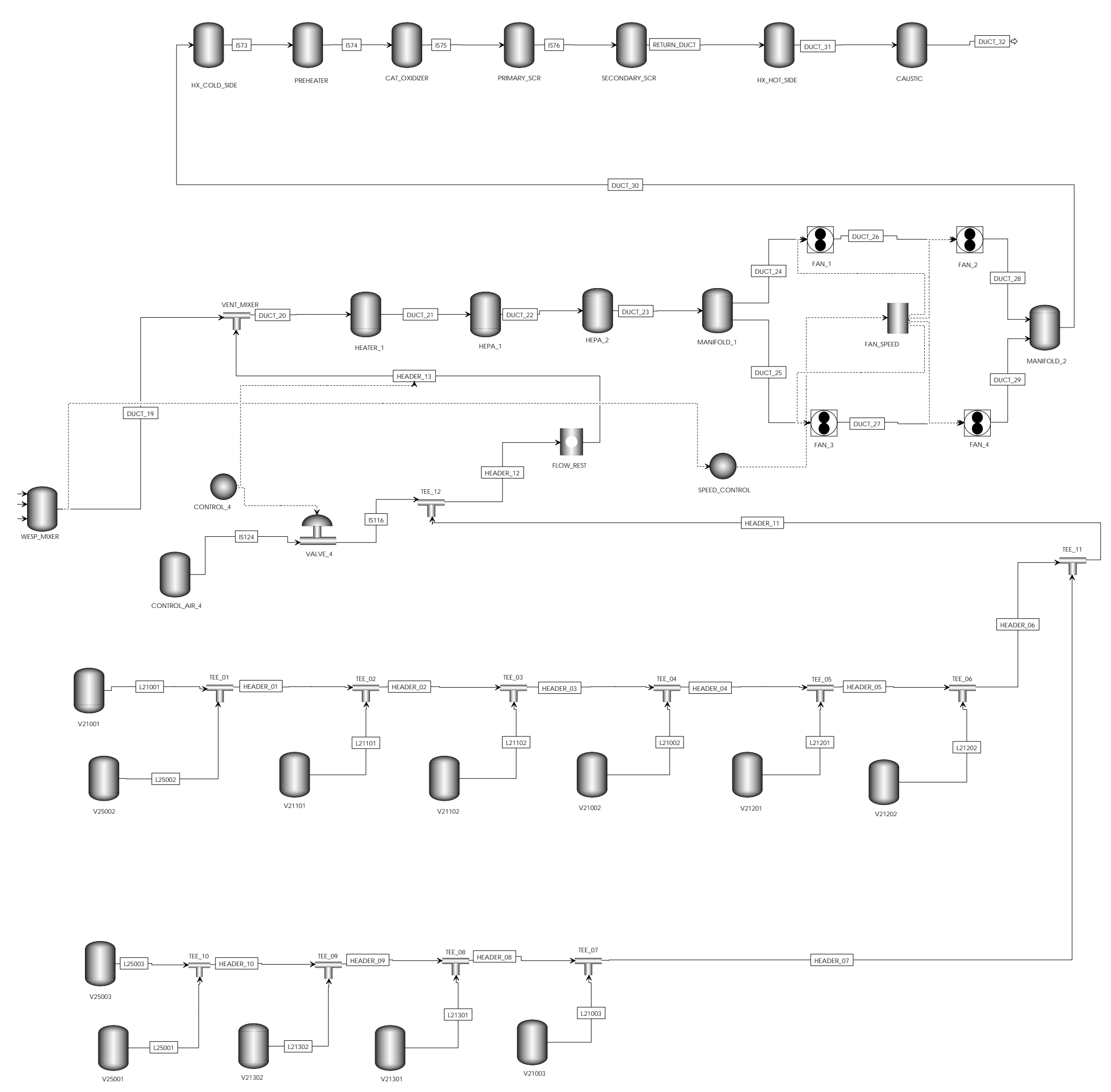




\section{$\underline{\text { Model Components }}$}

In this section of the report, gas physical property calculations and the individual models developed to describe the various components of the melter offgas system are described.

\section{Gas Physical Properties}

The gas is treated as an ideal mixture of air and water and the gas density is calculated from the ideal gas relationship:

$$
P V=N R\left(T_{g}+273\right) \text { or } \rho_{g}=\frac{P M_{a v g}}{R\left(T_{g}+273\right)} \text {. }
$$

The average molecular weight of the gas mixture is calculated as:

$$
M_{\text {avg }}=y_{\text {air }} M_{\text {air }}+y_{\text {water }} M_{\text {water }},
$$

where $y_{\text {air }}$ and $y_{\text {water }}$ are the gas phase mole fractions of air and water. The molecular weights of air and water are taken to be 29.0 and 18.0, respectively.

Gas viscosity, in units of Pa-s, is calculated for each of the components in the gas mixture using the equations recommended by Rouse (2000g):

$$
\begin{aligned}
& \mu_{\text {air }}=17.13 \cdot 10^{-6}+5.183 \cdot 10^{-8} T_{g}-3.161 \cdot 10^{-11} T_{g}^{2}, \\
& \mu_{\text {water }}=9.12 \cdot 10^{-6}+3.113 \cdot 10^{-8} T_{g}+2.000 \cdot 10^{-11} T_{g}^{2} .
\end{aligned}
$$

A mixture viscosity is calculated as the mass average of the component values:

$$
\mu_{g}=x_{\text {air }} \mu_{\text {air }}+x_{\text {water }} \mu_{\text {water }}
$$

where $x_{\text {air }}$ and $x_{\text {water }}$ are the mass fractions of air and water in the gas phase, respectively.

Gas specific enthalpy, in units of $\mathrm{kJ} / \mathrm{kg}$, is calculated for each of the components in the mixture using the temperature functions developed by Rouse as reported by Meeuwsen (2001):

$$
\begin{gathered}
h_{\text {air }}=0.991 T_{g}+1.077 \cdot 10^{-3} T_{g}^{2}, \\
h_{\text {water }}=1.818 T_{g}+3.144 \cdot 10^{-4} T_{g}^{2} .
\end{gathered}
$$

The enthalpy of air is the average of the equations for oxygen and nitrogen weighted by the respective mass fractions. A mixture enthalpy is calculated as the mass average of the component values:

$$
h_{g}=x_{\text {air }} h_{\text {air }}+x_{\text {water }} h_{\text {water }} \text {. }
$$


The saturation vapor pressure of water is calculated as a function of gas temperature using the Antoinne equation provided by Holland (1981):

$$
p_{\text {sat }}=(101325 / 760) \exp \left[18.344-3841.2 /\left(T_{g}+228\right)\right]
$$

As shown in Figure 4 below, Eq. (5) provides an excellent representation of the water vapor pressure data listed in Perry's Chemical Engineers' Handbook. Over the temperature range of 5 to $95{ }^{\circ} \mathrm{C}$, the average relative error in Eq. (5) is $-0.4 \%$ and the maximum error is $-2.0 \%$ at $5{ }^{\circ} \mathrm{C}$.

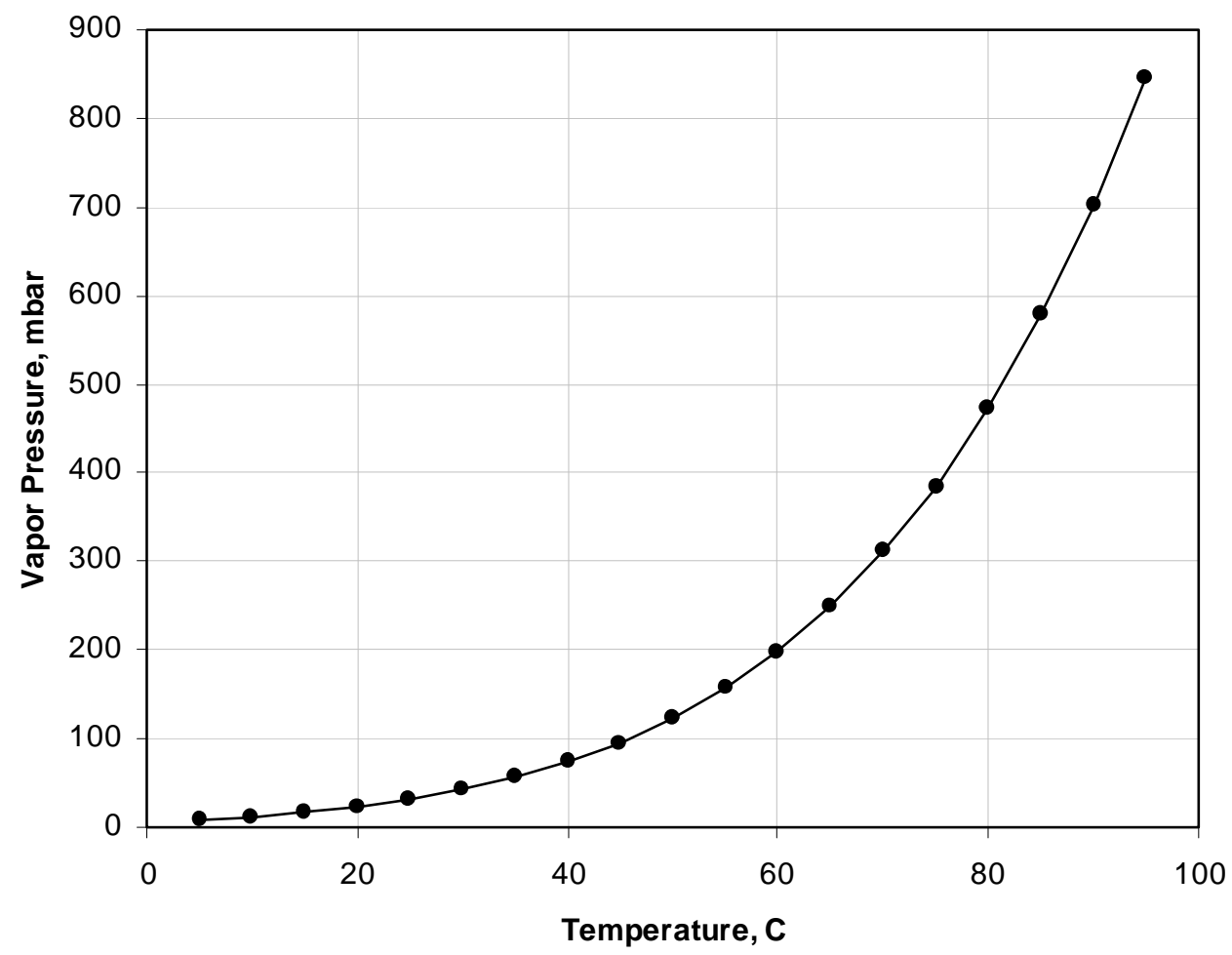

Figure 4. Calculation of water vapor pressure.

The saturation vapor pressure is used to calculate the composition of a gas stream from the specified stream humidity or to calculate the humidity if the stream composition is known. Fractional relative humidity $(R H)$ is the ratio of the partial pressure of water vapor in air divided by the saturation vapor pressure at the given temperature. Assuming an ideal mixture, the partial pressure of water vapor in the gas is the product of the mole fraction and total pressure. In equation form:

$$
R H=y_{\text {water }} P / p_{\text {sat }}=p_{\text {vap }} / p_{\text {sat }} \text {. }
$$




\section{Gas Sources}

Gas feeds into the system are processed through model Gas_Source where the user specifies the source gas temperature, pressure and humidity. The gas composition and enthalpy are calculated from these parameters using the property correlations discussed above. Model Gas_Source is used to set gas properties but not the gas flow rate. This model is typically connected to an orifice that calculates the flow rate from the pressure difference between the source and the vessel. For cases where the gas flow rate is fixed, a slightly different model named Gas_Profile is used. This model allows the user to specify a flow profile with as many as three consecutive linear ramps in gas flow. This is general enough to allow modeling steam surges and ADS steam profiles in the melter and can also be used to set a constant flow rate.

The features of the gas profile specification are illustrated in Figure 5. The user specifies three gas mass flow rates $\left(\mathrm{Qg}_{\mathrm{i}}\right)$ and three time increments $\left(\delta \mathrm{t}_{\mathrm{i}}\right)$ as well as a starting time $\left(t_{\text {start }}\right)$ when the gas flow begins. After $t_{\text {start }}$, the rate of change in gas flow is calculated from the linear slopes shown on the figure over the corresponding time intervals. At simulation times prior to $t_{\text {start }}$ and after $t_{\text {start }}+\delta t_{1}+\delta t_{2}+\delta t_{3}$, the change in gas flow is identically zero so that the gas flow remains constant. Gas flow can be ramped up to a specified value and held there by setting $\mathrm{Qg}_{2}=\mathrm{Qg}_{1}$ and $\delta \mathrm{t}_{2}$ to a value greater than the simulation run time.

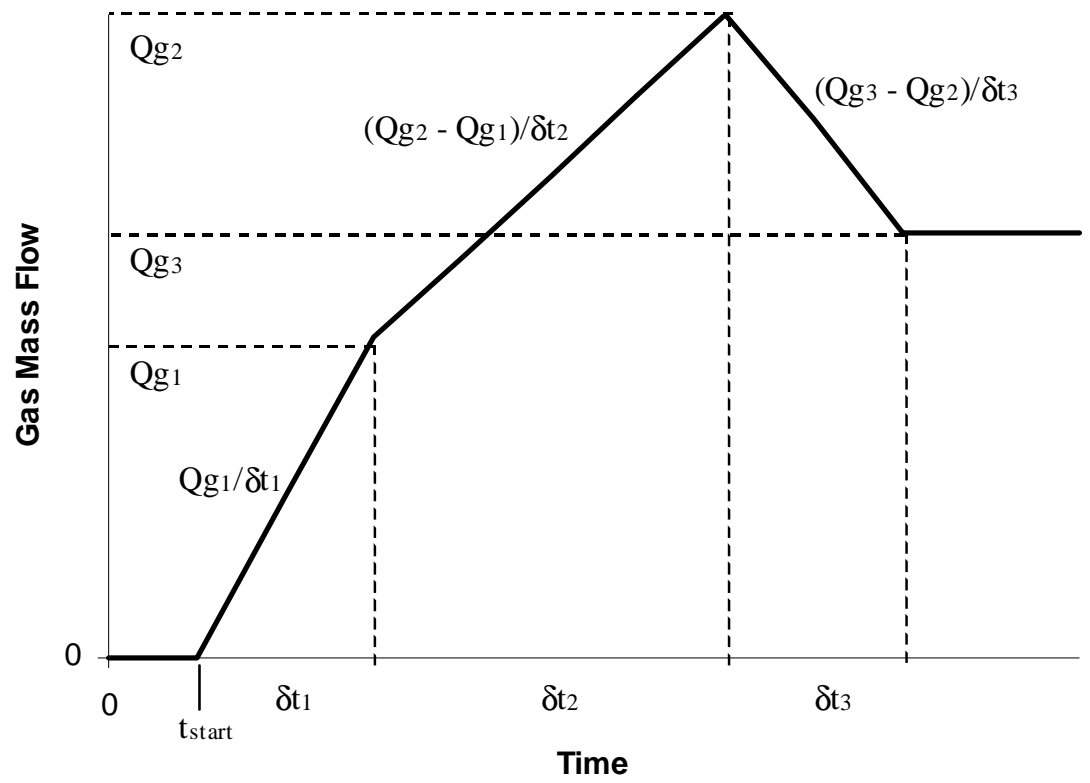

Figure 5. Specification of gas flow profiles. 


\section{Orifice}

Following Rouse (1999), model Orifice calculates flow through an orifice using the basic equation:

$$
\dot{m}_{g}=\rho_{g} Q_{g}=C_{v} D_{o}^{2} \sqrt{\rho_{g} \Delta p} .
$$

The orifice loss coefficient $C_{v}$ and the orifice diameter are specified through the input section of the code. Nominally we use the value $C_{v}=0.5715$. Air inleakage to the melter and VVS vessels is calculated as flow through an orifice and the model is also used for the restricting orifice in the LAW vessel ventilation system.

A difficulty arises in applying Eq. (7) since the numerical solution technique requires calculating the derivatives of the variables with respect to all dependent variables. Taking the derivative of gas flow with respect to pressure difference in Eq. (7) gives:

$$
\frac{\partial \dot{m}_{g}}{\partial \Delta p}=\frac{1}{2}\left(C_{v} D_{o}^{2} \sqrt{\rho_{g}}\right) \frac{1}{\sqrt{\Delta p}} .
$$

At a pressure drop of zero, Eq. (8) becomes singular and the solution fails. To overcome this problem, Eq. (7) is first rearranged into the form:

$$
\dot{m}_{g}=C_{v} D_{o}^{2} \sqrt{\rho_{g}} \frac{\Delta p}{f(\Delta p)} .
$$

To recover Eq.(7) would require the function of the pressure difference in the denominator of Eq. (9) to be:

$$
f(\Delta p)=\sqrt{|\Delta p|}
$$

Note that using Eqs. (9) and (10a) instead of Eq. (7) allows the correct assignment of the flow direction from the sign of the pressure difference. To avoid an infinite slope at zero pressure drop, Eq. (10a) is replaced with the alternative form:

$$
f(\Delta p) \equiv \sqrt{|\Delta p|+0.01 /(1+|\Delta p|)} .
$$

The behavior of this functional form is compared to that obtained from Eq. (10a) in Figure 6. The second term under the square root in Eq. (10b) ranges from 0.01 at small pressure drops to essentially zero as the pressure difference increases from zero toward a large value. For the purposes of the melter offgas system calculations, this function is indistinguishable from the square root of the pressure difference. 




Figure 6. Comparison of orifice pressure functions. 


\section{Air Duct}

Air ducts in the system are modeled as gas flow through pipes having flow resistances with the model Pipe_Flow and in the stream Gas_Pipe. Some of the nomenclature used in discussing the pipe flow model is illustrated in Figure 7.

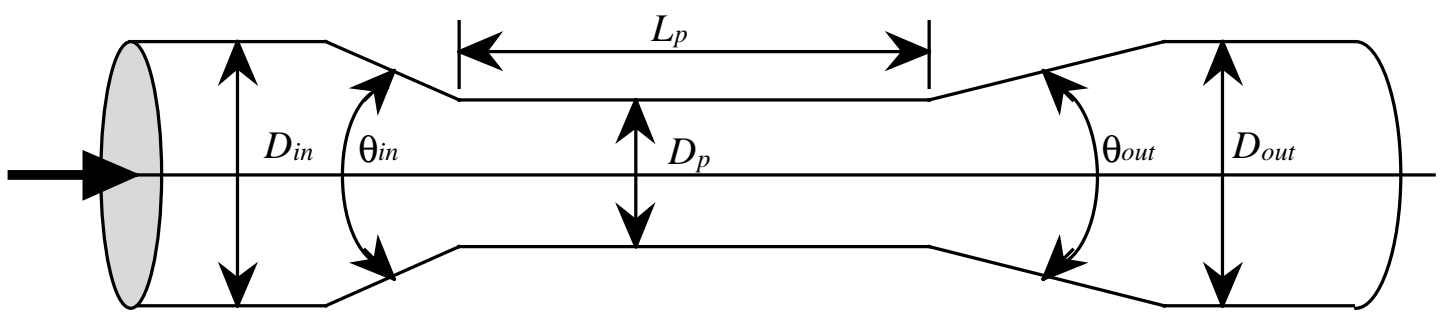

Figure 7. Schematic diagram of pipe model.

The pressure drop across the pipe is calculated from the equation:

$$
\Delta p=\frac{1}{2}\left\{f_{0}\left[\frac{L_{p}}{D_{p}}+\sum_{f} n_{f} C_{f}+K_{a d d}\right]+\left(C_{e n t} K_{e n t}+C_{e x t} K_{e x t}\right)\left|u_{g}\right|\right\} \rho_{g} u_{g} .
$$

Loss coefficients for the fittings listed in Table 3 have been automatically included in the pressure drop calculation. The user must only specify the number of each fitting $\left(n_{f}\right)$ in the duct through the tabular data entry for each section of piping. The parameter $K_{a d d}$ is included to allow the used to specify additional loss coefficients to account for nonstandard hardware configurations. This formulation is basically identical to that used by Rouse (2000g, 2000j).

Table 3. Model Fittings and Loss Coefficients

\begin{tabular}{|c|c|}
\hline Fitting & Loss Coefficient $C_{f}$ \\
\hline \hline $45^{\circ}$ Elbow & 16 \\
\hline $90^{\circ}$ Elbow & 30 \\
\hline Branch Tee & 60 \\
\hline Flow Through Tee & 20 \\
\hline Butterfly Valve & $51.4-52.36 D_{p}$ \\
\hline
\end{tabular}

Note that Eq. (11) uses the friction factor multiplied by gas velocity to the first power. The other fluid velocity that would normally appear in Eq. (11) has been incorporated into the definition of the friction factor $f_{0}$. This modified formulation is convenient for dealing with both laminar and turbulent flow regimes as shown below.

The friction factor in Eq. (11) is calculated as a function of the flow Reynolds number that is defined by the relationship: 


$$
N_{R e} \equiv \frac{D_{p} u_{g} \rho_{g}}{\mu_{g}}=\frac{4 \dot{m}_{g}}{\pi D_{p} \mu_{g}}
$$

The second equality in Eq. (12) is derived from the definition of mass flow:

$$
\dot{m}_{g}=\rho_{g} u_{g} A_{f}
$$

and by using the calculation of the flow area from $A_{f}=\pi D_{p}^{2} / 4$.

Laminar Flow Regime

At low fluid velocity, the laminar friction factor is calculated as:

$$
\left.f_{0}\right|_{\text {lam }} \equiv \frac{64}{N_{R e}} u_{g}=\frac{64 \mu_{g}}{D_{p} \rho_{g}} .
$$

By defining the friction factor to include the gas velocity, the laminar flow calculation avoids a numerical singularity in calculating the value of the friction factor at no flow conditions $\left(u_{g}=0\right)$. The last equality in Eq. (14) is used to calculate the modified laminar flow friction factor for all cases and Eq. (11) then correctly calculates a pressure drop of zero at no flow without the use of special logic tests. No flow conditions can occur during startup and during flow reversal.

\section{Turbulent Flow Regime}

In the turbulent flow regime, the friction factor is calculated using an explicit approximation to the Colebrook-White equation originally due to Jain (1976) and reported by Blevins (1984). This correlation, multiplied by the gas velocity, can be written as:

$$
\left.f_{0}\right|_{\text {turb }}=\left|u_{g}\right|\left[2 \log _{10}\left(\frac{k_{s}}{3.7 D_{p}}+\frac{5.74}{N_{R e}^{0.9}}\right)\right]^{-2},
$$

which is identical in form to that used by Rouse (2000j). In practice, we have scaled the Reynolds number defined in Eq. (12) by dividing by 1000 and added a small value (0.01) to it to avoid a division by zero when the Reynolds number is identically zero. These modifications give the functional form for the turbulent friction factor that is coded into the model:

$$
\left.f_{0}\right|_{\text {turb }}=\left|u_{g}\right|\left[2 \log _{10}\left(\frac{k_{s}}{3.7 D_{p}}+\frac{0.01145}{\left(N_{R e}+0.01\right)^{0.9}}\right)\right]^{-2} .
$$




\section{Transition Flow Regime}

To obtain a smooth transition between the laminar and turbulent flow regimes, the overall friction factor is calculated using the exponential interpolation scheme shown in Eq. (16):

$$
\begin{aligned}
f_{0} & =\left.f_{0}\right|_{\text {lam }} \exp \left(-2 N_{R e} / 3\right)+\left.f_{0}\right|_{\text {turb }}\left[1-\exp \left(-2 N_{R e} / 3\right)\right] \\
& =\left.f_{0}\right|_{\text {turb }}+\left\{\left.f_{0}\right|_{\text {lam }}-\left.f_{0}\right|_{\text {turb }}\right\} \exp \left(-2 N_{R e} / 3\right)
\end{aligned} .
$$

Clearly in the limit of the Reynolds number approaching zero Eq. (16) approaches the laminar flow friction factor and in the limit of a large Reynolds number the turbulent flow friction factor dominates. Figure 8 shows the friction factor approximation over the range of Reynolds number from 10 to $10^{5}$. The friction factor begins to transition from the laminar correlation at a Reynolds number of approximately 200 and is essentially using the turbulent friction factor at Reynolds numbers of 4000 and higher. As indicated on the figure, the transition flow regime is normally assumed to occur between Reynolds numbers of 2000 and 4000. However, if the laminar friction factor is followed to a Reynolds number of 2000 it will increase during the transition to turbulent flow. For a given pressure gradient, this increase in the friction factor will decrease the gas velocity and drive the flow back toward the laminar regime and the solution will have difficulty converging. Similar arguments apply when the flow is decreasing from turbulent flow to laminar. In either case, if the same value of the friction factor can be obtained with more than one value of gas velocity the code will have difficulty converging. The interpolation scheme in Eq. (16) eliminates this problem by creating a single valued function for the friction factor that monotonically decreases as the Reynolds number increases. The factor of $2 / 3$ in the exponential was chosen by trial and error to find a smoothing function that was both monotonic and accurately reproduced the friction factor in the turbulent regime where the gas flow predominantly occurs. 


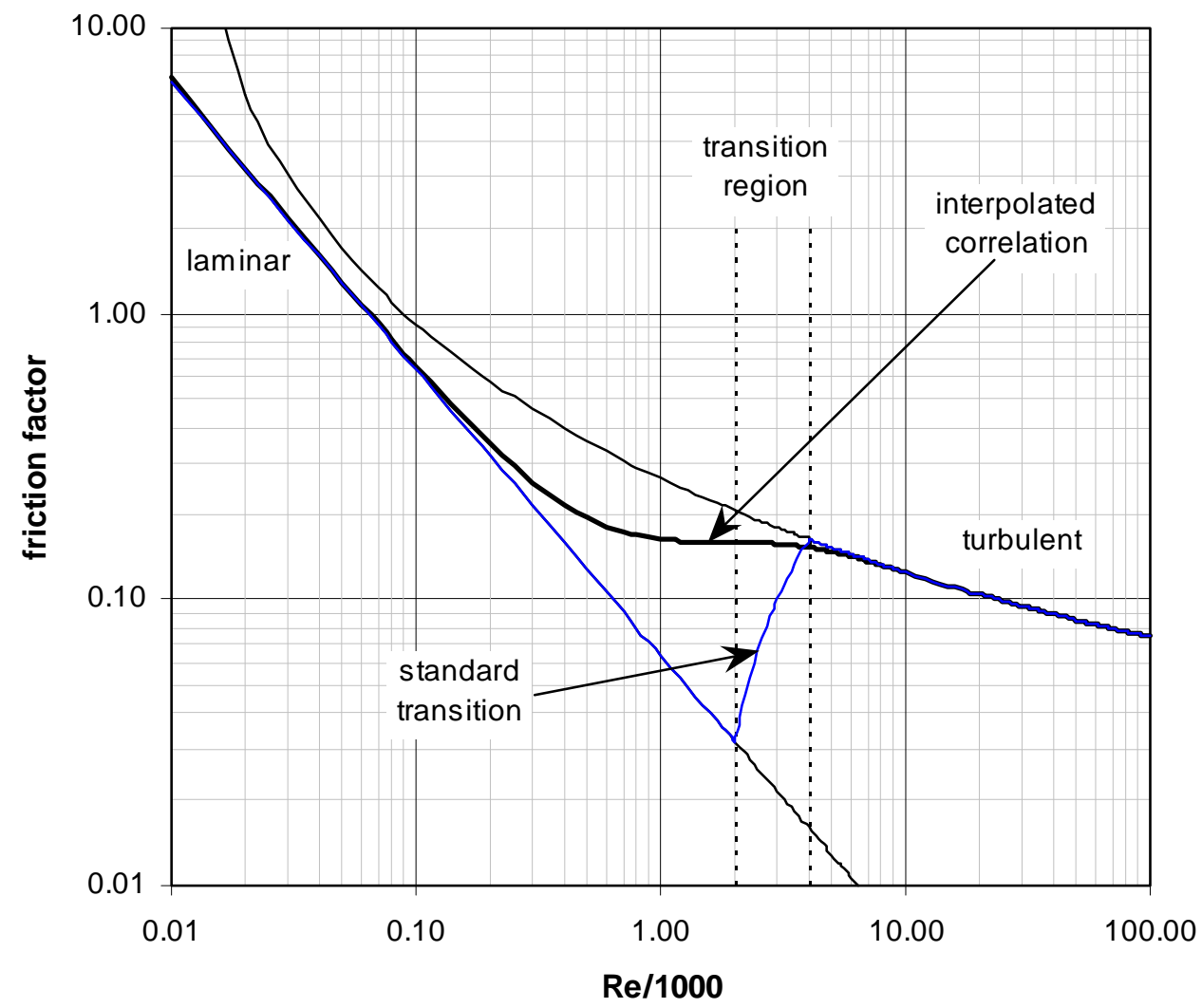

Figure 8. Friction factor correlation developed for dynamic model.

Table 4 lists parameters for the air ducts modeled in the HLW offgas system (Rouse, 2000k, Appendix c.3) while Table 5 gives parameters for the LAW offgas system ducts (Rouse, 20001, Appendix c.3). The added resistances in Duct 4 in the HLW system and Ducts 4, 10 and 16 in the LAW system account for the presence of non-standard elbows in those lines (Rouse, 2000g). The dynamic model uses a duct to connect the melter to the film cooler where, in reality, the film cooler is placed directly on the melter offgas port. Therefore, Duct 1 in the HLW model and Ducts 1, 7 and 13 in the LAW model are used to account for entrance losses into the film cooler with a small length of duct that offers negligible additional flow resistance. Duct 2 represents pressure losses through the film cooler itself. The entrance contraction in the first duct in the system represents the sudden contraction from the melter plenum into the duct which is assumed to be an abrupt change in duct diameter. Similarly, the expansion at the end represents flow out the stack and is again assumed to be an abrupt expansion. These sudden expansions and contractions are flagged by specifying a reducer angle of $180^{\circ}$. All other expansions and contractions in the system are assumed to be gradual changes in duct diameter with a reducer angle of $30^{\circ}$.

Entrance and exit losses in Eq. (11) are calculated using the following method. The user inputs diameters of inlet $\left(D_{i n}\right)$ and outlet $\left(D_{\text {out }}\right)$ fittings to the duct and inlet and outlet 
reducer angles. The code then checks whether there is an expansion or contraction at the inlet and outlet and calculates the corresponding loss coefficient using the equations given by Rouse $(2000 \mathrm{~g})$ as reproduced in Table 6 . The coefficients in Table 6 apply for sudden contractions or expansions. If reducer angles $\left(\theta_{\text {in }}\right.$ and $\left.\theta_{\text {out }}\right)$ less than $180^{\circ}$ are specified, the model adjusts the loss coefficients by multiplying by factors of $2.6 \sin (\pi \theta / 360)$ for a gradual expansion or $1.6 \sin (\pi \theta / 360)$ for a gradual contraction. This calculation is also used to account for the sudden contraction losses between the melter and film cooler and sudden expansion losses at the exit of the offgas system into the stack.

Table 4. HLW Offgas Air Duct Parameters

\begin{tabular}{|c||c|c|c|c|c|c|c|c|c|c|c|}
\hline $\mathbf{D u c t}$ & $\begin{array}{c}\mathbf{k}_{\mathbf{S}} \\
\left(\mathrm{mx} 10^{4}\right)\end{array}$ & $\begin{array}{c}\mathbf{L}_{\mathbf{p}} \\
(\mathrm{m})\end{array}$ & $\begin{array}{c}\mathbf{I D}_{\mathbf{p}} \\
(\mathrm{m})\end{array}$ & $\mathbf{n} \mathbf{4 5}$ & $\mathbf{n g 0}$ & $\mathbf{n}_{\mathbf{b t}}$ & $\mathbf{n}_{\mathbf{f t}}$ & $\mathbf{n}_{\mathbf{b v}}$ & $\mathbf{E x p}$ & $\mathbf{C o n}$ & $\mathbf{K}_{\mathbf{a d d}}$ \\
\hline \hline $\mathbf{1}$ & 9.1440 & 0.0305 & 0.2027 & 0 & 0 & 0 & 0 & 0 & 0 & 1 & 0 \\
\hline $\mathbf{2}$ & 9.1440 & 0.3048 & 0.2027 & 0 & 0 & 0 & 1 & 0 & 0 & 0 & 0 \\
\hline $\mathbf{3}$ & 9.1440 & 1.0668 & 0.2027 & 0 & 0 & 1 & 0 & 0 & 0 & 0 & 0 \\
\hline $\mathbf{4}$ & 9.1440 & 2.7432 & 0.2027 & 0 & 0 & 0 & 0 & 0 & 0 & 0 & 36.05 \\
\hline $\mathbf{5}$ & 0.4572 & 16.1544 & 0.2027 & 1 & 3 & 0 & 0 & 0 & 0 & 0 & 0 \\
\hline $\mathbf{6}$ & 0.4572 & 19.8120 & 0.2027 & 0 & 3 & 0 & 0 & 0 & 1 & 0 & 0 \\
\hline $\mathbf{7}$ & 0.4572 & 21.9456 & 0.2125 & 0 & 3 & 1 & 1 & 1 & 0 & 0 & 0 \\
\hline $\mathbf{8}$ & 0.4572 & 13.4112 & 0.2125 & 1 & 2 & 0 & 0 & 0 & 0 & 0 & 0 \\
\hline $\mathbf{9}$ & 0.4572 & 17.0688 & 0.3048 & 0 & 2 & 0 & 0 & 0 & 0 & 0 & 0 \\
\hline $\mathbf{1 0}$ & 0.4572 & 6.0960 & 0.3048 & 0 & 4 & 0 & 0 & 0 & 0 & 0 & 0 \\
\hline $\mathbf{1 1}$ & 0.4572 & 60.9600 & 0.3048 & 0 & 12 & 0 & 1 & 1 & 0 & 0 & 0 \\
\hline $\mathbf{1 2 , 1 3}$ & 0.4572 & 3.3528 & 0.2027 & 0 & 2 & 0 & 1 & 1 & 0 & 1 & 0 \\
\hline $\mathbf{1 4} \mathbf{1 5}$ & 0.4572 & 3.0480 & 0.2027 & 0 & 2 & 1 & 0 & 1 & 1 & 0 & 0 \\
\hline $\mathbf{1 6}$ & 0.4572 & 25.6032 & 0.2125 & 0 & 6 & 0 & 1 & 1 & 0 & 0 & 0 \\
\hline $\mathbf{1 7}$ & 0.4572 & 32.9184 & 0.2125 & 0 & 6 & 0 & 1 & 2 & 0 & 0 & 0 \\
\hline $\mathbf{1 8}$ & 0.4572 & 24.3840 & 0.3048 & 0 & 3 & 0 & 0 & 0 & 0 & 0 & 0 \\
\hline $\mathbf{1 9}$ & 0.4572 & 6.0960 & 0.3048 & 0 & 4 & 0 & 0 & 0 & 0 & 0 & 0 \\
\hline $\mathbf{2 0}$ & 0.4572 & 15.2400 & 0.3048 & 0 & 3 & 0 & 1 & 0 & 0 & 0 & 0 \\
\hline $\mathbf{2 1 , 2 2}$ & 0.4572 & 3.0480 & 0.2027 & 0 & 3 & 1 & 0 & 0 & 0 & 1 & 0 \\
\hline $\mathbf{2 3 , 2 4}$ & 0.4572 & 3.0480 & 0.2027 & 0 & 3 & 0 & 1 & 0 & 1 & 0 & 0 \\
\hline $\mathbf{2 5}$ & 0.4572 & 112.7760 & 0.3048 & 0 & 4 & 1 & 0 & 0 & 1 & 0 & 0 \\
\hline
\end{tabular}


Table 5. LAW Offgas Air Duct Parameters

\begin{tabular}{|c||c|c|c|c|c|c|c|c|c|c|c|}
\hline $\mathbf{D u c t}$ & $\begin{array}{c}\mathbf{k}_{\mathbf{s}} \\
\left(\mathrm{m} \times 10^{4}\right)\end{array}$ & $\begin{array}{c}\mathbf{L}_{\mathbf{p}} \\
(\mathrm{m})\end{array}$ & $\begin{array}{c}\mathbf{D}_{\mathbf{p}} \\
(\mathrm{m})\end{array}$ & $\mathbf{n}_{\mathbf{4 5}}$ & $\mathbf{n}_{\mathbf{9 0}}$ & $\mathbf{n}_{\mathbf{b t}}$ & $\mathbf{n}_{\mathbf{f t}}$ & $\mathbf{n}_{\mathbf{b v}}$ & $\mathbf{E x p}$ & $\mathbf{C o n}$ & $\mathbf{K}_{\mathbf{a d d}}$ \\
\hline \hline $\mathbf{1 , 7 , 1 3}$ & 9.1440 & 0.0305 & 0.2454 & 0 & 0 & 0 & 0 & 0 & 0 & 1 & 0 \\
\hline $\mathbf{2 , \mathbf { 8 } , \mathbf { 1 4 }}$ & 9.1440 & 0.3048 & 0.2454 & 0 & 0 & 0 & 1 & 0 & 0 & 0 & 0 \\
\hline $\mathbf{3 , 9 , 1 5}$ & 9.1440 & 1.2192 & 0.2454 & 0 & 0 & 1 & 0 & 0 & 0 & 0 & 0 \\
\hline $\mathbf{4 , 1 0 , 1 6}$ & 9.1440 & 3.3528 & 0.2454 & 0 & 0 & 0 & 0 & 0 & 0 & 0 & 36.05 \\
\hline $\mathbf{5 , 1 1 , 1 7}$ & 0.4572 & 16.1544 & 0.2454 & 1 & 3 & 0 & 0 & 0 & 0 & 0 & 0 \\
\hline $\mathbf{6 , 1 2 , 1 8}$ & 0.4572 & 15.2400 & 0.2454 & 0 & 2 & 0 & 0 & 0 & 0 & 0 & 0 \\
\hline $\mathbf{1 9}$ & 0.4572 & 12.4968 & 0.4286 & 0 & 0 & 1 & 1 & 0 & 1 & 0 & 0 \\
\hline $\mathbf{2 0}$ & 0.4572 & 5.4864 & 0.4778 & 0 & 1 & 0 & 0 & 0 & 0 & 0 & 0 \\
\hline $\mathbf{2 1}$ & 0.4572 & 41.1480 & 0.4778 & 0 & 6 & 0 & 0 & 0 & 0 & 0 & 0 \\
\hline $\mathbf{2 2}$ & 0.4572 & 3.0480 & 0.4778 & 0 & 4 & 1 & 2 & 0 & 0 & 0 & 0 \\
\hline $\mathbf{2 3}$ & 0.4572 & 31.3944 & 0.4778 & 0 & 5 & 0 & 0 & 1 & 0 & 1 & 0 \\
\hline $\mathbf{2 4 , 2 5}$ & 0.4572 & 5.7912 & 0.3334 & 0 & 1 & 0 & 0 & 1 & 1 & 0 & 0 \\
\hline $\mathbf{2 6 , 2 7}$ & 0.4572 & 3.6576 & 0.3334 & 0 & 2 & 0 & 0 & 0 & 0 & 0 & 0 \\
\hline $\mathbf{2 8 , 2 9}$ & 0.4572 & 5.7912 & 0.3334 & 0 & 3 & 1 & 0 & 0 & 0 & 0 & 0 \\
\hline $\mathbf{3 0}$ & 0.4572 & 21.6408 & 0.4286 & 0 & 8 & 0 & 1 & 0 & 0 & 0 & 0 \\
\hline $\mathbf{3 1}$ & 0.4572 & 96.6216 & 0.5746 & 2 & 6 & 0 & 0 & 0 & 0 & 0 & 0 \\
\hline $\mathbf{3 2}$ & 0.4572 & 83.8200 & 0.4286 & 0 & 8 & 0 & 0 & 0 & 1 & 0 & 0 \\
\hline
\end{tabular}

Table 6. Duct Entrance and Exit Loss Coefficient Calculation

\begin{tabular}{|c|c|c|}
\hline Test & Case & Loss Coefficient \\
\hline \hline$D_{\text {in }}<D_{p}$ & Entrance expansion & $K_{\text {ent }}=\left[1-\left(D_{\text {in }} / D_{p}\right)^{2}\right]^{2}$ \\
\hline$D_{\text {in }}>D_{p}$ & Entrance contraction & $K_{\text {ent }}=0.5\left[1-\left(D_{p} / D_{\text {in }}\right)^{2}\right]$ \\
\hline$D_{\text {out }}<D_{p}$ & Exit contraction & $K_{\text {ext }}=0.5\left[1-\left(D_{\text {out }} / D_{p}\right)^{2}\right]$ \\
\hline$D_{\text {out }}>D_{p}$ & Exit expansion & $K_{\text {ext }}=\left[1-\left(D_{p} / D_{\text {out }}\right)^{2}\right]^{2}$ \\
\hline
\end{tabular}




\section{Gas Volumes}

Gas volumes in the VVS vessels and smaller gas volumes where gases mix in the film cooler, pressure control mixer, WESP mixer, vent mixer, fan manifold, and vessel ventilation mixing tees are modeled with dynamic material and energy balances. Since the outlet temperature is specified, the gas space in the melter is modeled with a dynamic mass balance alone. In addition, gas-liquid mass transfer is considered in the VVS vessels. To accommodate the various requirements for gas space modeling, five separate models were required. The names and distinguishing characteristics of these models are listed in Table 7.

Table 7. Characteristics of Gas Space Models

\begin{tabular}{|c||c|c|c|c|}
\hline Model Name & $\begin{array}{c}\text { Number of } \\
\text { Inlet } \\
\text { Streams }\end{array}$ & $\begin{array}{c}\text { Dynamic } \\
\text { Mass } \\
\text { Balance }\end{array}$ & $\begin{array}{c}\text { Dynamic } \\
\text { Energy } \\
\text { Balance }\end{array}$ & $\begin{array}{c}\text { Gas-Liquid } \\
\text { Mass } \\
\text { Transfer }\end{array}$ \\
\hline \hline VVS Vessel & 2 & $\checkmark$ & $\checkmark$ & $\checkmark$ \\
\hline Plenum & 1 & $\checkmark$ & $\checkmark$ & \\
\hline Gas_Tank & 2 & $\checkmark$ & $\checkmark$ & \\
\hline Mixing_Volume & 3 & $\checkmark$ & $\checkmark$ & \\
\hline Melter & 5 & $\checkmark$ & & \\
\hline
\end{tabular}

In general, the dynamic mass balance equations used to calculate the change in mass of each gas component $(i=$ air, water $)$ in any gas space are:

$$
\frac{d m_{i}}{d t}=\sum_{j=1}^{N_{\text {inlest }}}\left(x_{i} \dot{m}\right)_{j}-\sum_{k=1}^{N_{\text {oulters }}}\left(x_{i} \dot{m}\right)_{k}+x_{i} \dot{e}
$$

where the summations are taken over the inlet and outlet streams, $x_{i}$ is the component mass fraction in the stream, and $\dot{e}$ is the rate of evaporation. The dynamic energy balance equations used to calculate the change in total enthalpy of material in the gas space $\left(H_{g}\right)$ are:

$$
\frac{d H_{g}}{d t}=\sum_{j=1}^{N_{\text {lnlets }}}\left(\dot{m}_{j} h_{j}\right)-\sum_{k=1}^{N_{\text {oultets }}}\left(\dot{m}_{k} h_{k}\right)+\dot{e} h_{e} .
$$

Specific enthalpies for the inlet and outlet gas streams and evaporation are calculated as:

$$
h_{j, k, e}=\left.\sum_{i}\left(x_{i} h_{i}\right)\right|_{j, k, e} .
$$

Specific enthalpies for the inlet streams are passed into the gas volumes as a property of the flow streams. Therefore, the gas volume must only locally calculate the mixture 
specific enthalpy which is the same as the outlet enthalpy assuming a well mixed volume. Evaporation is assumed to add water vapor to the gas phase at the liquid temperature. We assume that the heat of evaporation is supplied by the large mass of water in the liquid phase. The total enthalpy in the gas mixture is calculated as total mass multiplied by the mixture specific enthalpy:

$$
H_{g}=\left[\sum_{i} m_{i}\right]\left[\sum_{i}\left(x_{i} h_{i}\right)\right] .
$$

Equations (18) and (20) are solved for the temperature in the gas space. The gas spaces are assumed to be well-mixed volumes so that the gas composition, temperature and enthalpy in the outlet stream are the same as that within the volume.

In the VVS vessels, the evaporation of water from the liquid in the vessel into the gas phase is modeled. The rate of evaporation is calculated as:

$$
\dot{e}=A_{s} k_{c} M_{\text {water }} \frac{\left(p_{\text {sat }}-p_{\text {vap }}\right)}{R\left(T_{g}+273\right)} .
$$

In Eq. (21), $A_{s}$ is the surface area of the liquid $\left(\pi d_{t}^{2} / 4\right), k_{c}$ is the mass transfer coefficient in units of $\mathrm{m} / \mathrm{s}, p_{\text {sat }}$ is the saturation vapor pressure, and $p_{\text {vap }}$ is the vapor pressure of water in the gas. As shown in Eq. (6), the vapor pressure is calculated as the mole fraction of water vapor in the gas multiplied by the tank pressure. For estimation purposes, the gas space is assumed to be of uniform height and the flow is assumed to be parallel to the liquid surface as illustrated in Figure 9.

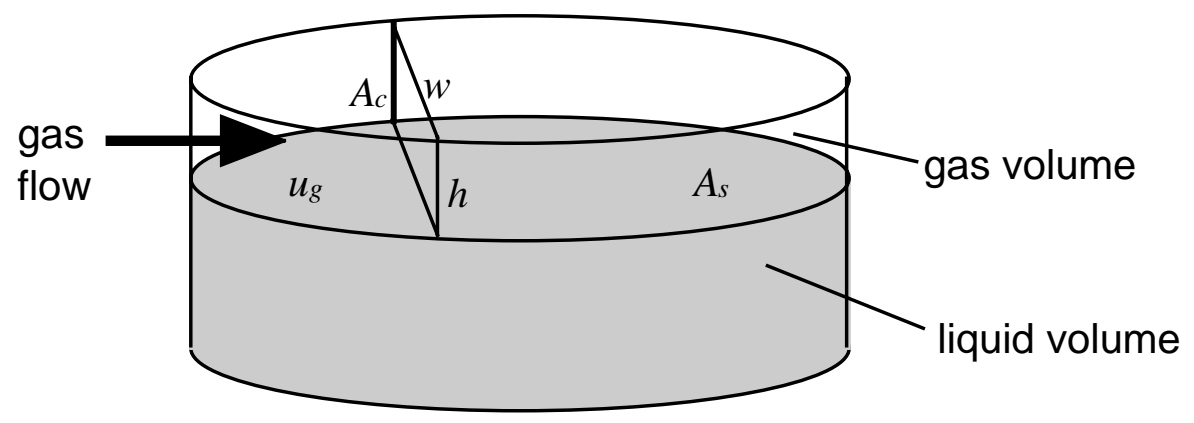

Figure 9. Schematic representation of flow through tank gas space.

The average width of the flow path through the vessel gas space can be shown to be

$$
w=\frac{\pi}{4} d_{t}
$$


The average cross-sectional flow area $\left(A_{c}\right)$ is the average flow width multiplied by the height of the gas layer $(h)$. The height of the gas layer is the gas volume divided by the tank surface area. Also, the average gas velocity is the volumetric flow $(Q)$ divided by the average flow area. Combining these definitions gives the relationships:

$$
A_{c}=w h=\frac{\pi}{4} d_{t} \frac{V}{A_{s}}=\frac{V}{d_{t}} \text { and } u_{g}=Q \frac{d_{t}}{V} .
$$

To evaluate the mass transfer coefficient, a characteristic Reynolds number for flow across the liquid surface must be defined. We assume that the correct length scale for the flow is the tank diameter and define the flow Reynolds number as:

$$
N_{R e}=\frac{d_{t} u_{g} \rho_{g}}{\mu_{g}} .
$$

A rough calculation using the above relationships indicates that gas flow across the surface of the tank will be in the laminar flow regime under any reasonable flow conditions. Therefore the laminar flow correlation in Eq. (23) for flow across a flat plate is used to estimate the mass transfer coefficient (Foust et al., 1967):

$$
\frac{k_{c}}{u_{g}}=\frac{0.65}{N_{R e}^{0.5}} \cong \frac{0.0206}{\left(\hat{N}_{R e}+0.01\right)^{0.5}} .
$$

The second equality in Eq. (23) is obtained by scaling the Reynolds number by a factor of $1000\left(\hat{N}_{R e}=N_{R e} \cdot 10^{-3}\right)$ and adding the constant 0.01 to avoid a division by zero when there is no gas flow through the tank.

Inlet streams and mixing volumes used in the system models are shown in Table 8 for both the LAW system and the HLW system. Gas volumes in the VVS vessels, the melter, and the SBS and WESP plenums were obtained from the reports by Rouse (2000m), Fergestrom and Meeuwsen, (2000), and Meeuwsen (2001). Other gas space volumes in the model are arbitrary and do not fully account for the gas volume of the offgas system. 
Table 8. Dynamic Gas Volumes in System Models

\begin{tabular}{|c|c|c|c|c|c|c|}
\hline Unit & $\begin{array}{c}\text { Inlet } \\
\text { Stream } \\
1\end{array}$ & $\begin{array}{c}\text { Inlet } \\
\text { Stream } \\
2\end{array}$ & $\begin{array}{c}\text { Inlet } \\
\text { Stream } \\
3\end{array}$ & $\begin{array}{c}\text { Inlet } \\
\text { Stream } \\
4\end{array}$ & $\begin{array}{c}\text { Inlet } \\
\text { Stream } \\
5\end{array}$ & $\begin{array}{c}\text { Volume } \\
\qquad\left(\mathbf{m}^{\mathbf{3}}\right)\end{array}$ \\
\hline HLW Melter & $\begin{array}{l}\text { Constant } \\
\text { steam }\end{array}$ & $\begin{array}{l}\text { Sparge } \\
\text { air }\end{array}$ & $\begin{array}{c}\text { Air } \\
\text { inleakage }\end{array}$ & $\begin{array}{r}\text { ADS } \\
\text { Steam }\end{array}$ & $\begin{array}{l}\text { Surge } \\
\text { Steam }\end{array}$ & 3.568 \\
\hline LAW Melter & $\begin{array}{c}\text { Constant } \\
\text { steam }\end{array}$ & $\begin{array}{l}\text { Sparge } \\
\text { air }\end{array}$ & $\begin{array}{c}\text { Air } \\
\text { inleakage }\end{array}$ & $\begin{array}{r}\text { ADS } \\
\text { Steam }\end{array}$ & $\begin{array}{l}\text { Surge } \\
\text { Steam }\end{array}$ & 9.175 \\
\hline Film Cooler & $\begin{array}{l}\text { Melter } \\
\text { offgas }\end{array}$ & $\begin{array}{l}\text { Cooling } \\
\text { air }\end{array}$ & LP steam & & & 0.25 \\
\hline $\begin{array}{c}\text { Pressure } \\
\text { Control Mixer }\end{array}$ & $\begin{array}{l}\text { Melter } \\
\text { offgas }\end{array}$ & $\begin{array}{l}\text { Control } \\
\text { air }\end{array}$ & & & & 0.25 \\
\hline $\begin{array}{l}\text { WESP Mixer } \\
\text { (LAW only) }\end{array}$ & $\begin{array}{c}\text { Melter \#1 } \\
\text { offgas }\end{array}$ & $\begin{array}{c}\text { Melter \#2 } \\
\text { offgas }\end{array}$ & $\begin{array}{c}\text { Melter \#3 } \\
\text { offgas }\end{array}$ & & & 0.25 \\
\hline Vent Mixer & $\begin{array}{l}\text { Melter } \\
\text { offgas }\end{array}$ & $\begin{array}{l}\text { VVS } \\
\text { offgas }\end{array}$ & & & & 0.25 \\
\hline Fan Manifold 1 & $\begin{array}{l}\text { Outlet of } \\
\text { Fan \#1 }\end{array}$ & $\begin{array}{c}\text { Outlet of } \\
\text { Fan \#2 }\end{array}$ & & & & 0.25 \\
\hline $\begin{array}{c}\text { Fan Manifold } 4 \\
\text { (HLW only) }\end{array}$ & $\begin{array}{l}\text { Outlet of } \\
\text { Fan \#3 }\end{array}$ & $\begin{array}{c}\text { Outlet of } \\
\text { Fan \#4 }\end{array}$ & & & & 0.25 \\
\hline Feed Vessels & Purge air & $\begin{array}{c}\text { Air } \\
\text { inleakage }\end{array}$ & & & & various \\
\hline Mixing Tees & Lateral & Header & & & & 0.01 \\
\hline SBS Plenum & $\begin{array}{c}\text { SBS } \\
\text { Offgas }\end{array}$ & & & & & 3.0 \\
\hline WESP Inlet & $\begin{array}{l}\text { Melter } \\
\text { Offgas }\end{array}$ & & & & & 2.0 \\
\hline WESP Outlet & $\begin{array}{l}\text { WESP } \\
\text { Offgas }\end{array}$ & & & & & 2.0 \\
\hline
\end{tabular}




\section{Air Filter}

The generic model Filter was developed to calculate the pressure drop across both a High Efficiency Particle Air (HEPA) Filter and a High Efficiency Mist Eliminator (HEME). Rouse (2000e) has shown that essentially the entire pressure drop across a HEME is created by flow through the filter elements with smaller contributions from a sudden expansion at the entrance and a sudden contraction at the discharge. Steady-state calculations by Rouse $(2000 \mathrm{~h})$ also show that the pressure drop across HEPA filters is a combination of losses from a sudden expansion at the inlet, a sudden contraction at the entrance to the filter elements, and a sudden contraction at the outlet. Smaller contributions to the HEPA filter pressure loss come from the flow through the filter elements themselves and flow through the filter housing sections. The generic model considers pressure losses from an inlet expansion, outlet contraction, contraction at the filter entrance, and flow through the filter elements. The model neglects losses from flow through the filter housing. A schematic representation of the filter model is shown in Figure 10.

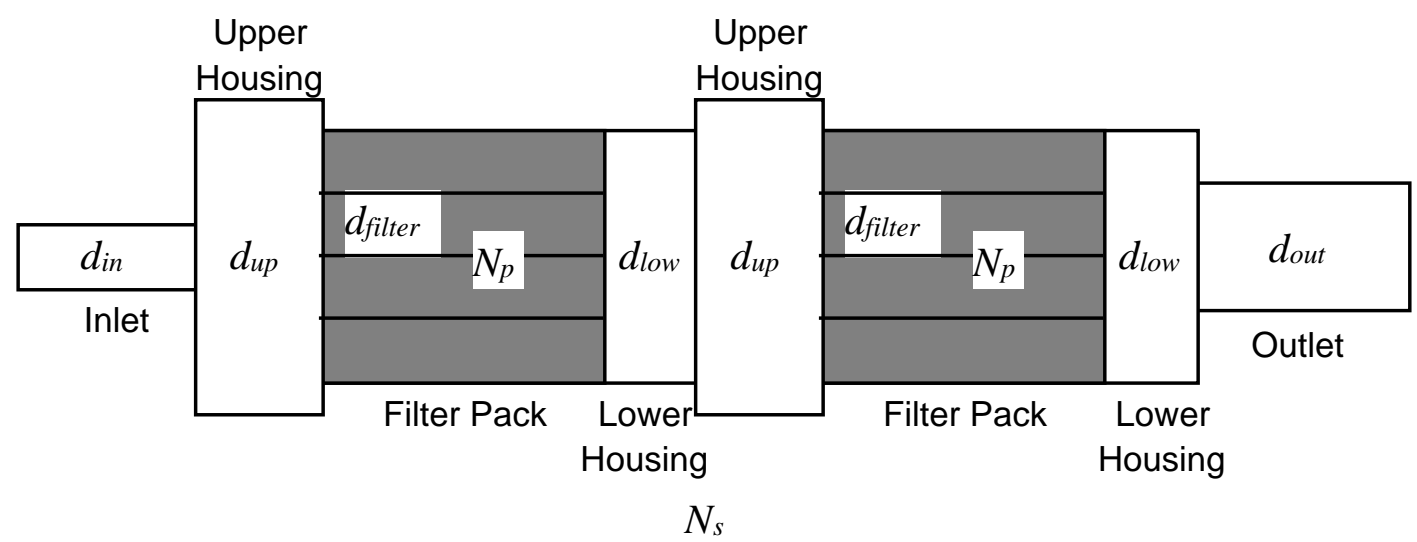

Figure 10. Schematic representation of general filter model.

Loss coefficients for the inlet expansion and outlet contraction are calculated as:

$$
K_{\text {in }}=\left[1-\left(d_{\text {in }} / d_{\text {up }}\right)^{2}\right]^{2} \text { and } K_{\text {out }}=\frac{1}{2}\left[1-\left(d_{\text {out }} / d_{\text {low }}\right)^{2}\right] \text {, }
$$

where $d_{u p}$ and $d_{\text {low }}$ are the upper and lower filter housing diameters at the inlet and outlet sides, respectively. In the code input, these diameters are entered separately and need not be the same value. Similarly, the loss coefficient for a sudden contraction at the entrance to the filter element is:

$$
K_{e n t}=\frac{1}{2}\left[1-\left(d_{\text {filter }} / d_{u p}\right)^{2}\right]
$$

where $d_{\text {filter }}$ is the diameter of a single filter unit. 
The pressure drop across a filter element is calculated by fitting data supplied by the manufacturer to an empirical equation of the form:

$$
\begin{gathered}
\Delta p_{f}=c_{1} u_{g}+c_{2} u_{g}^{2}=K_{f 1} \rho_{g} u_{g}+\frac{1}{2} K_{f 2} \rho_{g} u_{g}^{2}, \\
\text { where } K_{f 1} \equiv c_{1} / \rho_{g} \text { and } K_{f 2} \equiv 2 c_{2} / \rho_{g} .
\end{gathered}
$$

Rouse (2000e) has provided limited data for the pressure drop across the HEME for the HLW melter offgas system. The fit to this data is shown in Figure 11. Although the data is very limited, the assumed form of Eq. (27) appears to accurately represent the data trend. While the exact gas density at which the data was taken is not known, assuming a gas temperature of $50^{\circ} \mathrm{C}$ to match the steady-state HEME calculation, $\rho_{g}$ is 0.86 for air and the data fit implies equation coefficients of $K_{f 1}=19550$ and $K_{f 2}=88900$.

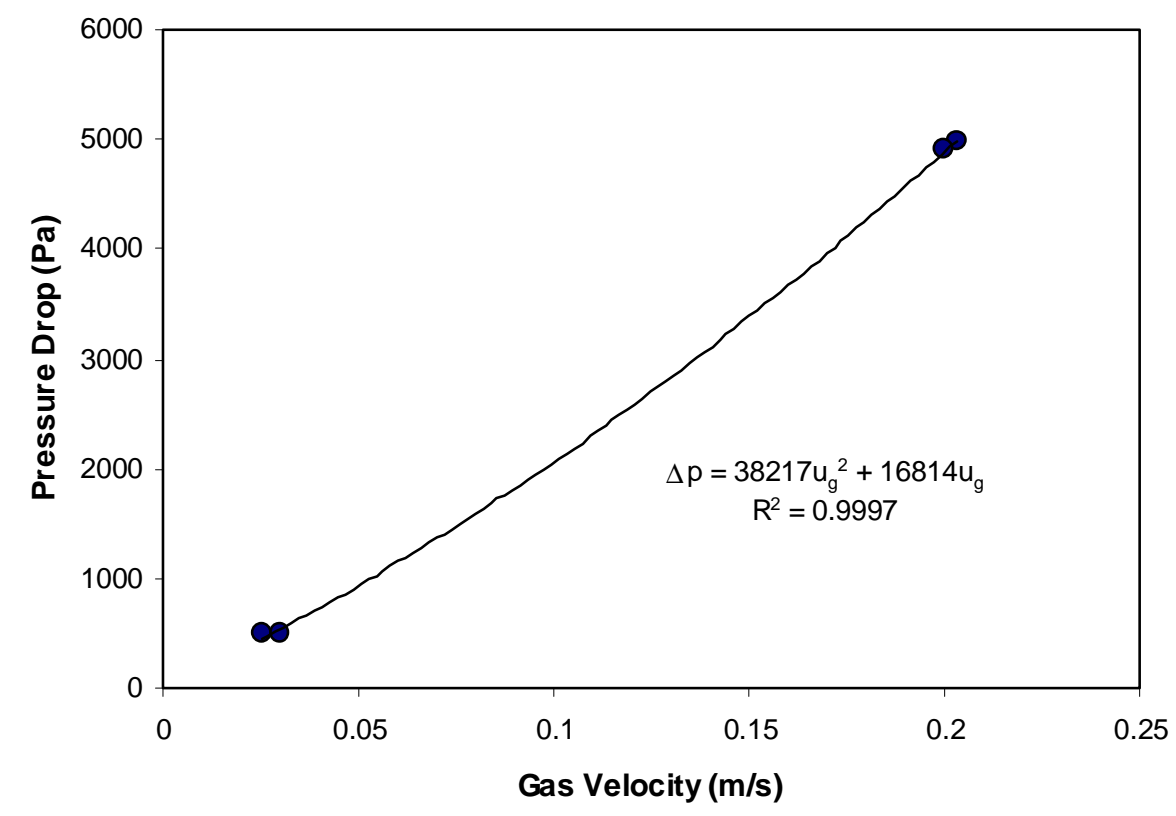

Figure 11. Fit to manufacturer's data for HEME pressure drop.

It is convenient for calculation purposes to convert from the gas velocity to the mass flow rate of gas as defined in Eq. (13) since this is a constant. Substituting Eq. (13) into Eq. (26) gives:

$$
\Delta p_{f}=K_{f 1} \frac{\dot{m}}{A_{f}}+\frac{1}{2} K_{f 2} \frac{\dot{m}^{2}}{\rho_{g} A_{f}^{2}} .
$$

Combining the second term in Eq. (28) with the entrance and exit loss coefficients from Eqs. (24) and (25) an overall loss coefficient can be written as: 


$$
K_{v}=\frac{1}{2}\left[\frac{K_{i n}}{A_{\text {in }}^{2}}+N_{s}\left(\frac{K_{e n t}}{A_{f e}^{2}}+\frac{K_{f 2}}{A_{f}^{2}}\right)+\frac{K_{o u t}}{A_{\text {out }}^{2}}\right] .
$$

In Eq. (29), $A_{f e}$ is the total area of the filter elements in the flow direction and $N_{s}$ is the number of filter banks in series. The area of the filter elements in the flow direction is:

$$
A_{f e}=N_{p} \pi \frac{d_{\text {filter }}^{2}}{4}
$$

where $N_{p}$ is the number of filter elements in parallel. The overall pressure drop across the filter unit is then calculated using the equation:

$$
\Delta p=N_{s} \frac{K_{f 1}}{A_{f}} \dot{m}+\frac{K_{v}}{\rho_{g}} \dot{m}^{2} .
$$

The flow area within the filters is designed to be much larger than the area of the elements. The filter model has been generalized to accept filters having either a rectangular or cylindrical cross-sectional area. The type of cross-sectional area is specified through the input parameter Shape where a value of 1 selects a cylindrical filter and any value other than 1 selects a rectangular filter. For cylindrical filters, such as the HEME, the flow area through the filter media is calculated as (Rouse, 2000e):

$$
A_{f}=N_{p} \pi\left(d_{\text {filter }}-2 t_{f}\right) H_{f},
$$

where $t_{f}$ is the filter element thickness and $H_{f}$ is the height of the filter elements. Equation (32) bases the gas flow through the filter medium on the inner surface area of the filter element as shown in Figure 12.

For rectangular filters, such as the HEPA filters, the flow area is calculated by:

$$
A_{f}=N_{p} H_{f} .
$$

Equation (33) is simply used to specify the area of a single filter through the value of the input parameter $H_{f}$.

Rouse (2000h) provides an equation to calculate the loss coefficient for flow through a HEPA filter as a function of the dust loading $L$ of the form:

$$
K_{f 2}=c_{l 2} L^{2}+c_{l 1} L+c_{l 0} .
$$

Rouse further defines the HEPA filter equation coefficients to be:

$$
c_{l 2}=33.6, c_{l 1}=123 \text {, and } c_{l 0}=6490 \text {. }
$$


The filter model uses this general functional form to calculate the filter loss coefficient. Following Rouse, we have used a dust loading of $10 \mathrm{~g} / \mathrm{m}^{2}$ for the HEPA filters. For the HEME we simply set:

$$
c_{l 2}=0, c_{l 1}=0, \text { and } c_{l 0}=88900
$$

to recover the appropriate loss coefficient from the data correlation.

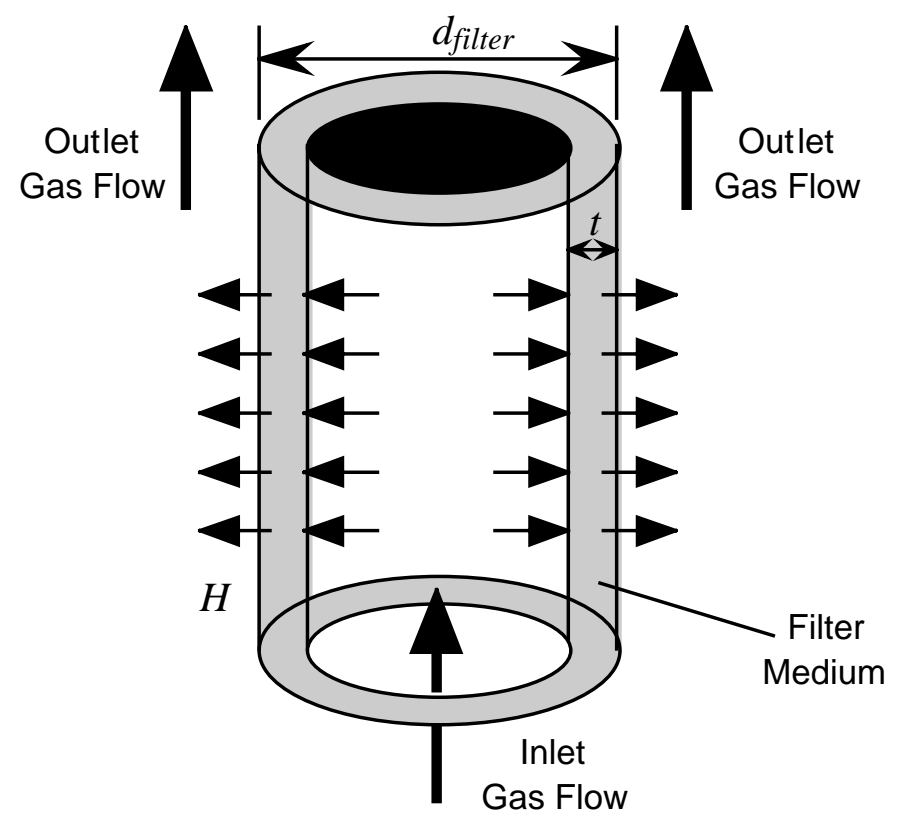

Figure 12. Illustration of gas flow through cylindrical HEME.

We note that the functional form of Eq. (31) is very convenient. The presence of the linear term avoids the singular derivative problems discussed in conjunction with Eqs. (7) and (8). To use Eq. (31) for HEPA filters as well as a HEME, we assign the small arbitrary value to the linear coefficient of $K_{f l}=100$. This value will have little effect on the pressure drop calculation except at very low gas flows.

From the steady state calculations performed by Rouse (2000e, 2000h), the filter model should account for essentially $100 \%$ of the pressure drop across a HEME and at least $90 \%$ of the pressure drop across HEPA filters. There is some additional frictional loss from the flow through the upper housing in HEPA filters that has been neglected in this model. 


\section{Wet Electrostatic Precipitator}

Pressure losses across the Wet Electrostatic Precipitator (WESP) are calculated by ACM model WESP. Steady-state calculations by Rouse (2000d) show that pressure loss from a sudden expansion at the inlet, pressure loss across the gas distribution plate, and pressure loss from a sudden contraction at the outlet dominate the total pressure drop across the WESP. A schematic diagram of the WESP model indicating some of the nomenclature used is shown in Figure 13.

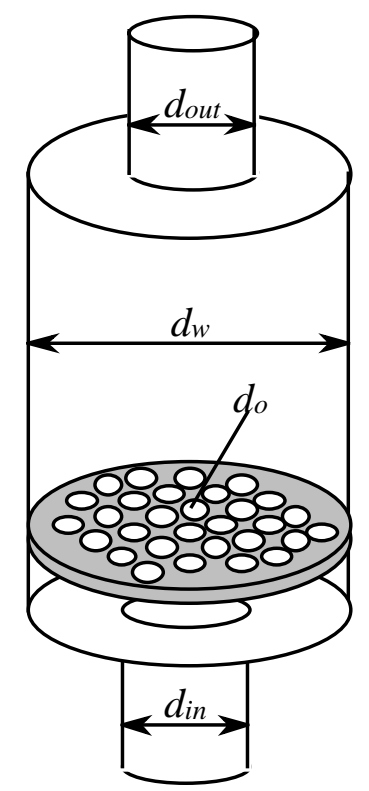

\section{Figure 13. Schematic diagram of WESP model.}

Loss coefficients used to calculate pressure drop across the WESP are given by:

$$
K_{\text {exp }}=\left[1-\left(d_{\text {in }} / d_{w}\right)^{2}\right]^{2}, K_{o}=(1 / 6)^{2}, \text { and } K_{\text {con }}=\frac{1}{2}\left[1-\left(d_{\text {out }} / d_{w}\right)^{2}\right] .
$$

As shown in Appendix A, an overall loss coefficient can be formulated as:

$$
K_{v}=\frac{1}{2}\left[\frac{K_{\text {exp }}}{A_{\text {in }}^{2}}+\frac{K_{o}}{A_{o}^{2}}+\frac{K_{c o n}}{A_{\text {out }}^{2}}\right] .
$$

In Eq. (36), $A_{o}$ is the total area of all of the orifices in the gas distribution plate which is calculated as $A_{o}=n_{o} \pi d_{o}^{2} / 4$ where $n_{o}$ is the number of orifice holes in the plate and $d_{o}$ is the orifice diameter.

The pressure drop across the WESP is calculated from the set of equations: 


$$
\begin{aligned}
& \Delta p=\sqrt{K_{v} \Delta p_{\text {min }} / \rho_{g}} \dot{m}_{g}, \quad \Delta p \leq \Delta p_{\text {min }} \\
& \Delta p=\left(K_{v} / \rho_{g}\right)\left|\dot{m}_{g}\right| \dot{m}_{g}, \quad \Delta p>\Delta p_{\text {min }} .
\end{aligned}
$$

The calculation of pressure difference across the WESP by the method shown in Eqs. (37a) and (37b) linearizes the calculation for pressure drops near zero. A minimum pressure drop $\left(\Delta p_{\min }\right)$ of $1.0 \mathrm{~Pa}$ is used in the evaluation. Squaring Eq. (37a) and dividing through by the minimum pressure drop leads to the alternative form:

$$
\frac{\Delta p|\Delta p|}{\Delta p_{\text {min }}}=\left(K_{v} / \rho_{g}\right)\left|\dot{m}_{g}\right| \dot{m}_{g}, \quad \Delta p \leq \Delta p_{\text {min }} .
$$

Steady-state calculations by Rouse (2000d) also consider pressure drops in the WESP associated with: contraction of the gas entering the electrode tubes, frictional loses from flow in the electrode tubes, and sudden expansion of the gas as it exits the electrode tubes. However, the total of these losses associated with the WESP electrode tubes is only $0.35 \mathrm{~Pa}$ for both the HLW and LAW systems. The overall pressure drop across the WESP is on the order of $254 \mathrm{~Pa}$. Therefore, these losses, which represent less than $0.15 \%$ of the total, have been neglected in the dynamic calculation. 


\section{Submerged Bed Scrubber}

The pressure drop across the Submerged Bed Scrubber (SBS) is calculated as the total of the static head created by the liquid in and above the bed plus the frictional loss from gas flow through the gas distribution plate and the packed bed. ACM model SBS calculates the pressure drop across the scrubber. The gas exiting the scrubber is assumed to be saturated air at the liquid temperature. Figure 14 shows a schematic diagram of the SBS model.

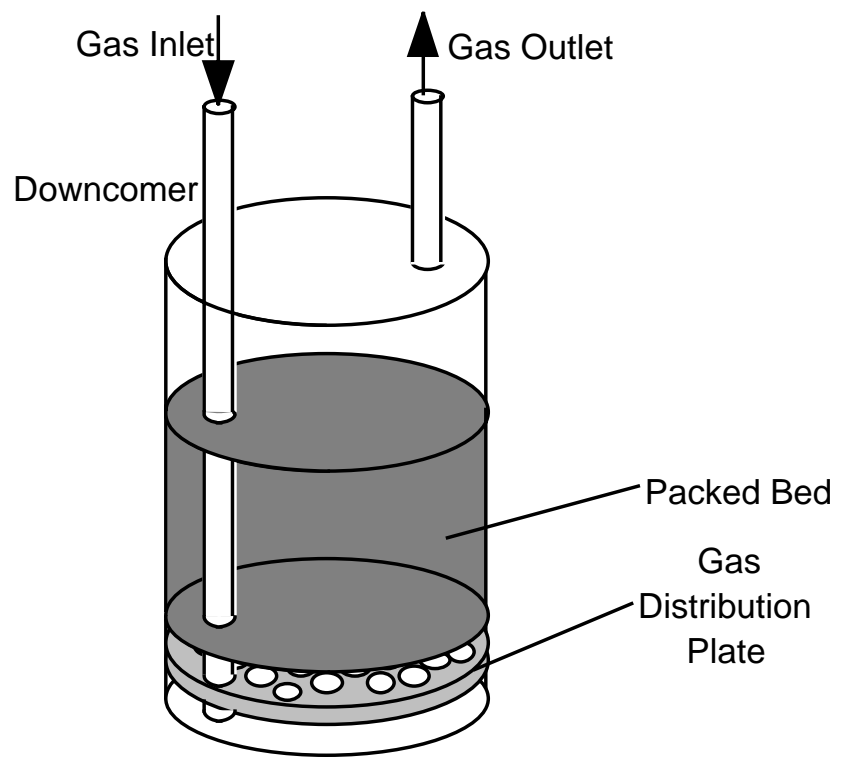

Figure 14. Schematic diagram of Submerged Bed Scrubber model.

The static liquid head is calculated using the expression:

$$
\Delta p_{H}=\rho_{l} g H_{l}
$$

where $H_{l}$ is the liquid depth in the scrubber in meters. The liquid depth is the sum of the bed height plus the bed submergence. The code user specifies these parameters and the liquid density through the input. When the offgas system is started from conditions of uniform pressure and no flow, the static head across the SBS must be overcome before significant gas flow starts.

Pressure drop from gas flow through the packed bed is calculated using the data based empirical equation:

$$
\Delta p_{B}=5650 u_{g}^{1.24} \text {. }
$$

In equation (39), $u_{g}$ is the superficial gas velocity based on the cross-sectional area of the packed bed and the pressure drop is in Pascals. 
The basis for Eq. (39) is data from experiments on a prototypical SBS conducted at the Vitreous State Laboratories as reported by Rouse (2000c). The data correlation includes the contribution to the pressure drop from flow across the SBS gas distribution plate. The model neglects pressure losses through the downcomer pipe and the offgas discharge tube. Rouse (2000c) has shown that these losses amount to less than $2 \%$ of the total pressure loss across the SBS.

Measurements on experimental Submerged Bed Scrubbers show significant pressure fluctuations across the bed. The amplitude of the oscillations increases as the gas flow increases. Experimental data on the oscillation amplitude supplied by Rouse $(2000 \mathrm{~m})$ was fit with a single adjustable parameter using the empirical equation:

$$
\Delta p_{o}=273.52\left(u_{g}+\sqrt{u_{g}}\right) .
$$

The data fit is shown in Figure 15. The pressure fluctuations have been observed to have a frequency of approximately $2 \mathrm{~Hz}$. The overall pressure drop across the SBS including pressure fluctuations is then calculated by combining Eqs. (38) through (40) as:

$$
\Delta p=\rho_{l} g H_{l}+5650 u_{g}^{1.24}+273.52\left(u_{g}+\sqrt{u_{g}}\right) \sin (2 \pi f t) .
$$

In Eq. (41), $f$ is the oscillation frequency and $t$ is time in seconds. Subtracting out the static pressure head, Eq. (41) can be rewritten in the equivalent form:

$$
\Delta p-\rho_{l} g H_{l}=\Delta p_{d}=c_{1} u_{g}^{a}+c_{2}\left(u_{g}+\sqrt{u_{g}}\right) \sin (2 \pi f t) .
$$

In practice, to implement Eq. (41), we use the following logic:

- If $\Delta p_{d} \leq 0$ then $u_{g}=0$. This prevents backflow of gas through the scrubber.

- If $\Delta p_{d} \leq \delta p_{\min }$, a linearized version of Eq. (41a) without the oscillating component is employed where $\Delta p_{d}=\delta p_{\text {min }}\left(c_{1} / \delta p_{\text {min }}\right)^{1 / a} u_{g}$. This relationship is derived by first evaluating Eq. (41a) for the gas velocity at the minimum pressure difference obtaining:

$$
\left.u_{g}\right|_{\min }=\left(\delta p_{\min } / c_{1}\right)^{1 / a}
$$

and then using the ratio

$$
\Delta p_{d} / \delta p_{\min }=u_{g} /\left.u_{g}\right|_{\min }
$$

to linearize the relationship between pressure difference and gas velocity.

- If $\Delta p_{d}>\delta p_{\text {min }}$, the full version of Eq. (41a) is used to solve for the gas velocity through the scrubber. The minimum pressure difference is set to be $1.0 \mathrm{~Pa}$. 
Adding the sinusoidal fluctuation term to the pressure drop calculation significantly increased the model computational time. Apparently, to resolve the solution to within the specified tolerance, this time variation in pressure leads to a significant decrease in the computational time step. Setting the frequency to zero eliminates the pressure fluctuation and restores the calculation speed to the original rate. The preliminary calculations in this report do not use the SBS pressure fluctuation term (i.e. $f=0$ in all of the calculations). Subsequent information supplied by Rouse $(2000 \mathrm{~m})$ indicates that the oscillation frequency is also a function of the gas velocity. No attempt has yet been made to include this dependence in the modeling.

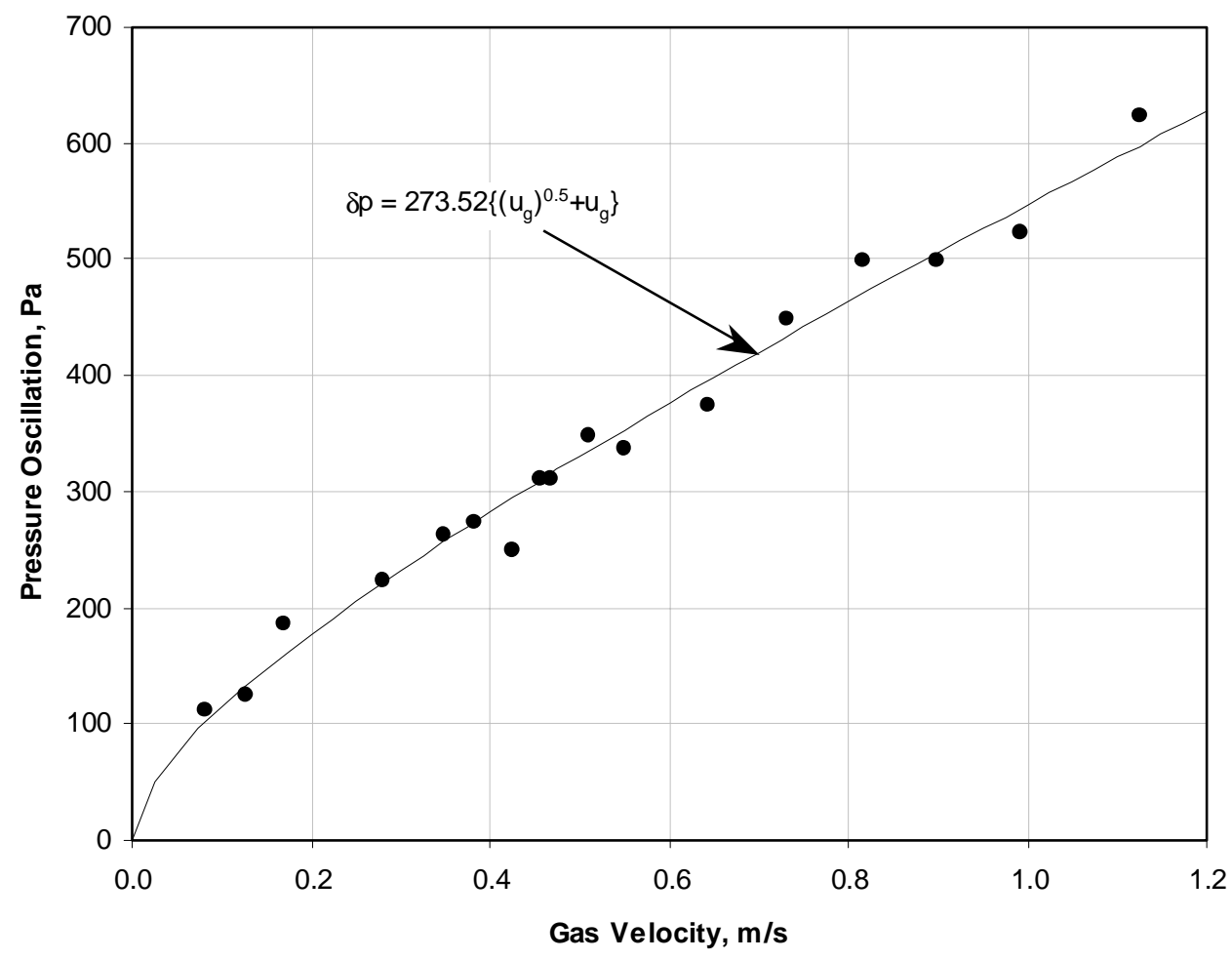

Figure 15. Correlation of SBS pressure oscillation amplitude as a function of gas velocity. 


\section{HEPA Preheater}

The pressure drop across the HEPA Preheater is modeled in model Heater as gas flow across a tube bank with entrance and exit losses. A schematic diagram of the model is shown in Figure 16.

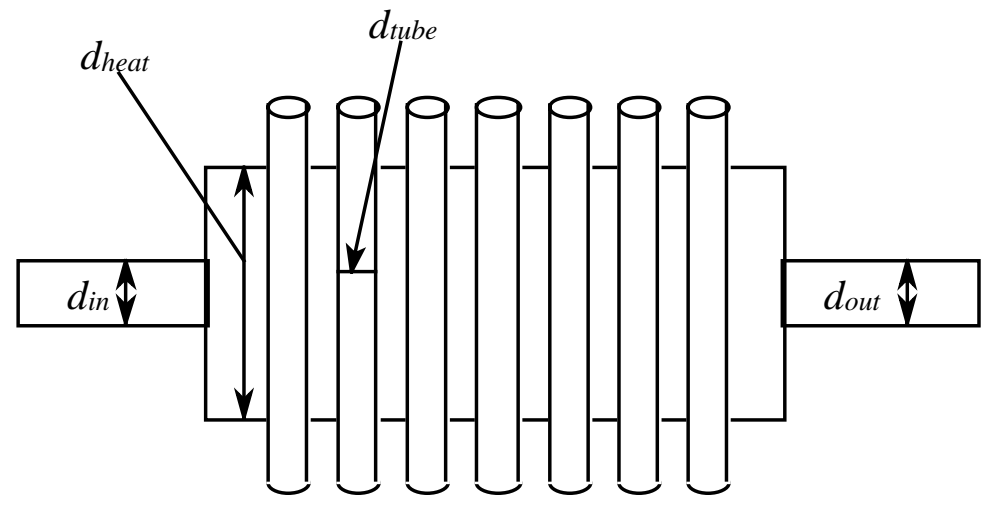

Figure 16. Schematic diagram of Heater model.

As in the other models, loss coefficients to calculate the pressure drop at the entrance expansion and exit contraction in the preheater are:

$$
K_{\text {exp }}=\left[1-\left(\frac{d_{\text {in }}}{d_{\text {heat }}}\right)^{2}\right]^{2} \text { and } K_{\text {con }}=\frac{1}{2}\left[1-\left(\frac{d_{\text {out }}}{d_{\text {heat }}}\right)^{2}\right] \text {. }
$$

Rouse (2000b) has provided drag coefficients for flow across a circular cylinder. This data was fit to a simple empirical correlation as shown in Figure 17. The flow Reynolds number based on the tube diameter is calculated as:

$$
N_{R e}=\frac{d_{\text {tube }} u_{g} \rho_{g}}{\mu_{g}}
$$

The overall drag coefficient is calculated using the empirical equation:

$$
C_{D}=N_{b a n k}\left[1+\frac{11.09}{N_{R e}+0.1}\right] \text {, }
$$

where $N_{\text {bank }}$ is the number of heater element banks in the preheater module. The form of Eq. (44) was chosen to give a smooth approach to a drag coefficient of 1.0 as the Reynolds number increases. As shown in Figure 17, this relatively simple empirical relationship was found to give a good representation to the published drag coefficients. 


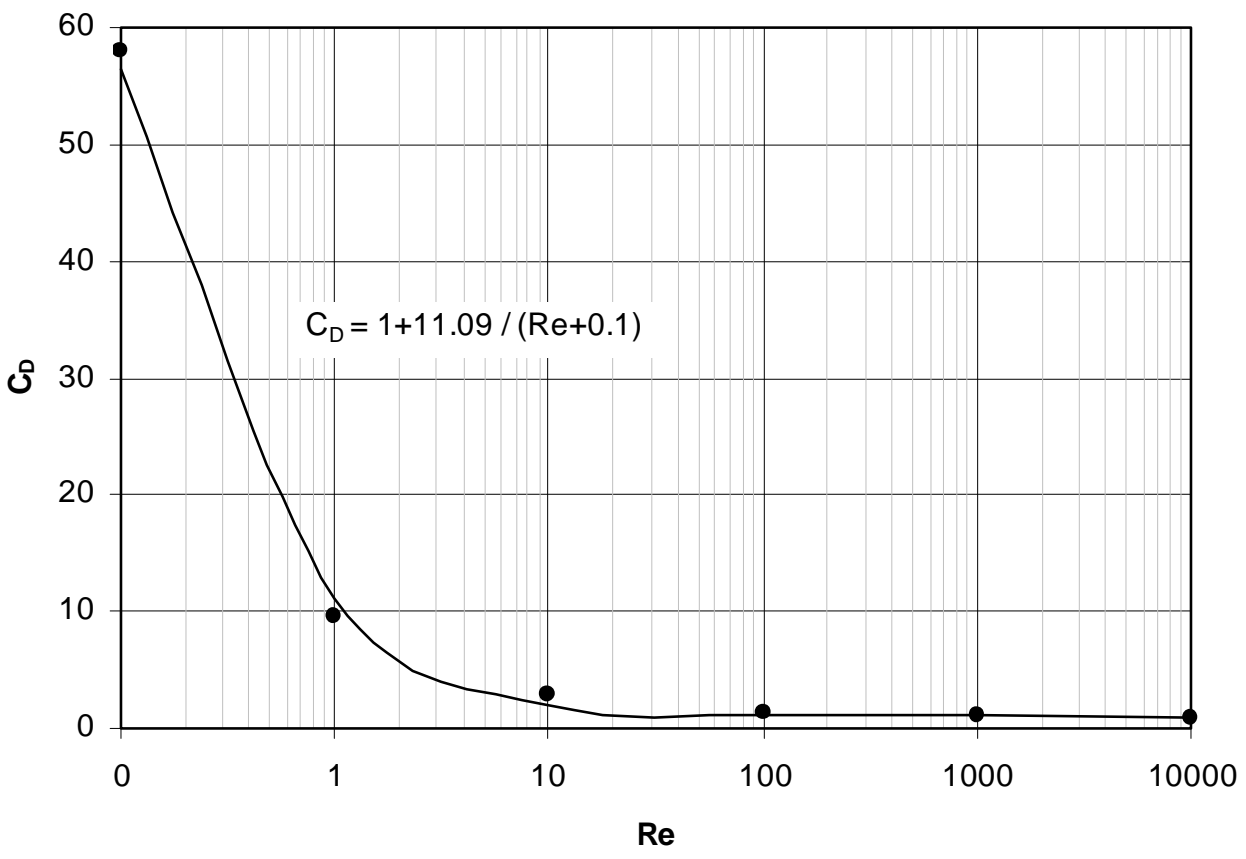

Figure 17. Pressure drop correlation for flow across tube bank.

Applying Eq. (A5), an overall loss coefficient is obtained by combining the above relationships into:

$$
K_{v}=\frac{1}{2}\left[\frac{K_{\text {exp }}}{A_{\text {in }}^{2}} \frac{T_{\text {in }}}{T_{\text {avg }}}+\frac{C_{D}}{A_{\text {heat }}^{2}}+\frac{K_{\text {con }}}{A_{\text {out }}^{2}} \frac{T_{\text {out }}}{T_{\text {avg }}}\right] .
$$

In Eq. (45) the average temperature is the mean of the inlet and outlet temperatures. As shown in Appendix A, the temperature ratios in Eq. (45) account for the change in gas density between the inlet and outlet. We assume that the best estimate of the drag across the heater tubes is calculated using the average gas temperature. The gas density and viscosity used to calculate the flow Reynolds number are also evaluated at the average temperature.

Finally, as was done for the WESP, the mass flow of gas is calculated using the set of equations:

$$
\begin{aligned}
& \Delta p=\sqrt{K_{v} \Delta p_{\text {min }} / \rho_{g}} \dot{m}_{g}, \quad \Delta p \leq \Delta p_{\text {min }} \\
& \Delta p=\left(K_{v} / \rho_{g}\right)\left|\dot{m}_{g}\right| \dot{m}_{g}, \quad \Delta p>\Delta p_{\text {min }} .
\end{aligned}
$$

The calculation of pressure difference across the HEPA Preheater by the method shown in Eqs. (46a) and (46b) linearizes the calculation around pressure drops near zero. A 
minimum pressure drop ( $\Delta p_{\text {min }}$ ) of $1.0 \mathrm{~Pa}$ is used in the evaluation. Squaring Eq. (46a) and dividing through by the minimum pressure drop leads to the alternative form:

$$
\frac{\Delta p|\Delta p|}{\Delta p_{\min }}=\left(K_{v} / \rho_{g}\right)\left|\dot{m}_{g}\right| \dot{m}_{g}, \quad \Delta p \leq \Delta p_{\text {min }} .
$$

Equations (46b) and (46c) were used for the model calculations. These two equations give the identical result when $\Delta p=\Delta p_{\min }$.

The development presented above neglects pressure losses from gas flow through the heater housing. As shown by Rouse (2000b), at steady state, these losses are very small representing less than $1 \%$ of the total pressure drop across the preheater.

Neglecting the heat capacity of the gas within the heater, a steady-state enthalpy balance is used to calculate the heat addition $\left(\Delta h_{g}\right)$ according to the equation:

$$
\dot{m}_{\text {out }}\left(\sum_{i} x_{i} h_{i}\right)_{\text {out }}-\dot{m}_{\text {in }}\left(\sum_{i} x_{i} h_{i}\right)_{\text {in }}=\Delta h_{g} .
$$

The summations in Eq. (47) are taken over the air and steam components of the inlet and outlet gas streams. The model is run specifying the outlet gas temperature with the model then calculating the required heat addition to the gas. Alternatively, with no change to the model, the heat addition could be specified and the outlet gas temperature calculated. 


\section{PID Controller}

The model of a Proportional-Integral-Derivative (PID) controller, coded in model PID_Controller, is a simplified model of the action of a proportional-integral-derivative controller. The basic equation to calculate controller output is:

$$
C_{\text {out }}=G\left(e+\frac{1}{\tau_{i}} \int e d t+\tau_{d} \frac{d \hat{e}}{d t}\right)
$$

The following nomenclature is used in Eq. (48):



The error is defined to be equal to the difference between the input to the controller $\left(C_{i n}\right)$ and the controller set point $\left(P_{\text {set }}\right)$ divided by the allowed input range:

$$
e \equiv \psi\left[\frac{C_{i n}-P_{s e t}}{\left.C_{i n}\right|_{\max }-\left.C_{i n}\right|_{\min }}\right] .
$$

The input parameter $\psi$ in Eq. (49) is an on off switch used to initiate the control action. With $\psi=0$ the controller is off while setting $\psi=1$ turns the controller on.

The rate of change of the error is approximated using the equation

$$
\frac{d \hat{e}}{d t}=\frac{e-\hat{e}}{\tau_{e}} .
$$

where $\tau_{e}$ is an error time constant. Integrating Eq. (50) assuming a constant error leads to the relationship

$$
e-\hat{e}=\left(e-\hat{e}_{0}\right) \exp \left(-t / \tau_{e}\right)
$$

which demonstrates that $\hat{e}$ will approach $e$ at long times under some conditions.

The controller model clips the input signal to lie between maximum and minimum values specified by the used through model input. The output signal is automatically clipped to lie in the range \pm 1 . The model also applies a time lag to the output response using the equation: 


$$
\frac{d \sigma}{d t}=\frac{\left(C_{o u t}-\sigma\right)}{\tau_{l}}
$$

where $\sigma$ is the final controller output and $\tau_{l}$ is the time constant for the lag.

A controller is used on each melter to control the pressure. There are also controllers in the HLW and LAW systems that control airflow out of the vessel ventilation systems. The LAW system has additional controllers on SBS flow and fan speed. Table 9 lists the parameters used for all of controllers in the model calculations. These parameters are rather arbitrary at this time and can have a significant influence on the transient response of the offgas system. Future model development will work to improve the simulation by providing more realistic parameters for the control systems.

Table 9. PID Controller Settings

\begin{tabular}{|c||c|c||c|c|c|c|}
\hline \multicolumn{1}{|c||}{} & \multicolumn{2}{c||}{ HLW System } & \multicolumn{4}{c|}{ LAW System } \\
Parameter & Pressure & VVS & Pressure & SBS Flow & Fan Speed & VVS \\
\hline \hline Gain & 10 & 10 & 10 & 10 & 5 & 5 \\
\hline $\begin{array}{c}\text { Integral Time } \\
\text { Constant (s) }\end{array}$ & 1000 & 1000 & 1000 & 1000 & 100 & 10 \\
\hline $\begin{array}{c}\text { Derivative Time } \\
\text { Constant (s) }\end{array}$ & 0.1 & 0.1 & 0.1 & 0.1 & 0.1 & 0.1 \\
\hline $\begin{array}{c}\text { Error Time } \\
\text { Constant (s) }\end{array}$ & 1 & 1 & 1 & 1 & 1 & 1 \\
\hline $\begin{array}{c}\text { Delay Time } \\
\text { Constant (s) }\end{array}$ & 1 & 1 & 1 & 5 & 1 & 1 \\
\hline \hline Units & mbar & mbar & mbar & $\mathrm{m}^{3} / \mathrm{s}$ & $\mathrm{mbar}$ & $\mathrm{m}^{3} / \mathrm{s}$ \\
\hline Set Point & 985.0 & 990.0 & 983.75 & 0.685 & 870.0 & 0.25 \\
\hline Input Min. & 975.0 & 980.0 & 978.75 & 0.370 & 850.0 & 0.00 \\
\hline Input Max. & 995.0 & 1000.0 & 988.75 & 1.000 & 890.0 & 0.50 \\
\hline
\end{tabular}




\section{Control Valve}

As shown in the flowsheet schematics, control valves are used only in conjunction with the controllers. The operation of these control valves is modeled using ACM model Control_Valve. The flow stream being controlled passes through the valve and the valve characteristics and the controller response determine the flowrate out of the valve. A fixed valve coefficient $\left(C_{v}\right)$ is specified through the code input. The mass flow through the valve is then calculated as a function of the pressure difference across the valve using:

$$
\dot{m}=C_{v} \phi \sqrt{\rho_{g}} \frac{\Delta p}{f(\Delta p)} .
$$

In Eq. (53), $\phi$ is the relative ( 0 to 1 ) valve stem position and the function $f(\Delta p)$ is the function defined in Eq. (10b) to approximate the square root of the pressure difference.

The change in the valve stem position $(\phi)$ is governed by a control signal $(\sigma)$ which is the output of the associated PID controller and by the valve time constant $\tau_{v}$ through the equation:

$$
\frac{d \phi}{d t}=\frac{\sigma}{\tau_{v}}
$$

Equation (54) adjusts the valve open position until the control signal reaches zero at a rate governed by the valve time constant. The function of Eq. (54) is augmented by two logic tests to keep the valve position in the physically meaningful range of zero to one. If the valve position is zero (fully closed) and the control signal is still trying to close the valve, the rate of change in valve position is set to zero. Similarly, if the valve position is one (fully opened) and the control signal is still trying to open the valve, the rate of change in the valve position is set to zero. Symbolically,

$$
\frac{d \phi}{d t}=0 \text { if }\left\{\begin{array}{l}
\phi=0 \text { and } \sigma \leq 0 \\
\phi=1 \text { and } \sigma \geq 0
\end{array}\right. \text {. }
$$

As a further check, the value of the valve position calculated by Eq. (54) is clipped to fall between zero and one before it is used in Eq. (53). All of the control valve time constants were arbitrarily set to one second for the preliminary model calculations reported here. As more information about the offgas control system becomes available, the valve parameters can be easily modified. 


\section{Caustic Scrubber}

The pressure drop across the caustic scrubber is calculated in model Caustic Scrubber. Following Rouse (2000i), the model considers pressure losses from:

1. Expansion at the entrance,

2. Gas flow through the packed bed,

3. Gas flow through the liquid distribution weirs,

4. Flow through the mesh demister,

5. Contraction at the discharge.

Figure 18 shows a schematic diagram of the caustic scrubber model.

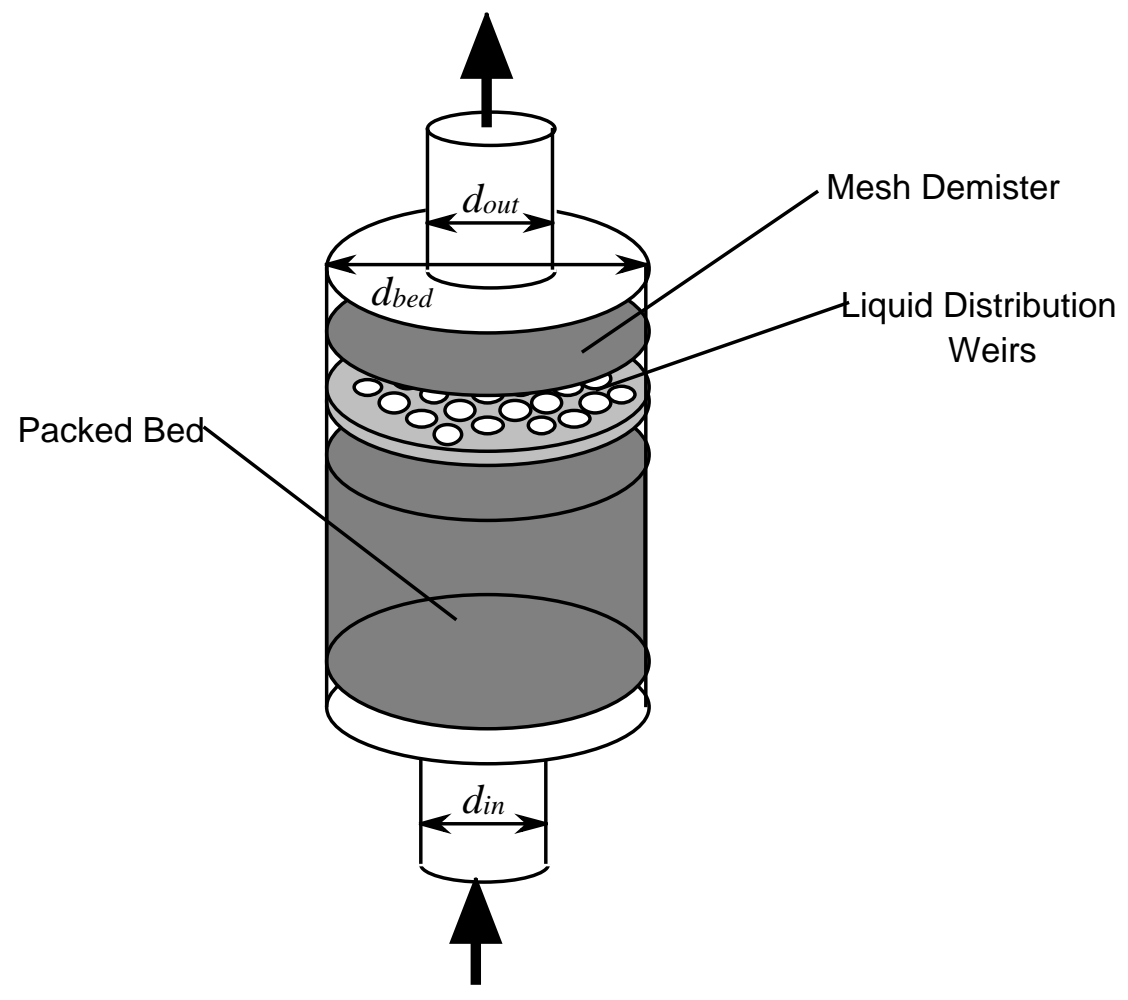

Figure 18. Schematic diagram of caustic scrubber model.

As was used in several of the other models, loss coefficients to calculate the pressure drop at the entrance expansion and discharge contraction to the caustic scrubber are:

$$
K_{\text {exp }}=\left[1-\left(\frac{d_{\text {in }}}{d_{\text {bed }}}\right)^{2}\right]^{2} \text { and } K_{c o n}=\frac{1}{2}\left[1-\left(\frac{d_{\text {out }}}{d_{\text {bed }}}\right)^{2}\right] \text {, }
$$


where $d_{b e d}$ is the diameter of the packed bed. A loss coefficient for gas flow through the liquid distribution weirs is calculated by:

$$
K_{o}=(1 / 6)^{2} .
$$

Rouse (2000i) has provided a correlation for the gas phase pressure loss in two-phase flow through a packed bed in the form:

$$
\Delta p_{p b}=h \gamma \frac{\dot{G}^{2}}{\rho_{g}} 10^{\left(\phi \dot{L} / \rho_{l}\right)} .
$$

In Eq. (57), $h$ is the height of the packed bed, $\gamma$ and $\phi$ are bed constants, $\dot{G}$ is the superficial gas mass velocity, $\dot{L}$ is the superficial liquid mass velocity, and $\rho_{l}$ is the liquid density. The superficial gas mass velocity is defined to be:

$$
\dot{G}=\frac{Q_{g} \rho_{g}}{A_{\text {bed }}}=\rho_{g} u_{g} .
$$

Using Eq. (58), Eq. (57) can be conveniently cast into the same form as that for calculating the pressure drop from flow through a resistance:

$$
\Delta p_{p b}=\frac{1}{2} K_{b e d} \rho_{g} u_{g}^{2} \text { with } K_{b e d} \equiv 2 h g \gamma \exp \left[\ln (10) \phi \dot{L} / \rho_{l}\right]
$$

The loss coefficient $K_{\text {bed }}$ defined in Eq. (59) has been converted into an exponential form to facilitate the model calculations. Rouse (2000i) has provided a table of bed coefficients, $\gamma$ and $\phi$, in English units. When converted to SI, the coefficient $\gamma$ has units of $\mathrm{s}^{2} / \mathrm{m}^{2}$. Since the loss coefficient must be dimensionless, the gravitational constant $g$ has been introduced into the definition of $K_{b e d}$ to make the product $h g \gamma$ dimensionless. To simplify the calculations and model input slightly, it is then convenient to combine the product $g \gamma$ into a modified $\gamma$ coefficient and $\ln (10) \phi$ into a modified $\phi$ coefficient. The ratio $\dot{L} / \rho_{l}$ in the exponential term in Eq. (59) can also be replaced with $Q_{l} / A_{\text {bed }}$. Making these changes, the bed loss coefficient can be written in the equivalent form:

$$
K_{\text {bed }} \equiv 2 h \gamma^{\prime} \exp \left[\phi^{\prime} Q_{l} / A_{\text {bed }}\right]
$$

Required model inputs are the bed height $(h)$, the bed diameter which is used to calculate the cross-sectional area, and the liquid volumetric flowrate $\left(Q_{l}\right)$. A list of parameters for both the HLW and LAW caustic scrubbers is given in Table 10. 
Table 10. Caustic Scrubber model parameters.

\begin{tabular}{|c||c|c|}
\hline Parameter & LAW System & HLW System \\
\hline \hline$\gamma^{\prime}\left(\mathrm{m}^{-1}\right)$ & 82.02 & 164.05 \\
\hline$\phi^{\prime}(\mathrm{s} / \mathrm{m})$ & 62.55 & 76.15 \\
\hline$d_{b e d}(\mathrm{~m})$ & 1.3208 & 1.0668 \\
\hline$h(\mathrm{~m})$ & 2.6412 & 5.1562 \\
\hline$Q_{l}\left(\mathrm{~m}^{3} / \mathrm{s}\right)$ & 1.89 & 7.57 \\
\hline$T_{l}(\mathrm{C})$ & 66 & 25 \\
\hline
\end{tabular}

Rouse (2000i) also provides manufacturer's data on the pressure drop across the mesh demister as a function of gas velocity. These data can be fit using a quadratic polynomial as shown in Figure 19.



Figure 19. Pressure drop correlation for flow through mesh demister.

To be compatible with the other pressure drop calculations, we assume that the pressure drop across the demister can be correlated using the equation:

$$
\Delta p_{d m}=c_{1} u_{g}+c_{2} u_{g}^{2}=K_{d 1} \rho_{g} u_{g}+\frac{1}{2} K_{d 2} \rho_{g} u_{g}^{2},
$$




$$
\text { where } K_{d 1} \equiv c_{1} / \rho_{g} \text { and } K_{d 2} \equiv 2 c_{2} / \rho_{g} \text {. }
$$

Assuming a gas density of approximately $1.0 \mathrm{~kg} / \mathrm{m}^{3}$, the data correlation implies demister loss coefficients of $K_{d 1}=70.318$ and $K_{d 2}=99.942$.

As shown in Appendix A, an overall loss coefficient can be used to combine all of the pressure losses that are quadratic in the gas velocity. This overall coefficient is calculated as:

$$
K_{v}=\frac{1}{2}\left[\frac{K_{e x p}}{A_{\text {in }}^{2}}+\frac{K_{b e d}}{A_{b e d}^{2}}+\frac{K_{o}}{A_{o}^{2}}+\frac{K_{d 2}}{A_{b e d}^{2}}+\frac{K_{c o n}}{A_{o u t}^{2}}\right] .
$$

In Eq. (63), $A_{o}$ is the total area of all of the orifices in the liquid distribution plate which is calculated as $A_{o}=n_{o} \pi d_{o}^{2} / 4$ where $n_{o}$ is the number of orifice holes in the plate and $d_{o}$ is the orifice diameter. Finally, the overall pressure drop across the caustic scrubber is calculated using the equation:

$$
\Delta p=\frac{K_{d 1}}{A_{b e d}} \dot{m}+\frac{K_{v}}{\rho_{g}} \dot{m}^{2}
$$

Equation (64) is particularly convenient to use since the linear term prevents singular behavior in the derivative when the gas flow is identically zero. With this pressure relationship no special logic is required to treat the case of no gas flow.

The gas exiting the scrubber is assumed to be saturated air at the liquid temperature. This assumption fixes the exit gas composition, temperature and enthalpy. We also assume that the liquid in the scrubber is saturated with air so that the mass flows of air entering and exiting the scrubber are the same. 


\section{Exhaust Blower}

A relatively simple model has been developed to calculate the pressure increase across the system exhaust fans or gas blowers. The model calculates the pressure change assuming that there is no change in gas temperature across the fan and no gas holdup in the fan. This model, implemented in model Blower, is able to accurately describe the operating pressure characteristics of the commercial fans that have been used in the preliminary offgas system designs.

In general, the pressure increase across the system fans is calculated using the equation:

$$
\Delta p=\left(c_{01} s+c_{02} s^{2}\right)+\left(c_{10}+c_{11} s+c_{12} s^{2}\right) Q_{g}+\left(c_{20}+c_{21} s+c_{22} s^{2}\right) Q_{g}^{2} .
$$

In Eq. (65), $s$ is either the fan speed in rpm or the fraction of full fan speed, $Q_{g}$ is the volumetric gas flow $\left(\mathrm{m}^{3} / \mathrm{s}\right)$ through the fan, and $c_{i j}$ are eight constant coefficients used to describe the fan operating curves. The naming convention for the coefficients is that the first subscript (i) represents the power of the multiplying gas flow and the second subscript ( $j)$ is the power of the multiplying fan speed.

\section{HLW Primary and Stack Exhaust Blowers}

Operating curves for the HLW primary exhaust blower were derived from manufacturer's data supplied by Rouse $(2000 \mathrm{~m})$ for a New York Blower Company model 2310 steel pressure blower. These data were converted to SI units and replotted as shown in Figure 20. The data covered the range of blower speeds from 0.641 to 0.916 of full speed. The best least squares fits to the relationship between gas flow and pressure rise over each of the four blower speeds provided by the manufacturer's data are shown on the graph. The

following set of coefficients provided the best overall fit to the set of four operating curves.

\begin{tabular}{|c|r|}
\hline Coefficient & Value \\
\hline \hline$c_{22}$ & -15.198 \\
\hline$c_{21}$ & 15.066 \\
\hline$c_{20}$ & -24.946 \\
\hline$c_{12}$ & 17.236 \\
\hline$c_{11}$ & 31.988 \\
\hline$c_{10}$ & 1.623 \\
\hline$c_{02}$ & 103.139 \\
\hline$c_{01}$ & 0.646 \\
\hline
\end{tabular}




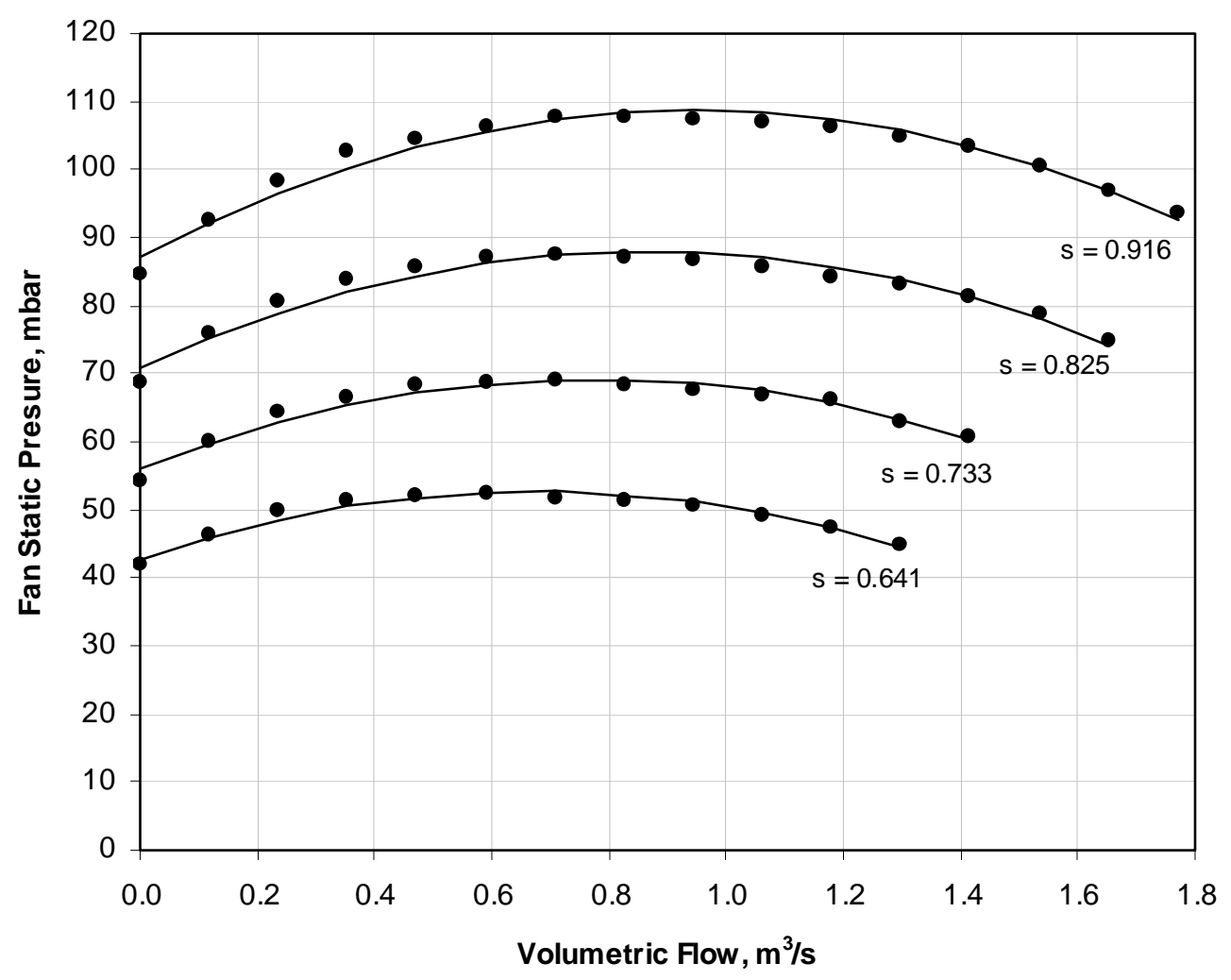

Figure 20. Correlations for HLW blower operating curves. 


\section{LAW Exhaust Blowers}

Operating curves for the primary LAW exhaust blower were derived from manufacturer's data referenced by Bustamante (2000) in his report on sizing the LAW exhaust blower. The recommendation from that report is to use type HP pressure blowers manufactured by the New York Blower Co. in the LAW offgas system. The reference report provides copies of some of the manufacturer's data and operating curves for Type HP pressure blowers with steel wheels operating at $3550 \mathrm{rpm}$. These data were used to develop the fan operating curves for the LAW dynamic model calculations.

Manufacturers performance curves for Type HP pressure blowers operating at $3550 \mathrm{rpm}$, are reproduced on page 47 of Bustamante (2000). These curves indicate a quadratic relationship between inlet airflow and static pressure across the blower. Nineteen data points were read from the operating curve for a Model Number 29012 blower (290 wheel diameter size with a 12 inch outlet), converted to SI units and plotted as shown in Figure 21.

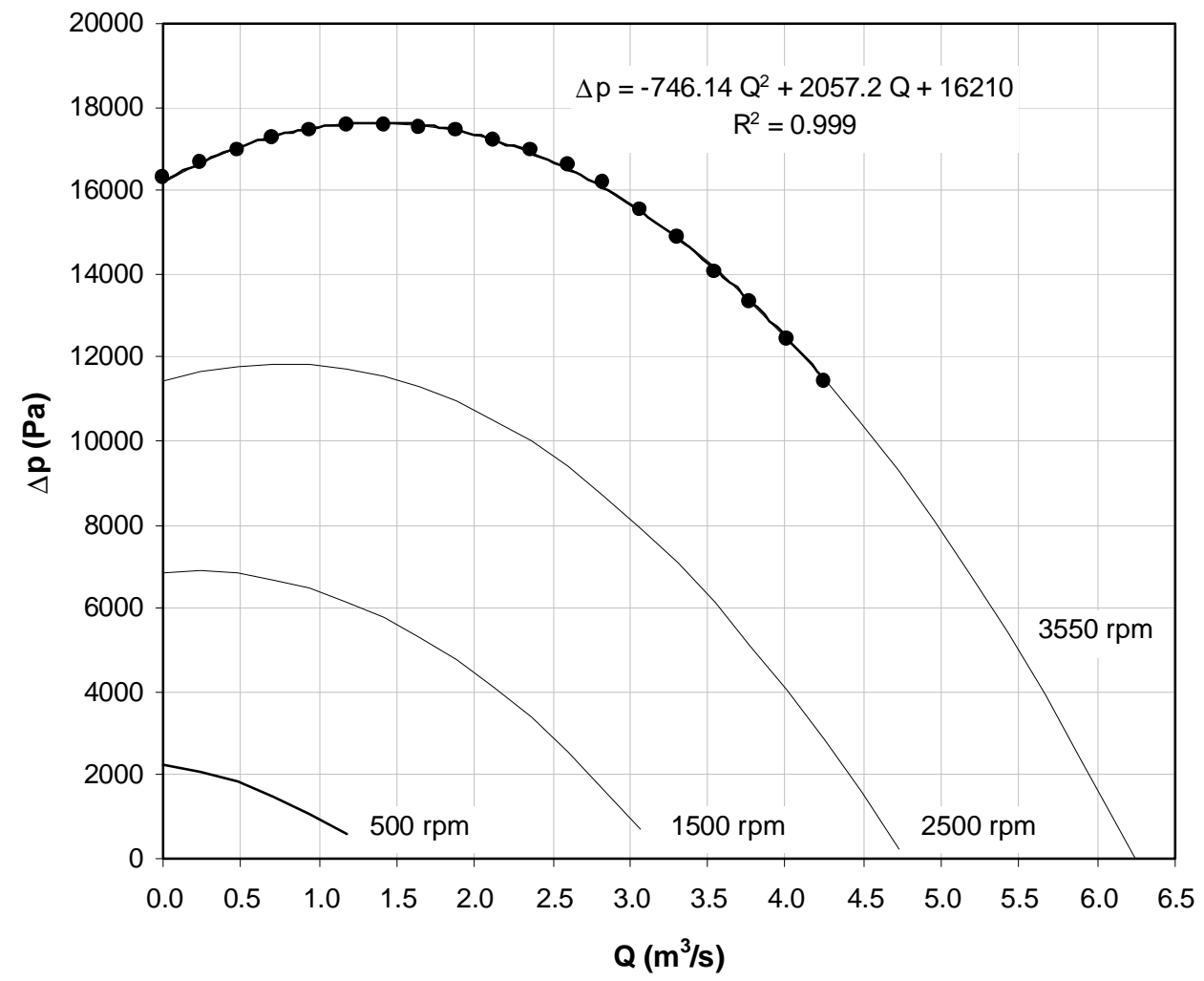

Figure 21. Operating curves for LAW primary blower.

$$
c_{01}=4.5662, c_{10}=-1000, c_{11}=0.8612, c_{20}=-746.14
$$


As shown in Figure 21, a least squares quadratic equation gives an excellent fit to these data points $\left(R^{2}=0.999\right)$. To model system startup and the system response to variations in the blower speed, performance curves at other operating speeds are required. Since this data was not available, it was assumed that the constant term in the least squares fit to the data at $3550 \mathrm{rpm}$ was a linear function of blower speed. This assumption leads to an estimation of the coefficient $c_{01}=16210 / 3550=4.5662$.

Initially it was assumed that the coefficient on the gas flow to the first power in the least squares fit was also a simple linear function of blower speed. However, with this model, the code repeatedly failed to converge at the point of flow breakthrough in the SBS. It was observed that the fan curves in the successful HLW blower model had a negative slope at the breakthrough point whereas the LAW blower curves had a positive slope. This difference is illustrated in Figure 22 where the arrows indicate the apparent stable solution path. The characteristic LAW fan curves were modified to give a negative slope at the point of flow breakthrough by setting the coefficient $c_{10}=-1000$. With this adjustment, the model was able to successfully compute through the flow breakthrough point. Using the set of coefficients listed in the caption to Figure 21, Eq. (69) was used to generate blower performance curves at the other fan speeds as shown in the figure.

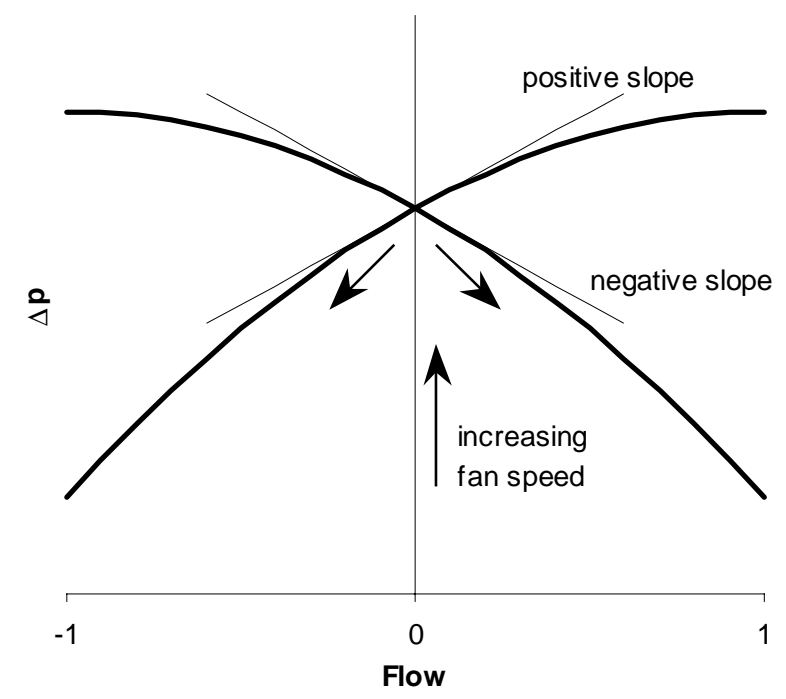

Figure 22. Schematic illustration of fan operating curves. 


\section{Thermal Catalytic Oxidizer Unit}

As described above, both offgas systems have Thermal Catalytic Oxidizer units with somewhat different configurations. A more detailed schematic diagram of the true configuration of this unit is shown in Figure 23 (Berrios, 2000).



Figure 23. Schematic diagram of Thermal Catalytic Oxidizer Unit.

In both systems, the gas flow enters on the cold side of a plate type heat exchanger. After the heat exchanger, the gas passes through a preheater, the Thermal Catalytic Oxidizer (TCO), through a return duct, and then through the hot side of the heat exchanger. Following the TCO in the LAW system, the gas also passes through two Selective Catalytic Reduction (SCR) units to remove ammonia, nitric oxide, and nitrogen dioxide from the stream. For calculation purposes, the entire unit is modeled as a series of subprocess units as shown in Figures 1 and 3b. The existing Heater and Pipe_Flow models are used to model the gas flow through the preheater and return duct, respectively. To complete the description of this unit, models of gas flow through a plate heat exchanger, the TCO, and the SCR were developed. The heat exchanger model was applied twice to separately calculate the pressure drop across the hot and cold sides of the heat exchanger. The heat exchanger model does not treat the coupled heat transfer between the hot and cold sides but uses a specified outlet temperature to estimate the heat load. 


\section{Thermal Catalytic Oxidizer/Selective Catalytic Reducer}

Pressure losses across the Thermal Catalytic Oxidizer and the Selective Catalytic Reducer are both calculated using the model Catalytic. Gas flow through the catalyst monolith is modeled as flow through small channels (Rouse, 2000f). The catalyst is contained inside a housing so there are pressure losses from contraction as the flow enters the catalyst channels and expansion as the flow exits the channels. Since the catalyst channels are small it is assumed that the gas flow within the channels is laminar. Figure 24 shows a schematic diagram of the catalytic unit model where $d_{h}$ is the diameter of the housing and $d_{c a t}$ is the diameter of a single flow channel through the catalyst.

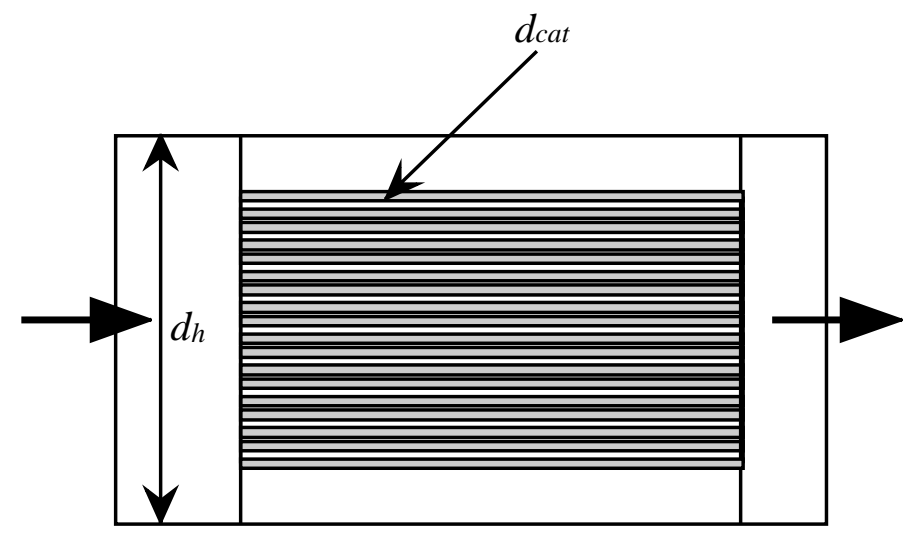

Figure 24. Schematic diagram of catalytic unit model.

Loss coefficients for the pressure drop at the entrance contraction and discharge expansion to the catalyst bed are calculated as:

$$
K_{c o n}=\frac{1}{2}\left[1-\left(\frac{d_{c a t}}{d_{h}}\right)^{2}\right] \text { and } K_{e x p}=\left[1-\left(\frac{d_{c a t}}{d_{h}}\right)^{2}\right]^{2}
$$

Since both pressure losses are based on the flow through the catalyst, a relatively simple overall loss coefficient can be written as:

$$
K_{v}=\frac{1}{2 A_{c a t}^{2}}\left[K_{c o n}+K_{e x p}\right]
$$

Following Rouse (2000f), the total flow area through the catalyst is estimated as:

$$
A_{c a t}=N_{m o n} H_{m o n} W_{m o n} \phi_{c a t} \text { with } \phi_{c a t}=\left(\frac{d_{c a t}}{d_{c a t}+t_{c a t}}\right)^{2}
$$

In Eq. (68), $N_{m o n}$ is the number of catalyst monoliths stacked in the flow direction, $H_{m o n}$ is the height of a single monolith, $W_{\text {mon }}$ is the monolith width and $\phi_{c a t}$ is the fraction of the 
surface area occupied by catalyst pores. The fraction of catalyst surface occupied by pores in both linear directions is estimated as the ratio of the pore diameter to the sum of the pore diameter and the thickness of the catalyst solid $\left(t_{c a t}\right)$.

Since we can assume laminar flow through the catalyst channels, the friction factor is given by:

$$
\left.f_{o}\right|_{\text {lam }}=\frac{64 \mu_{g}}{d_{c a t} \rho_{g}} .
$$

The total pressure loss across the catalytic unit is then calculated as:

$$
\Delta p=\left.\frac{N_{l a y}}{2} f_{0}\right|_{l a m} \frac{L_{c a t}}{d_{c a t}} \frac{\dot{m}_{g}}{A_{c a t}}+\frac{K_{v}}{\rho_{g}} \dot{m}_{g}^{2} .
$$

In Eq. (70), $L_{c a t}$ is the length of a catalyst monolith and $N_{\text {lay }}$ is the number of catalyst layers in series. The laminar contribution to the pressure drop is linear in gas flowrate. Therefore, no special logic is required to assure that the calculation is well behaved at zero flow.

Both the TCO and SCR units can be modeled using the same general form if only pressure losses are required. As a future extension of the offgas system model it is anticipated that other species will be added to the gas phase and the chemical reactions in the TCO and SCR units accounted for. In this eventuality, the models would have to be separated to include individual reaction mechanisms. 


\section{Heat Exchanger}

Pressure losses from the gas flow through either side of the plate type heat exchanger are calculated using model Heat_Exchanger. Figure 25 shows a schematic diagram of the ACM heat exchanger model.

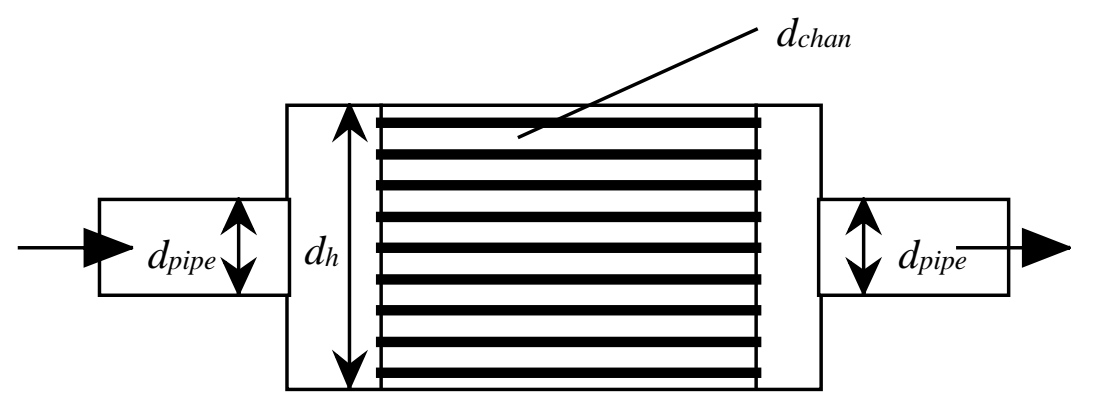

Figure 25. Schematic diagram of plate heat exchanger model.

As shown in Figure 25, $d_{\text {chan }}$ is the hydraulic diameter of the flow channel between the heat exchanger plates and $d_{h}$ is the hydraulic diameter of the heat exchanger housing. Hydraulic diameter is four times the flow area divided by the wetted perimeter. Therefore, for a rectangular heat exchanger of height $H$ and width $W$ with spacing $P$ between the plates and plate thickness $X$, we use (Rouse, 2000f):

$$
d_{h}=\frac{2 W H}{W+H} \text { and } d_{c h a n}=\frac{2 P H}{P+H} .
$$

The total flow area between the plates is:

$$
A_{f}=W H \frac{P}{P+X},
$$

where $P /(P+X)$ is the fraction of space between plates in the heat exchanger.

Loss coefficients for the pressure drop at the entrance contraction and discharge expansion of flow through the heat exchanger plates are calculated as:

$$
K_{c o n}=\frac{1}{2}\left[1-\left(\frac{d_{c h a n}}{d_{h}}\right)^{2}\right] \text { and } K_{e x p}=\left[1-\left(\frac{d_{c h a n}}{d_{h}}\right)^{2}\right]^{2} \text {. }
$$

The friction factor for flow through the plate channels is calculated using the method described in Eqs. (14) - (16) for flow through a duct. 
As shown in Figure 25, the hot side of the heat exchanger has a contraction loss from flow exiting the unit while the cold side has an expansion loss from flow entering the unit. Including the temperature correction, these losses are calculated as:

$$
K_{\text {out }}=\frac{1}{2}\left[1-\left(\frac{d_{\text {pipe }}}{d_{h}}\right)^{2}\right] \frac{T_{\text {out }}}{T_{\text {avg }}} \text { and } K_{\text {in }}=\left[1-\left(\frac{d_{\text {pipe }}}{d_{h}}\right)^{2}\right]^{2} \frac{T_{i n}}{T_{\text {avg }}} .
$$

An integer flag is specified through the input to select which of the loss coefficients from Eq. (74) is applied. Combining the loss terms defined above, an overall pressure loss coefficient is calculated as

either

$$
\begin{gathered}
K_{v}=\frac{1}{2}\left[\frac{K_{\text {in }}}{A_{\text {pipe }}^{2}}+\frac{K_{\text {con }}}{A_{f}^{2}} \frac{T_{\text {in }}}{T_{\text {avg }}}+\frac{K_{\text {exp }}}{A_{f}^{2}} \frac{T_{\text {out }}}{T_{\text {avg }}}\right] \\
K_{v}=\frac{1}{2}\left[\frac{K_{\text {out }}}{A_{\text {pipe }}^{2}}+\frac{K_{\text {con }}}{A_{f}^{2}} \frac{T_{\text {in }}}{T_{\text {avg }}}+\frac{K_{\text {exp }}}{A_{f}^{2}} \frac{T_{\text {out }}}{T_{\text {avg }}}\right]
\end{gathered}
$$

at the inlet and outlet, respectively. The pressure drop from gas flow through one side of the heat exchanger is calculated using the relationship:

$$
\Delta p=\frac{1}{2} f_{0} \frac{L_{\text {chan }}}{d_{\text {chan }}} \frac{\dot{m}_{g}}{A_{f}}+\frac{K_{v}}{\rho_{g}} \dot{m}_{g}^{2} .
$$

The flow friction factor is calculated using the method described in the Air Duct section for model Pipe_Flow to capture both laminar and turbulent flow regimes.

The model is run specifying outlet gas temperatures on both the hot and cold sides. The model calculates the heat addition to or the heat removal from the gas. Alternatively, the heat input could be specified and the outlet gas temperature calculated. Neglecting the heat capacity of the gas within the heater, a steady-state enthalpy balance is used to calculate the heat addition $\left(\Delta h_{g}\right)$ according to the steady-state equation:

$$
\dot{m}_{\text {out }}\left(\sum_{i} x_{i} h_{i}\right)_{\text {out }}-\dot{m}_{\text {in }}\left(\sum_{i} x_{i} h_{i}\right)_{\text {in }}=\Delta h_{g}
$$

The summations in Eq. (77) are taken over the air and steam components of the inlet and outlet streams. 


\section{Flow Splitting}

An additional unit operation is required at the inlet to the exhaust blowers where the gas stream splits into two streams to enter the parallel blowers. The ACM model Flow_Split takes the inlet gas stream and splits it into two outlet streams. The model requires almost no computations since the composition, temperature, pressure and enthalpy of the gas in the outlet streams are equal to the inlet values. The model does calculate the gas density and inlet volumetric flow since this is used as a control variable in the HLW system. The flow split is determined by pressure balances around the system and is not specified directly in the model. The model only sets the sum of the mass flows in the outlet streams to equal the inlet mass flow to conserve mass.

\section{Fan Speed Control}

Another small model used in the package to set the blower fan speed is ACM model Speed_Set. Starting at time zero, this model ramps the fan speed from zero to the maximum speed at a linear rate of increase. The user sets the rate of increase in fan speed and the time over which the ramp is applied thereby indirectly specifying the maximum speed. At times greater than the ramp time, the model calculates the change in fan speed as the product of a time constant and a control signal. This allows the LAW system to attempt to control fan speed in response to the system pressure at the point where the three melter offgas streams combine while the control signal can be set to zero in the HLW system to maintain a constant fan speed. This model can also be used to simulate a fan failure accident by using the time constant or control signal for a particular fan to ramp down the blower speed and turn off the blower. The Task structure in ACM can be conveniently used to adjust coefficient values, such as the blower time constant, at specific times in the simulation to model accident scenarios. 


\section{List of System Models}

There are a total of 23 individual models of specific unit operations in the simulation package. A listing of the model names and a brief description of the units they model is provided in Table 11. In addition, there are four submodels used to evaluate gas physical properties also listed in Table 11.

Table 11. List of ACM Models

\begin{tabular}{|r|l|l|}
\hline & Model Name & \multicolumn{1}{|c|}{ Unit Modeled } \\
\hline \hline 1 & Blower & Exhaust and stack blowers \\
\hline 2 & Catalytic & Selective Catalytic Reducers \\
\hline 3 & Caustic_Scrubber & Caustic scrubbers \\
\hline 4 & Control_Valve & Control valves \\
\hline 5 & Filter & HEME and HEPA filters \\
\hline 6 & Flow_Split & Inlet fan manifolds \\
\hline 7 & Gas_Profile & Time dependent feed streams \\
\hline 8 & Gas_Source & Constant feed streams \\
\hline 9 & Gas_Tank & Tees and junctions \\
\hline 10 & Heat_Exchanger & Heat exchangers \\
\hline 11 & Heater & HEPA preheaters \\
\hline 12 & Melter & Melters \\
\hline 13 & Mixing_Volume & Tees and junctions \\
\hline 14 & Orifice & Air leaks and restricting orifices \\
\hline 15 & PID_Controller & PID controllers \\
\hline 16 & Pipe_Flow & Film cooler \\
\hline 17 & Plenum & Equipment gas volumes \\
\hline 18 & SBS & Submerged Bed Scrubbers \\
\hline 19 & Speed_Set & Blower speed control \\
\hline 20 & Vessel & VVS vessels \\
\hline 21 & Vessel_System & VVS Vessel, gas source, and orifice \\
\hline 22 & WESP & Wet Electrostatic Precipitators \\
\hline 23 & Gas_Pipe & Air ducts \\
\hline \hline 24 & P_Sat & Saturation vapor pressure \\
\hline 25 & Vapor_Density & Gas mixture density \\
\hline 26 & Vapor_Enthalpy & Gas mixture enthalpy \\
\hline 27 & Vapor_Viscosity & Gas mixture viscosity \\
\hline & & \\
\hline
\end{tabular}




\section{$\underline{\text { Calculation Basis }}$}

Three calculations were run for both the HLW and LAW melter offgas systems:

1. Steady-state operating conditions,

2. Startup transient,

3. Best estimate melter steam surges.

As specified by Rouse $(2000 \mathrm{~m})$, for all of the calculations, the ambient atmospheric pressure at the Hanford Site is assumed to be 100,000 Pa. The HLW melter cell pressure is taken to be $99,750 \mathrm{~Pa}$ which is approximately -1.0 inch water from ambient while the LAW melter cell pressure is assumed to be $99,625 \mathrm{~Pa}$ or approximately -1.5 inches water. Cell air conditions on the high-pressure side of the melter air inleakage orifice are assumed to be $45{ }^{\circ} \mathrm{C}$ and $50 \%$ relative humidity. The humidity is used to calculate the inleakage gas composition by applying Eqs. (5) and (6).

Since no detailed startup sequence has been specified for the melter systems, assumptions used for the startup transient are rather arbitrary in this preliminary calculation. The calculation is intended to demonstrate the model capability to perform this particular calculation rather than to present an accurate picture of how the actual system startup will take place. Starting up the offgas system from conditions of uniform pressure and no flow is a particularly challenging calculation that forces model parameters to change over a wide range and exercises the flow regime logic. The ability of the models to make his calculation demonstrates that the models are relatively robust and stable.

Figure 26 shows the melter steam surge assumed to take place in the HLW melter. The nominal 7X surge profile was obtained from Peters (2000). Also shown on Figure 26 are the fluctuations in the HLW melter steam flow caused by the Air Displacement Slurry (ADS) pumps. Figure 27 shows the LAW melter steam surge transient that was assumed to occur in the model calculations. The nominal $4 \mathrm{X}$ surge profile was obtained from a graph provided by Rouse $(2000 \mathrm{~m})$ for a $10 \mathrm{MT} /$ day LAW melter. The calculations assume that the surge occurs in only one of the three LAW melters (specifically in LAW Melter \#1). Also shown on Figure 27 are the fluctuations in the LAW melter steam flow caused by the ADS pumps. For both systems, the ADS fluctuations are controlled through an ACM Task that increments the starting time for the specified gas profile to create a uniformly repeating pattern of gas flow. 


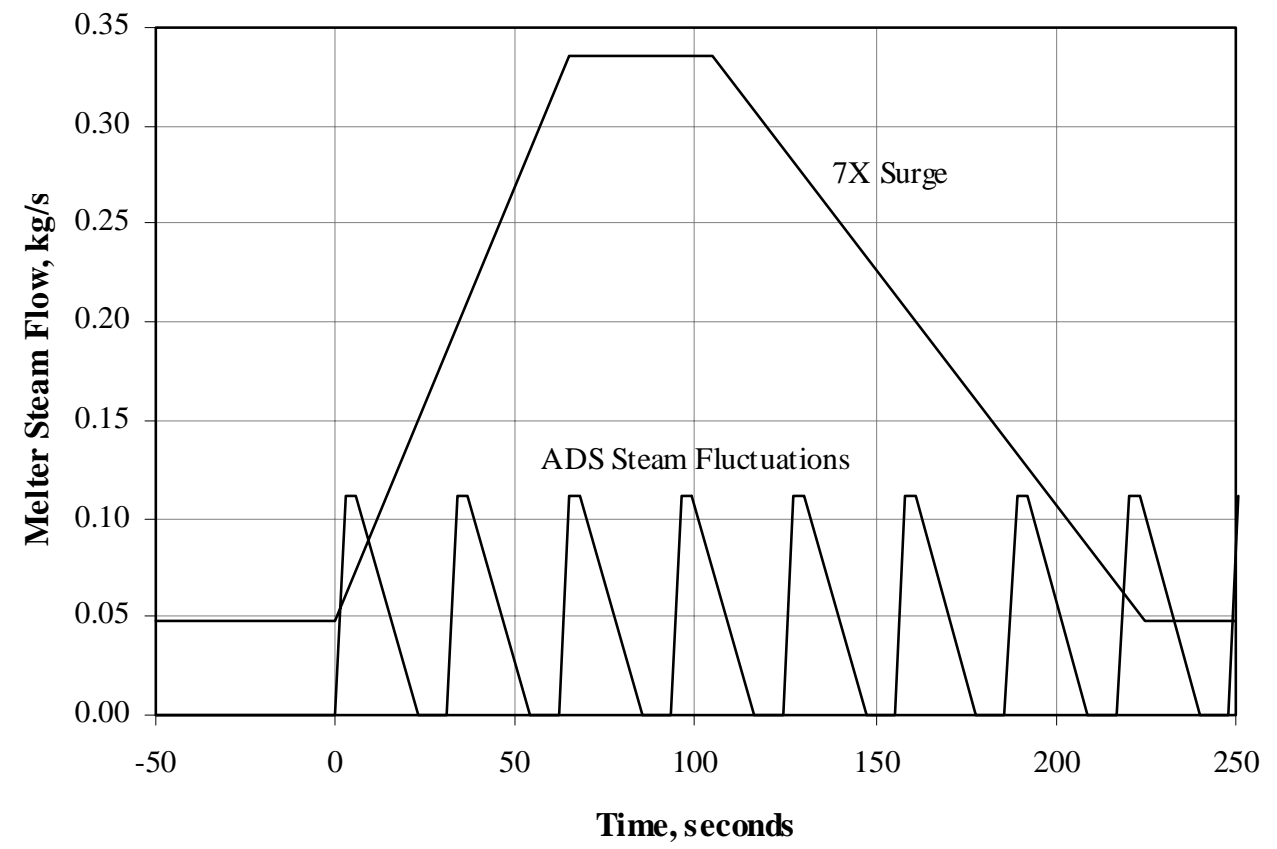

Figure 26. HLW melter steam surge and ADS steam fluctuations.

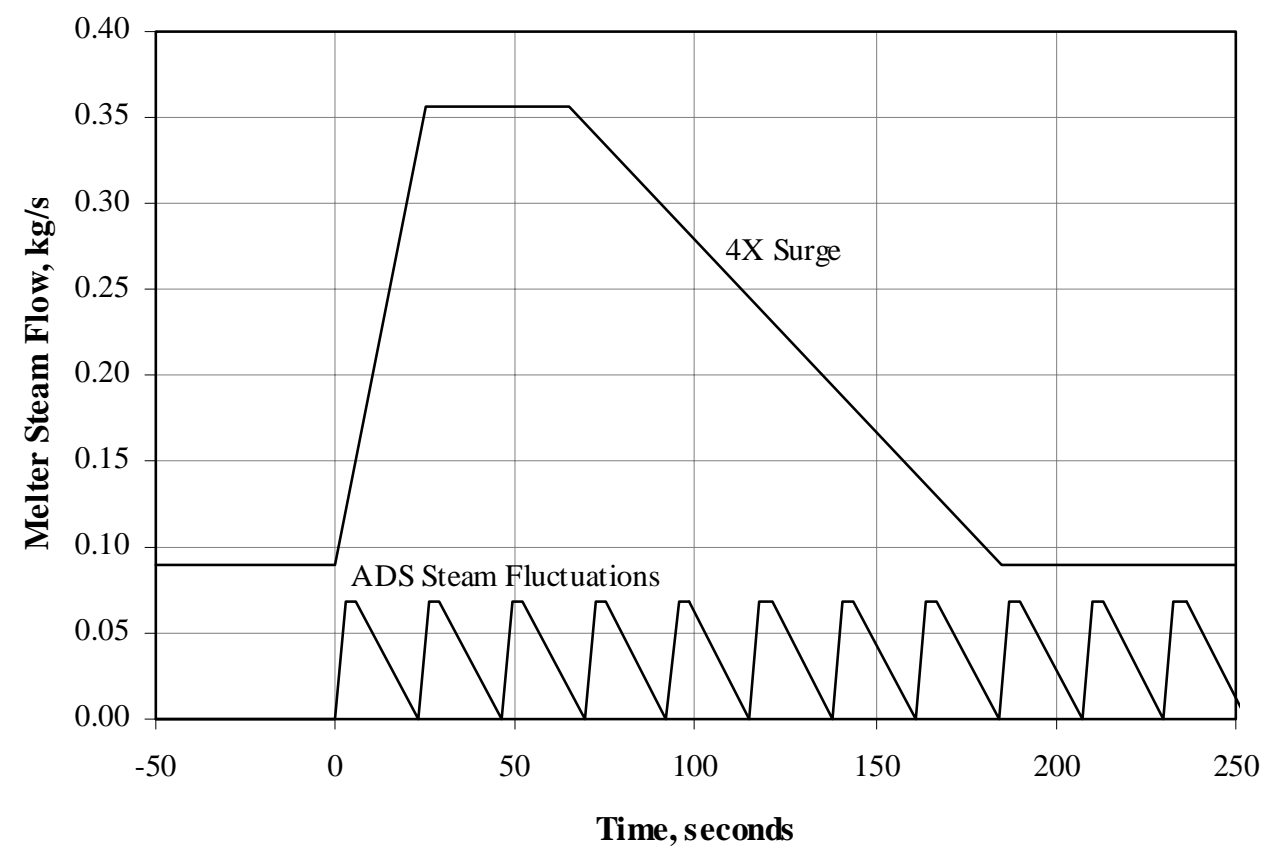

Figure 27. LAW melter steam surge and ADS steam fluctuations. 


\section{HLW Offgas System Calculations}

For the calculations in this report, the orifice diameter for melter air inleakage is taken to be 3.0 inches and an orifice coefficient of 0.5715 is used (Rouse, $2000 \mathrm{~m}$ ). Air and steam flows into the HLW VVS vessels were set to the nominal flows specified by Meeuwsen (2001).

\section{HLW Steady-State Operation}

The model was first run through a startup scenario and melter surge transient. Following these calculations, the model was allowed to run for an additional 300 seconds of simulated time until a steady-state operation was reached. At this point, the pressures and gas flows recorded in Tables 12 and 13 were observed. One difference between the steady-state and the usual dynamic calculation was that the fluctuating ADS flow was replaced with a constant average value to obtain the steady-state results reported in the tables. Table 12 compares the pressures, mass flows, and volumetric flows calculated by the HLW dynamic model to the values reported on the material and energy balance flowsheet provided by Rouse (2000k, Appendix A). The lower part of Table 12 gives the system gauge pressures in inches of water. The two sets of calculations are in fair agreement. The largest difference between the calculations appears to be that the dynamic ACM model is predicting a significantly smaller control air flow than was used in the spreadsheet calculation. The source of this discrepancy has not been identified. Steady-state pressure drops calculated across the HLW system ducts by the dynamic model are reported in Table 13. The dynamic model predicts a total system pressure drop of about 18.4 inches water. 
Table 12. HLW Steady-State Unit Outlet Pressures and Gas Flows

\begin{tabular}{|l||c|c|c|c|c|c|}
\hline \multicolumn{1}{|c||}{ Offgas Unit } & \multicolumn{2}{c|}{ Pressure (mbar) } & \multicolumn{2}{c|}{ Volumetric Flow $\left(\mathbf{m}^{\mathbf{3}} / \mathbf{s}\right)$} & \multicolumn{2}{c|}{ Mass Flow (kg/s) } \\
\hline \hline Melter & ACM & Excel & ACM & Excel & ACM & Excel \\
\hline Film Cooler & 983.9 & 985 & 0.616 & 0.607 & 0.252 & 0.252 \\
\hline Pressure Control & 983.5 & 980 & 0.783 & 0.782 & 0.432 & 0.435 \\
\hline SBS & 980.2 & 977 & 0.790 & 0.878 & 0.436 & 0.557 \\
\hline WESP & 883.7 & 874 & 0.406 & 0.576 & 0.367 & 0.512 \\
\hline Vent Mixer & 880.4 & 867 & 0.408 & 0.568 & 0.368 & 0.506 \\
\hline HEME & 877.8 & 861 & 0.638 & 0.794 & 0.594 & 0.707 \\
\hline HEPA Heater & 866.6 & 848 & 0.644 & 0.812 & 0.594 & 0.711 \\
\hline HEPA Bank 1 & 864.5 & 846 & 0.675 & 0.869 & 0.594 & 0.711 \\
\hline HEPA Bank 2 & 863.3 & & 0.703 & & 0.594 & \\
\hline Booster Fan Inlet Manifold & 861.8 & 836 & 0.704 & 0.879 & 0.594 & 0.711 \\
\hline Booster Fan 1, Fan 2 & 857.5 & & 0.708 & & 0.594 & \\
\hline Booster Fan Discharge Manifold & 944.1 & & 0.321 & & 0.297 & \\
\hline Caustic Scrubber & 942.5 & 934 & 0.644 & 0.806 & 0.594 & 0.711 \\
\hline Heat Exchanger Cold Side & 930.5 & 919 & 0.566 & 0.729 & 0.568 & 0.701 \\
\hline HEPA Preheater & 926.1 & 916 & 0.642 & 1.098 & 0.568 & 0.701 \\
\hline Catalytic Oxidizer & 925.7 & 916 & 0.887 & 1.312 & 0.568 & 0.701 \\
\hline Heat Exchanger Hot Side & 924.8 & 914 & 1.020 & 1.316 & 0.568 & 0.701 \\
\hline Stack HEPA Bank 1 & 924.4 & 909 & 0.910 & 0.960 & 0.568 & 0.701 \\
\hline Stack HEPA Bank 2 & 922.6 & & 0.800 & & 0.568 & \\
\hline Stack Fan Inlet Manifold & 921.0 & 901 & 0.802 & 0.968 & 0.568 & 0.701 \\
\hline Stack Fan 1, Fan 2 & 919.7 & & 0.803 & & 0.568 & \\
\hline Stack Fan Discharge Manifold & 1005.8 & & 0.367 & & 0.284 & \\
\hline
\end{tabular}

\begin{tabular}{|l||r|r|}
\hline \multicolumn{1}{|c||}{ Offgas Unit } & \multicolumn{2}{c|}{ Inches Water Gauge } \\
\cline { 2 - 3 } \multicolumn{1}{|c|}{} & ACM & Excel \\
\hline \hline Melter & -6.4 & -6.0 \\
\hline Film Cooler & -6.6 & -8.0 \\
\hline Pressure Control & -7.9 & -9.2 \\
\hline SBS & -46.5 & -50.4 \\
\hline WESP & -47.8 & -53.2 \\
\hline Vent Mixer & -48.9 & -55.6 \\
\hline HEME & -53.4 & -60.8 \\
\hline HEPA Heater & -54.2 & -61.6 \\
\hline HEPA Bank 2 & -55.3 & -65.6 \\
\hline Booster Fan Discharge Manifold & -23.0 & -26.4 \\
\hline Caustic Scrubber & -27.8 & -32.4 \\
\hline Heat Exchanger Cold Side & -29.6 & -33.6 \\
\hline HEPA Preheater & -29.7 & -33.6 \\
\hline Catalytic Oxidizer & -30.1 & -34.4 \\
\hline Heat Exchanger Hot Side & -30.2 & -36.4 \\
\hline Stack HEPA Bank 2 & -31.6 & -39.6 \\
\hline Stack Fan Discharge Manifold & 1.8 & 3.2 \\
\hline
\end{tabular}


Table 13. HLW Steady-State Duct Pressure Drops

\begin{tabular}{|c|c|c|}
\hline Duct Number & $\begin{array}{c}\text { ACM Pressure } \\
\text { Drop (Pa) }\end{array}$ & $\begin{array}{c}\text { ACM Pressure } \\
\text { Drop (in W) }\end{array}$ \\
\hline 1 & 37.2 & 0.149 \\
\hline 2 & 7.5 & 0.030 \\
\hline 3 & 325.7 & 1.303 \\
\hline 4 & 251.6 & 1.006 \\
\hline 5 & 247.3 & 0.989 \\
\hline 6 & 258.7 & 1.035 \\
\hline 7 & 379.1 & 1.516 \\
\hline 8 & 167.7 & 0.671 \\
\hline 9 & 82.0 & 0.328 \\
\hline 10 & 99.1 & 0.396 \\
\hline 11 & 437.3 & 1.749 \\
\hline $12 / 13$ & 139.9 & 0.560 \\
\hline $14 / 15$ & 160.0 & 0.640 \\
\hline 16 & 444.4 & 1.778 \\
\hline 17 & 414.1 & 1.656 \\
\hline 18 & 137.0 & 0.548 \\
\hline 19 & 113.0 & 0.452 \\
\hline 20 & 129.4 & 0.518 \\
\hline $21 / 22$ & 189.4 & 0.758 \\
\hline $23 / 24$ & 137.3 & 0.549 \\
\hline 25 & 446.9 & 1.788 \\
\hline \hline System Total & 4604.6 & 18.418 \\
\hline
\end{tabular}

\section{HLW Startup Transient}

HLW system startup is assumed to occur according to the following scenario:

- At time zero, the primary and stack offgas blowers are started and the fan speed is linearly ramped from zero to full operating speed over 50 seconds.

- At approximately 36 seconds into the transient, the blower generates a pressure drop of about 91.2 mbar (36.5 inches water) across the Submerged Bed Scrubber which is enough to break the water seal. After this point, flow through the offgas system increases rapidly and pressure in the melter begins to drop. The control systems are programmed to activate when melter pressure drops below 980.0 mbar $(-8.0$ inches WG).

- Between 50 and 100 seconds, the melt cell pressure is linearly decreased from 1000 mbar to 997.5 mbar to create the -1.0 inch WG operating vacuum.

- Between 100 and 200 seconds, the fixed air and steam feeds to the melter, film cooler, and VVS vessels are linearly ramped from no flow to full steady-state flow and the melter offgas temperature is ramped from $50{ }^{\circ} \mathrm{C}$ to $400{ }^{\circ} \mathrm{C}$. 
- At 200 seconds the ADS steam flow in the melter is started. Once ADS flow is initiated, the system will not operate at steady-state.

- Between 200 and 300 seconds, the model is run without changing the input to allow a nominal operating condition to be reached.

\section{HLW Steam Surge}

Figure 28 shows model calculated results for the melter pressure during startup followed by a nominal $7 \mathrm{X}$ steam surge with the offgas blowers operating at $92 \%$ maximum fan speed. The steam surge starts at time 300 seconds on the graph. One inch of water is very closely approximated as 2.5 mbar. Therefore, each grid division on the pressure scale represents 1.0 inch water. The melt cell vacuum of -1 inch WG (997.5 mbar) and the melter pressure set point of -5 inches WG with respect to the melt cell (985.0 mbar) are indicated on the figure. During startup, SBS breakthrough occurs at about 40 seconds and the melter pressure reaches a minimum of about -9 inches WG within a few seconds of breakthrough. The control system returns the pressure to the set point of $985 \mathrm{mbar}$. At 100 seconds, the system is perturbed as gas flows to the melter, film cooler, and HLW VVS vessels are ramped in. At 200 seconds, the ADS steam flow starts and the system thereafter operates in a transient fashion. The ADS steam fluctuations create melter pressure disturbances of from +4 inches to -1 inch so that the melter reaches a maximum pressure of about -2 inches WG during the ADS cycle. At 300 seconds, the melter experiences the start of the $7 \mathrm{X}$ steam surge. During the surge, the melter pressure increases +5 inches to about -1 inch and briefly exceeds the cell pressure at two points where maximums in the ADS surges superimpose on the maximum in the steam surge.

Figure 29 shows stem position of the two control valves during the transient. The control valve on VVS flow, shown by the darker line, is able to maintain a relatively constant position at about $20 \%$ full open during the transient. However, once gas flows are established in the system, the melter pressure control valve is operating at the lower end of its range and is shutting off during the ADS surges. During the melter steam surge, the valve shuts off almost immediately and does not recover any control function until the end of the surge. Therefore, under the assumptions used in this calculation, the melter is operating without pressure control during the steam surge.

As shown in Figures 30 and 31, the control action is improved by operating the blowers at $100 \%$ capacity. Under this condition, ADS steam fluctuations cause melter pressure disturbances of from +2.5 inches to -3 inches. During the steam surge, melter pressure increases by a maximum of 3.5 inches leaving a margin of 1.5 inches between the melter and the cell. Figure 31 shows that the melter pressure control valve is now normally operating at an average of $20 \%$ capacity and looses control function only briefly at the peak of the steam surge.

All of these results depend on control system and control valve parameters that have not been specified by the Hanford design team at this point and certainly are not optimized in these calculations. Therefore, the results should be taken as only a preliminary indication of the system behavior pending refinement of the models. 




Figure 28. HLW melter pressure during startup and 7X steam surge.

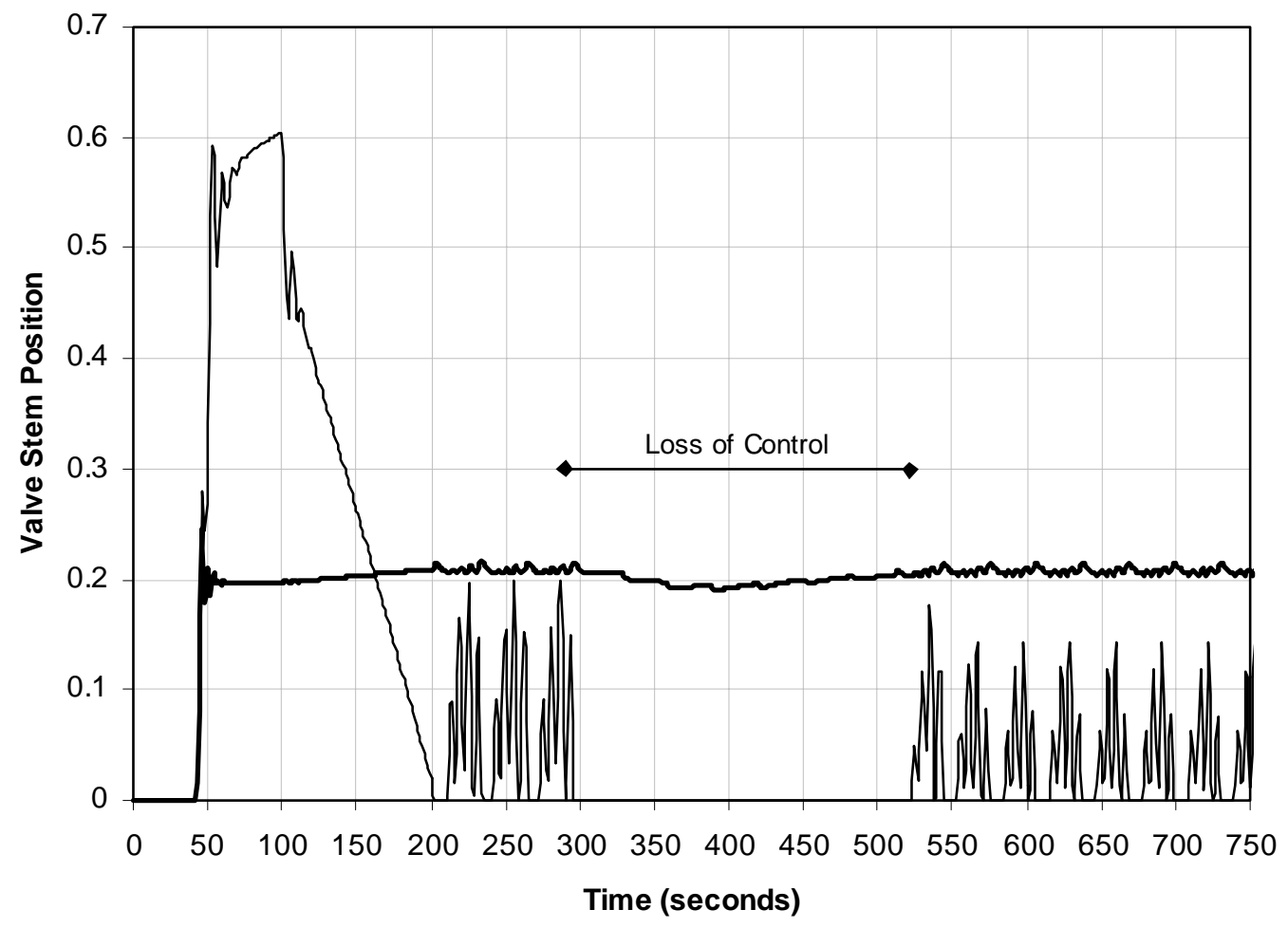

Figure 29. HLW control valve operation at $92 \%$ full blower speed. 


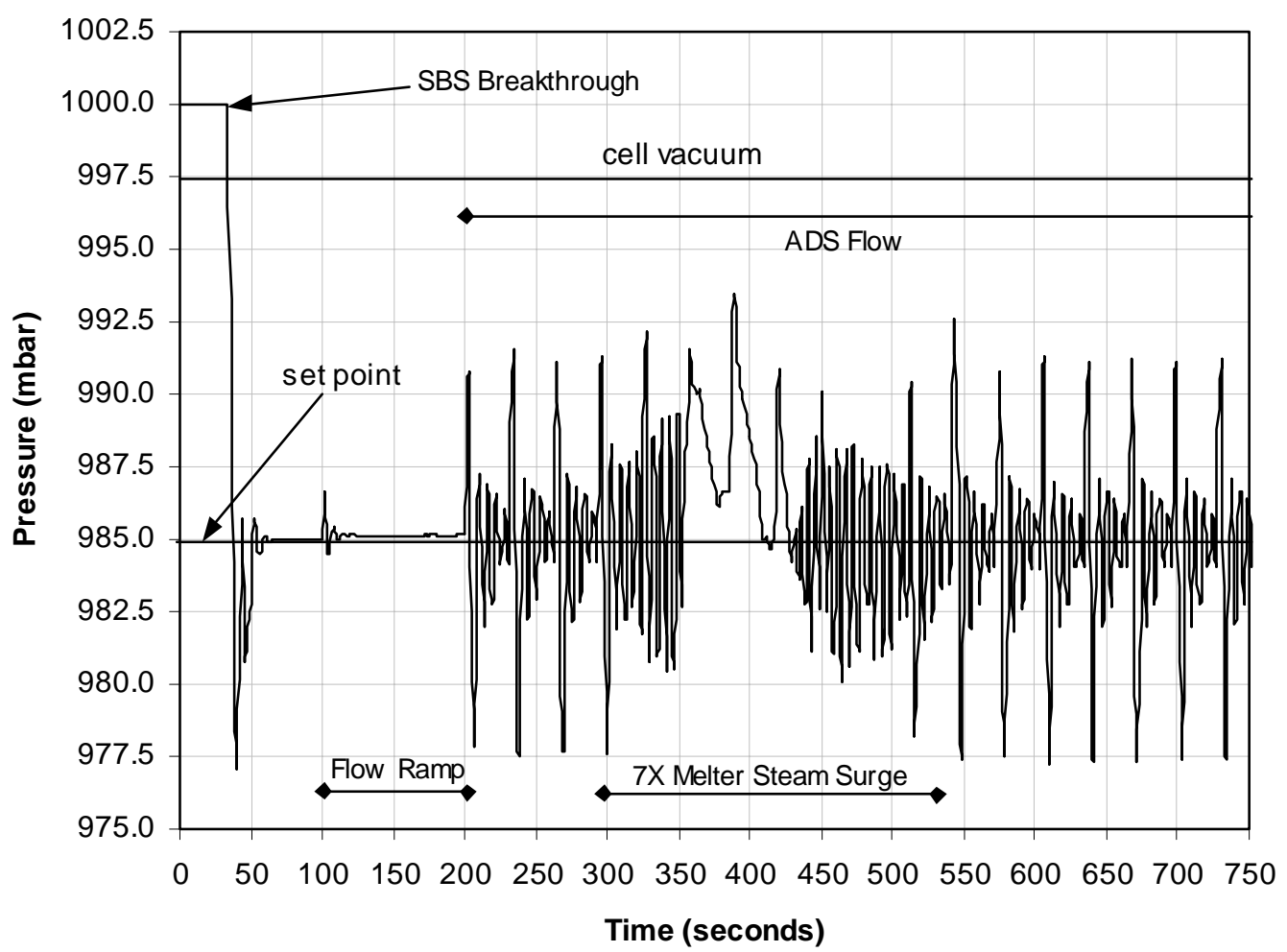

Figure 30. HLW melter pressure during startup and 7X steam surge.

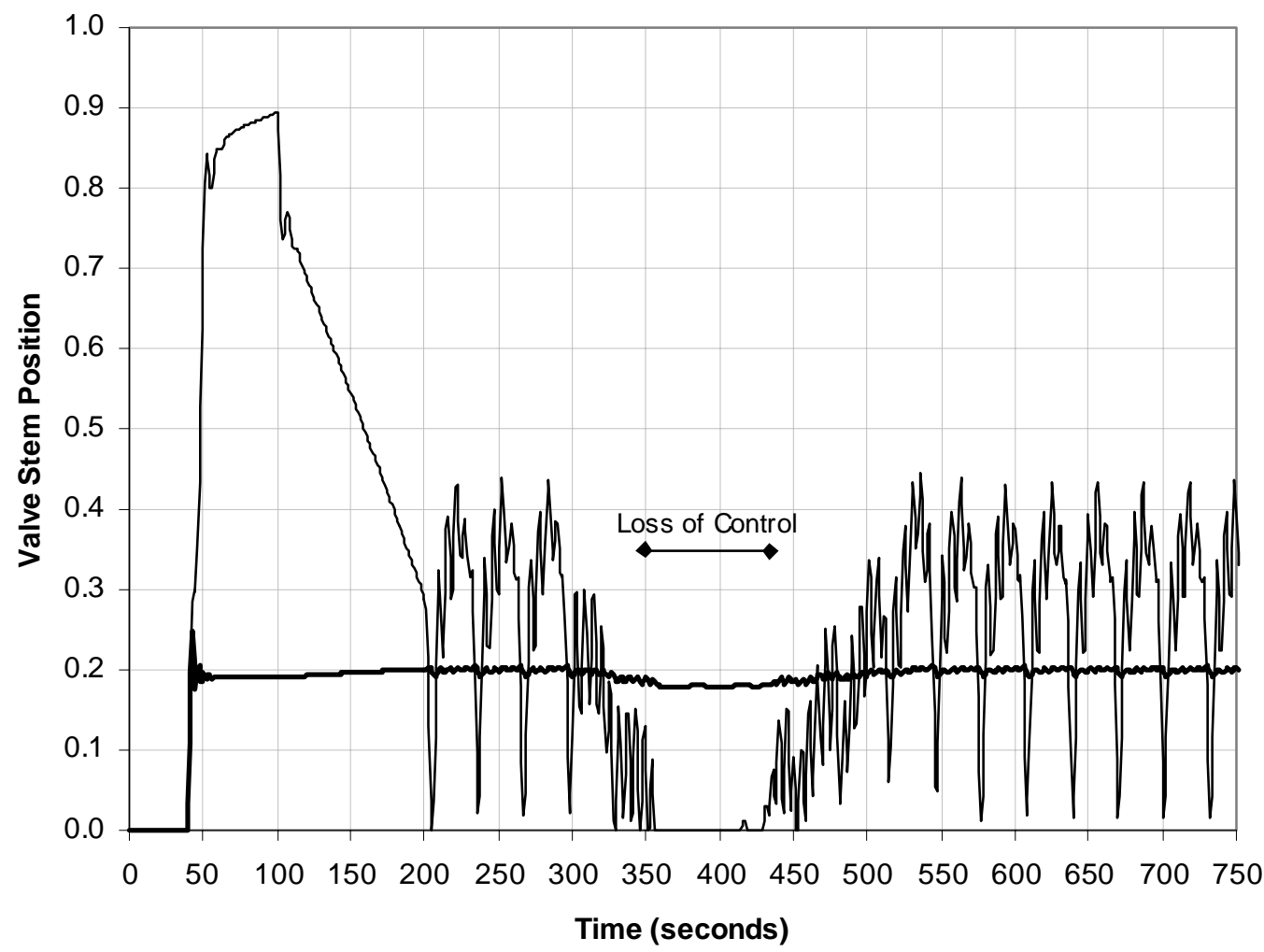

Figure 31. HLW control valve operation at $100 \%$ full blower speed. 


\section{LAW Offgas System Calculations}

For the calculations described in this report, the orifice diameters for melter air inleakage are taken to be (Rouse, 2000m):

LAW Melter \#1 - 3.00 inches

LAW Melter \#2 - 3.75 inches

LAW Melter \#3 - 4.25 inches

Variable orifice diameters were used to reflect the uncertainty and range of air inleakage expected for the three LAW melters. An orifice coefficient of 0.5715 is used. Air and steam flows into the LAW vessels were set to the nominal flows specified by Fergestrom and Meeuwsen (2000).

\section{LAW Steady-State Operation}

As described below, the model was run through a startup scenario and melter surge transient. Following these calculations, the model was allowed to run for an additional 300 seconds of simulated time until steady-state operation was reached. At this point, the pressures and gas flows recorded in Tables 14 and 15 were observed. As in the HLW steady-state calculation, the fluctuating ADS flow was replaced with a constant average value to obtain the LAW steady-state results reported in the tables. Table 14 compares pressures, mass flows, and volumetric flows calculated by the LAW dynamic model to those reported on the material and energy balance flowsheet provided by Rouse (20001, Appendix A). The lower part of Table 14 gives the system gauge pressures in inches of water. The two sets of calculations are in reasonably good agreement. As opposed to the HLW model, the LAW dynamic model predicts essentially the same control air flow. A source of significant difference between the two sets of calculations is the assumed VVS gas flow. The Excel spreadsheet calculation is adding about twice the gas flow from the VVS as is predicted at nominal vessel flow by the dynamic model. However, the dynamic model has more air coming out of the combined melter systems which offsets the lower VVS flow. Steady-state pressure drops calculated across the LAW system ducts are reported in Table 15. Comparable steady-state calculations from the Hanford spreadsheets were not available for comparison. From previous comparisons, it is expected that if both sets of calculations were made under identical conditions there would be good agreement between the results. The dynamic model predicts a total system pressure drop (through Melter \#2 and the common offgas train) of about 21.5 inches water.

\section{LAW Startup Transient}

LAW system startup is assumed to occur according to the following scenario:

- At time zero, the offgas blowers are started and the fan speed is linearly ramped from zero to full operating speed of 3000 rpm over 100 seconds. 
- At approximately 40 seconds into the transient, the blower generates a pressure drop of about 91.2 mbar (36.5 inches water) across the Submerged Bed Scrubber which is enough to break the water seal. After this point, flow through the offgas system increases rapidly and pressure in the melter begins to drop. The control systems are programmed to activate when the melter pressure drops below -8.5 inches WG.

- Between 50 and 100 seconds, the melt cell pressure is linearly decreased from an initial ambient pressure of 1000 mbar to 996.25 mbar to create the -1.5 inch operating vacuum which is then held constant.

- Between 100 and 200 seconds, the fixed air and steam feeds to the melter, film cooler, and VVS vessels are linearly ramped from no flow to full steady-state flow and the melter offgas temperature is ramped from $50{ }^{\circ} \mathrm{C}$ to $400{ }^{\circ} \mathrm{C}$.

- At 200 seconds the ADS steam flow in the melter is started.

- Between 200 and 300 seconds, the model is run without changing the input to allow a nominal operating conditions to be reached. With the fluctuating ADS flow, the operation will no longer be steady-state. 
Table 14. LAW Steady-State Unit Outlet Pressures and Gas Flows

\begin{tabular}{|l||c|c|c|c|c|c|}
\hline \multicolumn{1}{|c||}{ Offgas Unit } & \multicolumn{2}{c|}{ Pressure (mbar) } & \multicolumn{2}{c|}{ Volumetric Flow $\left(\mathbf{m}^{3} / \mathbf{s}\right)$} & \multicolumn{2}{c|}{ Mass Flow (kg/s) } \\
\hline \hline Melter 1 & ACM & Excel & ACM & Excel & ACM & Excel \\
\hline Film Cooler 1 & 983.9 & & 0.583 & & 0.271 & \\
\hline Pressure Control 1 & 983.7 & & 0.793 & & 0.419 & \\
\hline SBS 1 & 982.5 & & 1.093 & & 0.743 & \\
\hline WESP 1 & 878.8 & & 0.788 & & 0.708 & \\
\hline \hline Melter 2 & 872.6 & & 0.805 & & 0.720 & \\
\hline Film Cooler 2 & 983.9 & & 0.718 & & 0.338 & \\
\hline Pressure Control 2 & 983.7 & & 0.931 & & 0.487 & \\
\hline SBS 2 & 982.0 & & 1.160 & & 0.730 & \\
\hline WESP 2 & 878.4 & & 0.771 & & 0.692 & \\
\hline \hline Melter 3 & 872.5 & & 0.788 & & 0.705 & \\
\hline Film Cooler 3 & 983.9 & 975 & 0.825 & 0.804 & 0.392 & 0.357 \\
\hline Pressure Control 3 & 983.6 & 972 & 1.039 & 1.000 & 0.540 & 0.504 \\
\hline SBS 3 & 981.5 & 970 & 1.209 & 1.171 & 0.719 & 0.687 \\
\hline WESP 3 & 878.1 & 865 & 0.755 & 0.685 & 0.678 & 0.605 \\
\hline \hline WESP Mixer & 872.7 & & 0.772 & & 0.691 & \\
\hline Vent Mixer & 870.2 & 861 & 2.396 & 1.994 & 2.132 & 1.777 \\
\hline HEPA Heater & 868.1 & 859 & 2.741 & 2.603 & 2.451 & 2.358 \\
\hline HEPA Bank 1 & 866.4 & 854 & 2.834 & 2.821 & 2.451 & 2.358 \\
\hline HEPA Bank 2 & 861.1 & & 2.942 & & 2.451 & \\
\hline Booster Fan Inlet Manifold & 856.5 & 837 & 2.958 & 2.877 & 2.451 & 2.358 \\
\hline Booster Fan 1, Fan 3 & 852.3 & & 2.973 & & 1.226 & \\
\hline Booster Fan 2, Fan 4 & 964.5 & & 1.314 & & 1.226 & \\
\hline Booster Fan Discharge Manifold & 1078.2 & & 1.175 & & 1.226 & \\
\hline Heat Exchanger Cold Side & 1077.2 & 1064 & 2.353 & 2.382 & 2.451 & 2.358 \\
\hline HEPA Preheater & 1069.9 & 1063 & 3.497 & 4.067 & 2.451 & 2.358 \\
\hline Catalytic Oxidizer & 1059.8 & 1063 & 4.660 & 4.448 & 2.451 & 2.358 \\
\hline Primary SCR & 1055.2 & 1058 & 4.692 & 4.468 & 2.451 & 2.358 \\
\hline Secondary SCR & 1047.1 & 1050 & 4.713 & 5.237 & 2.451 & 2.366 \\
\hline Heat Exchanger Hot Side & 1043.2 & 1040 & 5.879 & 5.323 & 2.451 & 2.366 \\
\hline Caustic Scrubber & 1042.1 & 1028 & 4.848 & 3.699 & 2.451 & 2.366 \\
\hline & 1014.2 & 1011 & 3.660 & 2.349 & 2.729 & 2.495 \\
\hline
\end{tabular}

\begin{tabular}{|l||r|r|}
\hline \multicolumn{1}{|c||}{ Offgas Unit } & \multicolumn{1}{c|}{ Inches Water Gauge } \\
\hline \hline Melter 3 & ACM & Excel \\
\hline Film Cooler 3 & -6.4 & -10.0 \\
\hline Pressure Control 3 & -6.6 & -11.2 \\
\hline SBS 3 & -7.4 & -12.0 \\
\hline WESP Mixer & -48.8 & -54.0 \\
\hline Vent Mixer & -51.9 & -55.6 \\
\hline HEPA Heater & -52.8 & -56.4 \\
\hline HEPA Bank 2 & -53.4 & -58.4 \\
\hline Booster Fan Discharge Manifold & -57.4 & -65.2 \\
\hline Heat Exchanger Cold Side & 30.9 & 25.6 \\
\hline HEPA Preheater & 28.0 & 25.2 \\
\hline Catalytic Oxidizer & 23.9 & 25.2 \\
\hline Primary SCR & 22.1 & 23.2 \\
\hline Secondary SCR & 18.8 & 20.0 \\
\hline Heat Exchanger Hot Side & 17.3 & 16.0 \\
\hline Caustic Scrubber & 16.8 & 11.2 \\
\hline
\end{tabular}


Table 15. LAW Steady-State Duct Pressure Drops

\begin{tabular}{|c|c|c|c|}
\hline & $\begin{array}{c}\text { Duct } \\
\text { Number }\end{array}$ & $\begin{array}{c}\text { ACM Pressure } \\
\text { Drop (Pa) }\end{array}$ & $\begin{array}{c}\text { ACM Pressure } \\
\text { Drop (in W) }\end{array}$ \\
\hline \multirow[t]{6}{*}{ Melter System 1} & 1 & 15.3 & 0.061 \\
\hline & 2 & 2.3 & 0.009 \\
\hline & 3 & 122.0 & 0.488 \\
\hline & 4 & 220.6 & 0.882 \\
\hline & 5 & 320.1 & 1.280 \\
\hline & 6 & 233.7 & 0.935 \\
\hline \multirow[t]{6}{*}{ Melter System 2} & 7 & 23.5 & 0.094 \\
\hline & 8 & 3.1 & 0.012 \\
\hline & 9 & 165.4 & 0.662 \\
\hline & 10 & 230.6 & 0.922 \\
\hline & 11 & 307.2 & 1.229 \\
\hline & 12 & 224.4 & 0.898 \\
\hline \multirow[t]{6}{*}{ Melter System 3} & 13 & 31.2 & 0.125 \\
\hline & 14 & 3.8 & 0.015 \\
\hline & 15 & 204.1 & 0.816 \\
\hline & 16 & 237.1 & 0.948 \\
\hline & 17 & 295.8 & 1.183 \\
\hline & 18 & 216.1 & 0.864 \\
\hline \multirow[t]{11}{*}{ Balance of System } & 19 & 207.7 & 0.831 \\
\hline & 20 & 65.4 & 0.262 \\
\hline & 21 & 452.1 & 1.808 \\
\hline & 22 & 386.8 & 1.547 \\
\hline & 23 & 415.9 & 1.664 \\
\hline & $24 / 25$ & 171.3 & 0.685 \\
\hline & $26 / 27$ & 122.2 & 0.489 \\
\hline & $28 / 29$ & 102.5 & 0.410 \\
\hline & 30 & 650.9 & 2.604 \\
\hline & 31 & 421.5 & 1.686 \\
\hline & 32 & 1423.3 & 5.693 \\
\hline Total (System 2) & & 5373.8 & 21.495 \\
\hline
\end{tabular}




\section{LAW Steam Surge}

It has proved difficult to emulate the intended LAW control system function. As proposed, the LAW control system will hold the gas flow out of the SBS constant as long as melter pressure is within \pm 2.0 inch $W G$ of the set point. Outside this range, the system will control melter pressure directly. It was attempted to model this by using a combination of control signals from SBS gas flow and melter pressure to operate a single control valve. Both control signals were sampled and, within the flow control region, the flow control signal was used exclusively. Within 0.5 inch WG of the flow control region a polynomial transition to pressure control was attempted. However, in practice, this scheme did not work well since almost always the control signals tried to drive the control valve in opposing directions. That is, an increase in melter pressure decreases air inleakage and consequently flow out of the SBS. Therefore, as melter pressure increases, the flow control wants to open the control valve to increase flow while the pressure control signals to shut the valve to decrease melter pressure. These opposing signals combine to create a point where the composite signal is zero and the system no longer responds. The issue of LAW control is still unresolved so two sets of calculations were made for the LAW system: (1) a calculation with the melter under pressure control only and (2) a calculation using the combined pressure and flow control scheme.

Figure 32 shows model calculated results for the melter pressure during system startup and a nominal $4 \mathrm{X}$ steam surge (the surge is assumed to occur in Melter 1 only) using pressure control alone. As before, each grid division on the pressure scale represents 1.0 inch WG. During startup, SBS breakthrough occurs at about 40 seconds and the melter pressure reaches a minimum of about -9.0 inch WG within 10 seconds of breakthrough. The control system returns the pressure to the set point of 983.75 mbar at about 100 seconds into the transient. At 100 seconds, the system is perturbed as gas flows to the melter, film cooler, and LAW VVS vessels are started. At 200 seconds, the ADS steam flow starts and the system begins to operate in a constantly transient fashion. The ADS steam fluctuations create melter pressure disturbances of approximately \pm 1.0 inch WG. The steam surge starts at time 300 seconds on the graph. At 300 seconds, the melter experiences the start of the $4 \mathrm{X}$ steam surge. During the surge, the melter pressure fluctuations increases to about \pm 1.5 inch WG. This relatively small increase in the pressure fluctuations is similar to that observed in the HLW system. In the LAW system, the pressure control valve continues to operate during the surge and does not loose control function as was observed in the HLW system with a larger steam surge.

Figure 33 shows model calculated results for the melter pressure during system startup and a nominal $4 \mathrm{X}$ steam surge in Melter 1 using combined flow and pressure control. Event timing is identical to that described for Figure 32. Melter pressure is simply floating between the upper (988.75 mbar) and lower (978.75 mbar) bounds of the control range depending on whether the gas flow out of the SBS is below or above its set point. This creates a smooth pressure profile with the ADS pressure fluctuations clearly visible as superimposed pressure spikes on the profile. However, as discussed above, the control scheme is actually not functioning since the opposing signals are canceling out to give a net control signal of zero which the system interprets as being in the desired condition. 
During the meter steam surge, the pressure peaks at about -5.0 inch WG which is well below the cell vacuum of -1.5 inch WG.

Figure 34 shows the SBS outlet gas flow profile for the design basis case of combined flow and pressure control. The gas flow is not being controlled with any precision by the model control scheme. Note that when the flow crosses the set point of $0.685 \mathrm{~m}^{3} / \mathrm{s}$ at about 70 seconds and again at about 250 seconds, the melter pressure simply flips from maximum to minimum and back to the maximum value. Figure 35 shows the response of the melter pressure control valves for the case of combined flow and pressure control. The valves are able to respond to the ADS fluctuations although, for the parameter values assumed in this calculation, the valve is operating undesirably close to a fully closed position. The $4 \mathrm{X}$ steam surge has minimal effect on valve operation. At long times, the volumetric flow does reach a roughly steady-state condition at the correct SBS gas flow but melter vacuum remains higher than desirable.

These results show that control of the LAW melter plenum vacuum is difficult to achieve with the proposed control system design. The function of the LAW melter pressure control system is to maintain melter plenum vacuum in the range of $-6.5 \pm 2.5 \mathrm{in}$. WG and to control the offgas flow downstream of the SBS at a constant flowrate. As proposed, it would accomplish this through two competing control loops with the flow control being the dominant response when the melter vacuum is within the specified pressure range. However, because of the competing control loops and the transient nature of the offgas system, the proposed LAW melter pressure control scheme does not appear to be able to control either the SBS discharge flow or the melter plenum vacuum. The melter plenum vacuum simply bounces between the upper and lower break points between the two competing control loops. At the break points, the two control loops cancel each other out resulting in no control response at all. The SBS discharge flow does converge to the desired setpoint at long times in the simulation but during strong system transients the flow is not controlled and varies based on the amount of offgas being generated or added.

As with the HLW system, all of these results strongly depend on control system and control valve parameters that have not been specified by the Hanford design team at this point and are not optimized in these calculations. Therefore, the results should be taken as only a preliminary indication of the system behavior pending refinement of the models. 


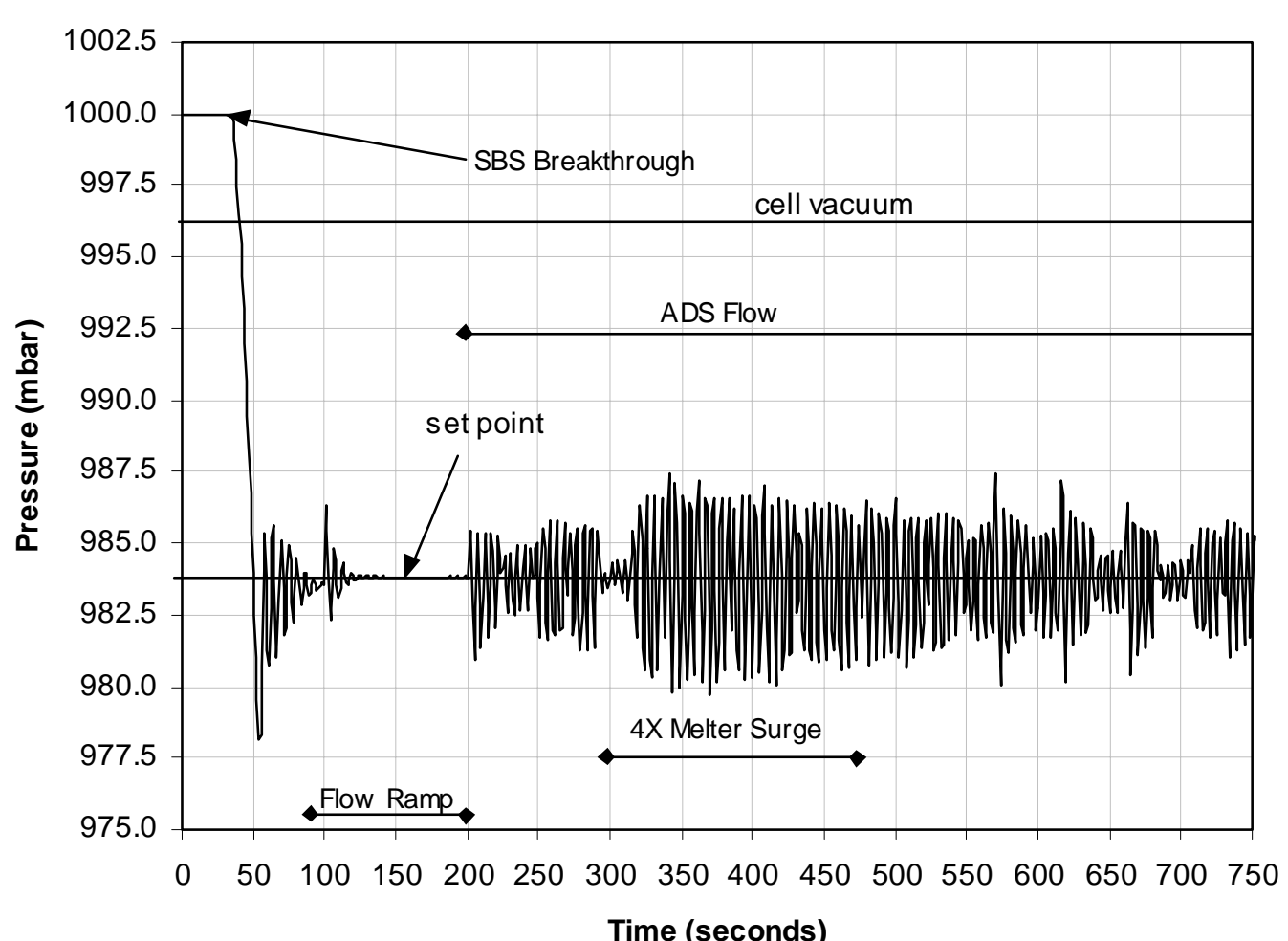

Figure 32. LAW Melter 1 pressure during startup and $4 \mathrm{X}$ steam surge with pressure control.



Figure 33. LAW Melter 1 pressure during startup and 4X steam surge with design basis flow and pressure control. 


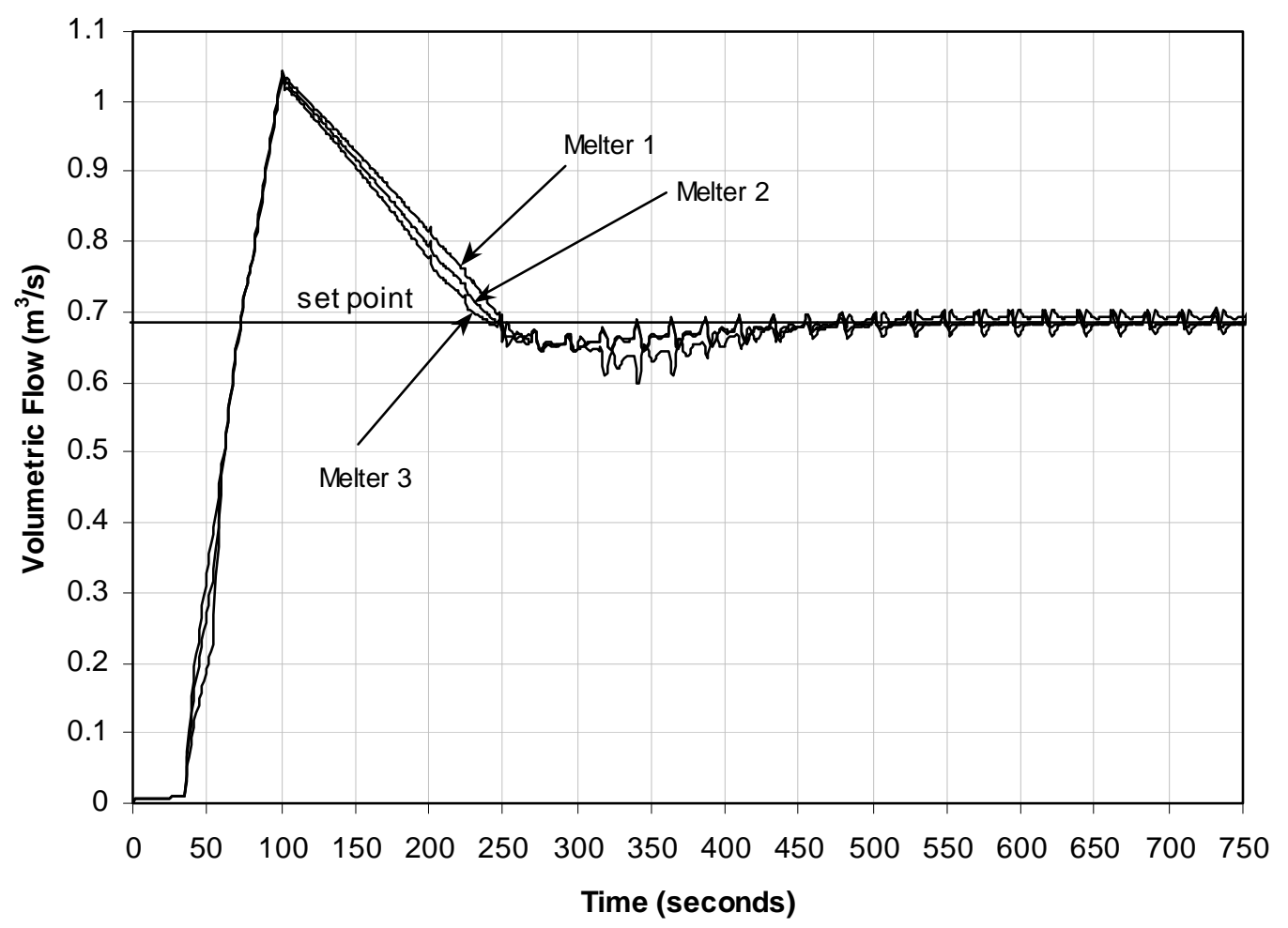

Figure 34. LAW SBS gas flow during startup and 4X steam surge in Melter 1 with design basis flow and pressure control.

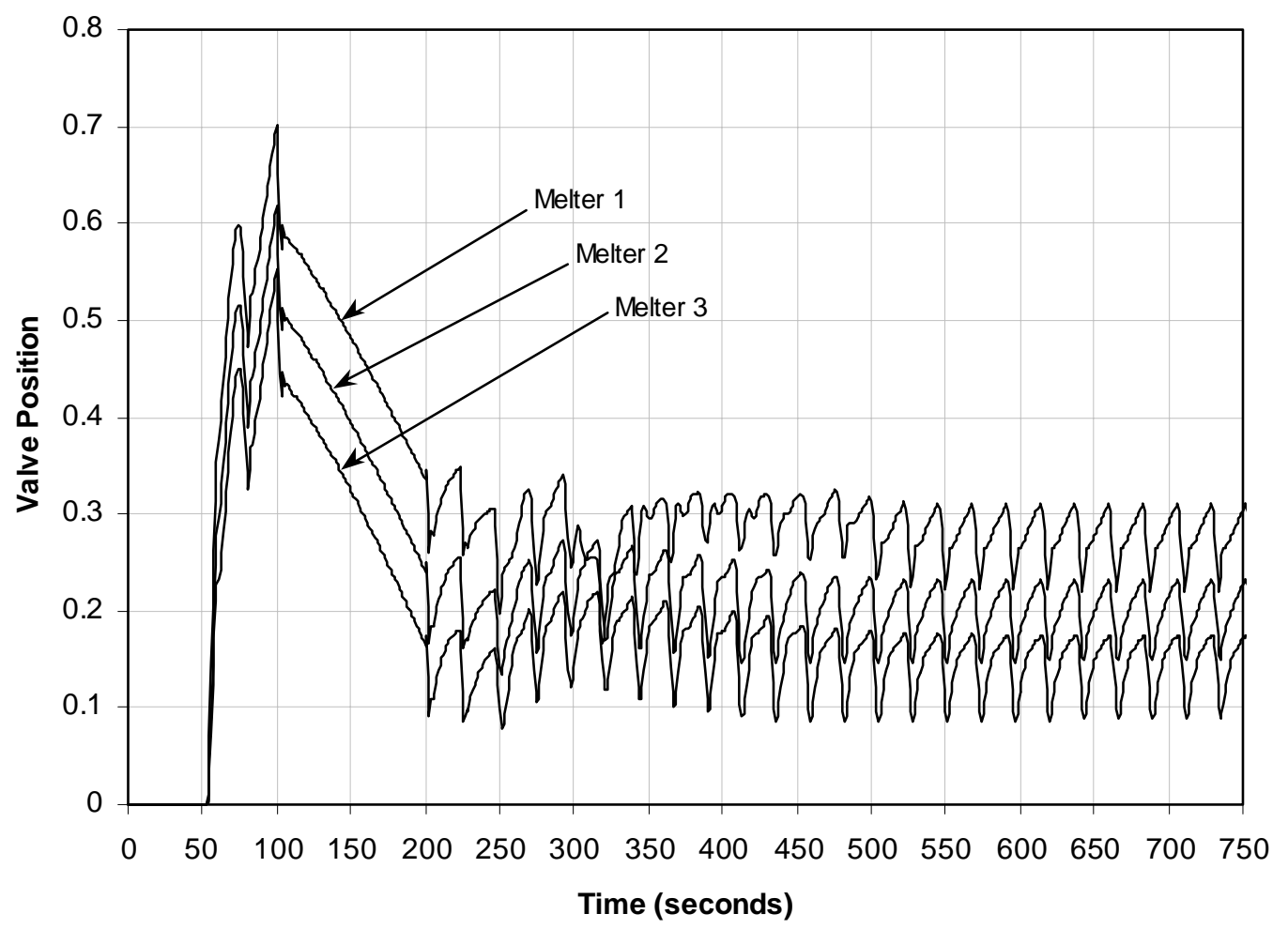

Figure 35. LAW control valve action during startup and 4X steam surge in Melter 1 with design basis flow and pressure control. 


\section{Conclusions}

Dynamic models of the High Level Waste and Low Activity Waste melter offgas systems for the proposed River Protection Project Waste Treatment Plant at the Hanford Site have been developed. The models treat the systems from the melters through the offgas stacks and include the vessel ventilation systems. The models have been applied to make calculations of steady-state operation, melter startup, and melter surge scenarios. While these calculations were successfully completed, the resulting pressure transients depend on the operation of the control systems, which have not been completely defined. Preliminary comparisons of model calculated pressures and gas flows to independent steady-state calculations show good agreement.

The modeling assumes that, in all cases, the offgas leaving the Submerged Bed Scrubber is saturated air at $50{ }^{\circ} \mathrm{C}$. That assumption means that gas flow past the scrubber actually falls as steam surges in the melter. The steam surge increases melter pressure which acts to decreases the air inleakage. Since the scrubber is assumed to completely absorb the steam a decrease in gas flow is seen downstream of the scrubber during steam surges in the melter. Without variation in the melter steam flow caused by the ADS pumps, the model runs very quickly requiring on the order of 60 seconds of CPU time for a complete transient calculation of system startup through a melter surge and back to steady-state operation. With the ADS fluctuations included, model run time increased significantly to require on the order of 10 minutes for a 10 minute transient simulation.

As noted in the introduction, modeling was stopped before all of the planned work could be completed. However, the modeling is sufficiently complete that meaningful results can be generated. To fully complete the offgas system modeling, the following items need to be included:

1. Offgas pressure control interlocks.

2. Standby offgas duct between melter and SBS.

3. HLW control valve $\mathrm{C}_{\mathrm{v}}$ curve. Manufacturer's data is available for the control valve in the HLW VVS but it has not been incorporated into the model.

4. SBS pressure fluctuations. Preliminary trials indicate that this may be difficult to include in the models.

5. Offgas equipment gas volumes. Gas volumes for the SBS and WESP plenums, which represent the largest gas volumes, were included in the model. However, gas volumes in the filters, caustic scrubber, and catalyst skids have not been included. Including significant gas volume in equipment will more accurately model surge suppression and time delays in the system.

In addition, control system parameters have not been tuned and the model has not been independently verified or completely validated. 
For quality assurance, electronic copies of the files used to generate the results in this report have been archive. The archived material includes all Excel spreadsheets used to develop pressure drop correlations used in the models, the ACM model files, and an electronic copy of this report. The material is archived in the site DFS file storage system in folder

dce.srs.gov/project/rpp/smith/offgas.

The two ACM models named:

$$
\text { hlw_mog_v1.acmf and law_mog_v1.acmf }
$$

are in folders HLW Model and LAW Model, respectively. These acmf files contain all of the input parameters, individual unit models, and the offgas flowsheet. An additional copy of the project files resides on the author's personal computer in folder

\section{E: \Hanford RPP\Off Gas}

These files will be frozen and new working versions of the ACM models, reports and Excel spreadsheets used to provide input to the ACM model will be created for future revisions. 


\section{$\underline{\text { Nomenclature }}$}

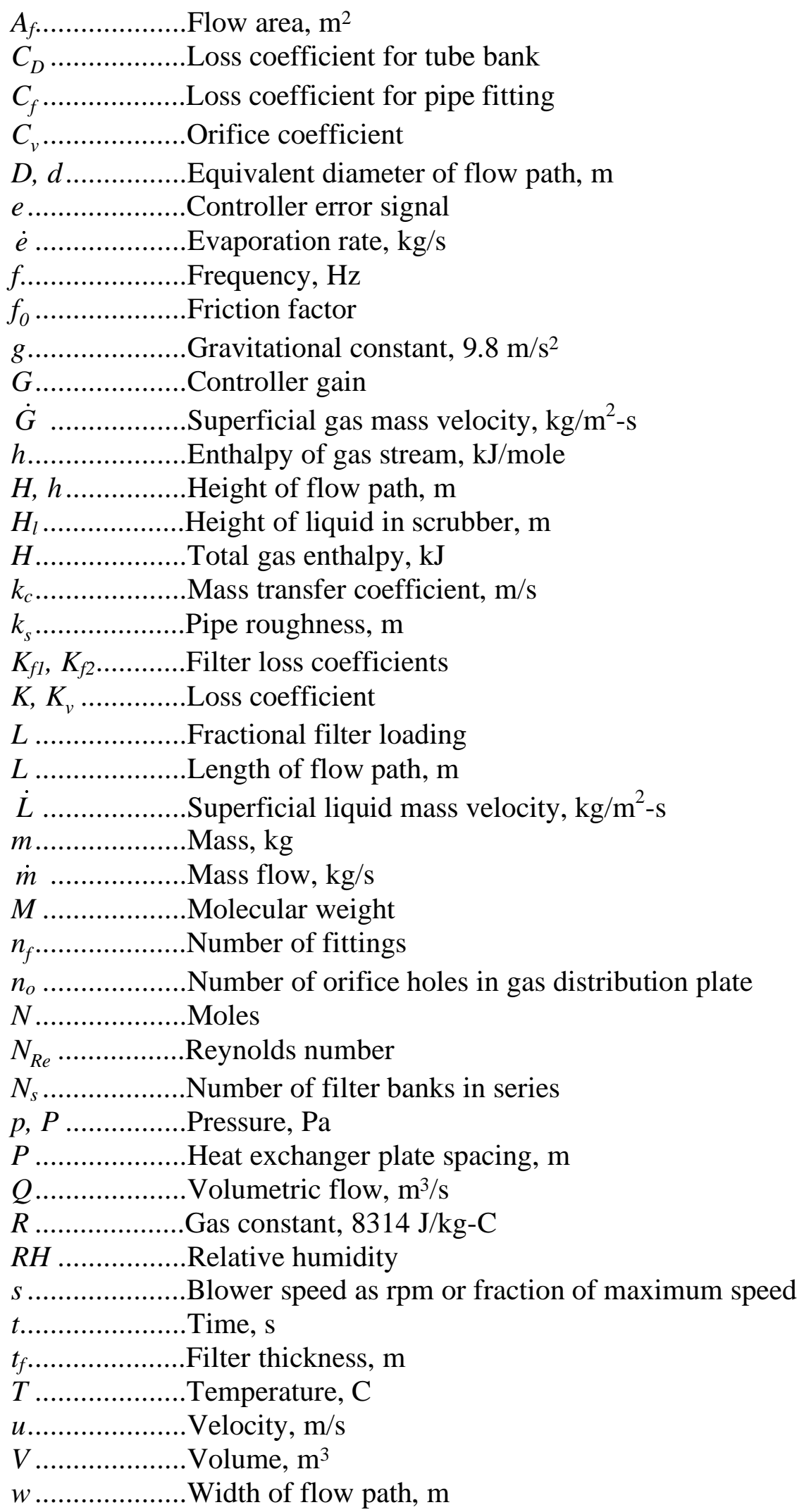


$x_{i} \ldots \ldots \ldots \ldots \ldots . . . . .$. Mass fraction of component $i$ in gas mixture

$X$...................Heat exchanger plate thickness, $\mathrm{m}$

$y_{i} \ldots \ldots \ldots . . . . . . . .$. Mole fraction of component $i$ in gas mixture

\section{Greek Symbols}

$\gamma, \phi \ldots \ldots \ldots \ldots . . . .$. Scrubber constants

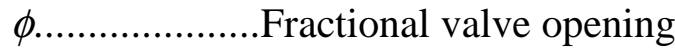

$\phi_{\text {cat }}$................Fraction of catalyst surface occupied by pores

$\mu$..................Viscosity, Pa-s

$\psi$...................Controller on/off switch



$\sigma$................... Control output signal, 0 to 1

$\tau$..................Time constant, $\mathrm{s}$

$\theta$.................Angle, degrees

\section{Subscripts}

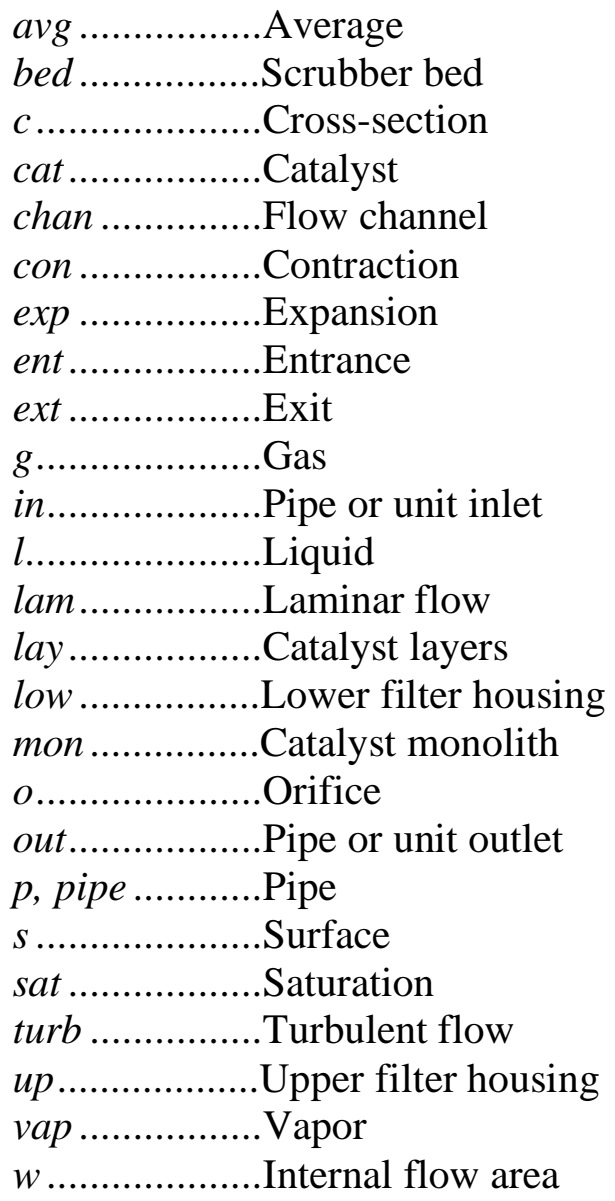




\section{$\underline{\text { References }}$}

Anderson, T, and Berrios, E., "LAW Melter Offgas System Design Basis," Draft A, January 22, 1999, BNFL Inc., Richland, Washington.

Berrios, E., 2000, "Systems 231, 232, 233 and 234: LAW Melter Offgas System Description,” SD-W375LV-PR00004, Rev. E, BNFL Inc., Richland, Washington.

Blevins, R. D., 1984, Applied Fluid Dynamics Handbook, Van Nostrand Reinhold, New York.

Bustamante, I., 2000, "Sizing of the LAW Exhauster Booster Fans," CALC-W375LVPR00017, Rev. 1, February 7, 2000, BNFL Inc., Richland, Washington.

Fergestrom, L., and W. Meeuwsen, 2000, "LAW Vessel Ventilation Calculation," CALC-W375LV-PR00022, Rev. 1, November 6, 2000, CH2MHill Hanford Group, Inc., Richland, Washington.

Foust, A. S., L. A. Wenzel, C. W. Clump, L. Maus, and L. B. Andersen, 1967, Principles of Unit Operations, John Wiley \& Sons, New York, pp. 160-182.

Holland, C. D., 1981, Fundamentals of Multicomponent Distillation, McGraw-Hill, New York, p. 608.

Jain, A. K., 1976, “Accurate Explicit Equation for Friction Factor,” ASCE J. Hydraulics Div. 102, pp. 674-677.

Meeuwsen, W., 2001, "HLW Vessel Ventilation Calculation," CALC-W375HVPR00033, Rev. 1, January 29, 2001, CH2MHill Hanford Group, Inc., Richland, Washington.

Peters, R., 2000, “Technical Basis for HLW Melter Pressure Control," RPT-W375HVPR00004, Rev. 0, May 24, 2000, BNFL Inc., Richland Washington.

Rouse, J. K., 1999, "Prediction of Melter Air Inleakage Based on Plenum Vacuum," CALC-W375HV-PR00062, Rev. 0, November 30, 1999, BNFL Inc., Richland, Washington.

Rouse, J. K., 2000a, "System 231: HLW Vitrification Offgas Treatment System Description," SD-W375HV-PR00002, Rev. C, January 21, 2000, BNFL Inc., Richland, Washington.

Rouse, J. K., 2000b, "High Efficiency Particulate Air Filter Electric Preheater Overall Pressure Drop Determination," CALC-W375HV-PR00023, Rev. 0, May 3, 2000, BNFL Inc., Richland, Washington. 
Rouse, J. K., 2000c, "Submerged Bed Scrubber Overall Pressure Drop Determination," CALC-W375HV-PR00065, Rev. 0, March 23, 2000, BNFL Inc., Richland, Washington.

Rouse, J. K., 2000d, "Wet Electrostatic Precipitator Overall Pressure Drop Determination," CALC-W375HV-PR00074, Rev. 0, March 23, 2000, BNFL Inc., Richland, Washington.

Rouse, J. K., 2000e, "High Efficiency Mist Eliminator Overall Pressure Drop Determination," CALC-W375HV-PR00075, Rev. 0, March 23, 2000, BNFL Inc., Richland, Washington.

Rouse, J. K., 2000f, "Thermal Catalytic Oxidizer/Nox SCR Overall Pressure Drop Determination," CALC-W375HV-PR00078, Rev. 0, May 3, 2000, BNFL Inc., Richland, Washington.

Rouse, J. K., 2000g, “Offgas Ducting Overall Pressure Drop Determination," CALCW375HV-PR00079, Rev. 0, May 3, 2000, BNFL Inc., Richland, Washington.

Rouse, J. K., 2000h, "High Efficiency Particulate Air Filter Overall Pressure Drop Determination," CALC-W375HV-PR00089, Rev. 0, March 23, 2000, BNFL Inc., Richland, Washington.

Rouse, J. K., 2000i, "Caustic Scrubber Overall Pressure Drop Determination," CALCW375HV-PR00090, Rev. 0, May 3, 2000, BNFL Inc., Richland, Washington.

Rouse, J. K., 2000j, "Definition of Fundamental Equations to Predict Offgas Pressure Losses," CALC-W375HV-PR00091, Rev. 0, March 14, 2000, BNFL Inc., Richland, Washington.

Rouse, J. K., 2000k, "HLW Melter Offgas Material and Heat Balance," CALCW375HV-PR00014, Rev. 1, June 28, 2000, BNFL Inc., Richland, Washington.

Rouse, J. K., 20001, "LAW Melter Offgas Material and Heat Balance," CALC-W375LVPR00029, Rev. 1, July 20, 2000, BNFL Inc., Richland, Washington.

Rouse, J. K., 2000m, "Dynamic Pressure Modeling Revised Assumptions," memorandum, December 21, 2000. 


\section{Appendix A: Derivation of Loss Coefficient Relationship}

The total pressure drop across a flow path with several resistances in series can be calculated using the summation

$$
\Delta p=\frac{1}{2} \rho_{g} \sum_{i} K_{i} u_{i}^{2}
$$

The fluid velocity at each node is related to the volumetric flow $Q_{g}$ and the flow area $A_{i}$ through the relationship $u_{i}=Q_{g} / A_{i}$. Substituting this expression for the velocity into Eq. (A1) and multiplying and dividing the right hand side by the gas density gives

$$
\Delta p=\frac{1}{2} \sum_{i} \frac{K_{i}}{A_{i}^{2}} \frac{\rho_{g}^{2} Q_{g}^{2}}{\rho_{g}}
$$

The mass flow of fluid across each of the resistances is assumed to be constant in this analysis. The mass flow is related to volumetric flow by $\dot{m}_{g}=\rho_{g} Q_{g}$. Substituting into Eq. (A2) and rearranging to solve for the mass flow gives

$$
\dot{m}_{g}=\sqrt{\frac{\rho_{g}}{K_{v}}} \sqrt{\Delta p} \text { where } K_{v}=\frac{1}{2} \sum_{i} \frac{K_{i}}{A_{i}^{2}}
$$

Equation (A3) is the formulation used for several of the model calculations.

Equation (A3) can be also modified to account for temperature changes in the gas. In Eq. (A2) the gas density is more accurately the density at flow point $i$. Assuming ideal gas behavior, the gas density is $\rho_{i}=P_{i} M W / R T_{i}$. Taking $\rho_{g}$ to be the average gas density at average temperature $T_{g}$, the local density can be calculated as

$$
\rho_{i}=\rho_{g} \frac{T_{g}}{T_{i}} \frac{P_{i}}{P_{g}} \cong \rho_{g} \frac{T_{g}}{T_{i}}
$$

Equation (A3) then becomes

$$
\dot{m}_{g}=\sqrt{\frac{\rho_{g}}{K_{v}}} \sqrt{\Delta p} \text { where } K_{v}=\frac{1}{2} \sum_{i}\left(\frac{K_{i}}{A_{i}^{2}} \frac{T_{i}}{T_{g}}\right)
$$

Equation (A5) is used to calculate pressure losses across heaters and heat exchangers where there is a significant change in gas temperature. 